Transionospheric Propagation Calculations for the Output of Two EMP Simulators

Robert Roussel-¿iupré

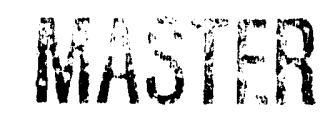

DSTRIBUTION OF TIIS ODCUMENT IS LIUIIMITEL 


\title{
TRANSIONOSPHERIC PROPAGATION CALCULATIONS FOR THE OUTPUT OF TWO EMP SIMULATORS
}

by

\author{
Robert Roussel-Dupré
}

\begin{abstract}
The Los Alamos Transionospheric Propagation Code (TIPC) was used to calculate the transionospheric signals corresponding to the computed output of two electromagnetic pulse (EMP) simulators, the NA VES II vertical polarization dipole and the TACAMO horizontal polarization dipole. The EMP calculations used as input to TIPC were performed by Mission Research Corporation. The 1986 International Reference Ionosphere code was used to generate vertical profiles of electron density over a twenty-four hour period for the geographical location of the NA VES II EMP simulator and for a solar activity projected for April, 1990, the original period of interest. A total electron content, used as input to TIPC, was calculated from the electron density profiles by integrating along a given line of sight. The maximum root mean square power densities to be expected in each of eight broadband receivers with handwidths of 5 and $20 \mathrm{MHz}$ centered at $200,120,80$, and $40 \mathrm{MHz}$ are presented.
\end{abstract}

\section{INTRODUCTION}

The purpose of this repori is to present results of calculations performed at the request of AFTAC using the Los Alamos Transionospheric Propagation Code (TIPC) to obtain the transionospheric signal corresponding to the output of the NAVES II vertical polarization dipole (VPD) and the TACAMO horizontal polarization dipole (HPD) as computed by Ed Savage and Neal Carron of Mission Research Corporation (MRC). A brief description of the output pulses is given in Section II while the model ionosphere used for these calculations is presented in

17 May 19\%, Contract No. F62400-90)-0034

Prepared for Headquarters, AFlAC, Patrick AFB, FI. 32925
Section III. The maximum RMS power density to be expected in each of eight broadband receivers with bandwidths of 5 and $20 \mathrm{MHz}$ centered at 200, 120, 80, and $40 \mathrm{MHz}$ was calculated for TECs ranging from $0.0001-20 \times 10^{17} \mathrm{~m}^{-2}$. The results are discussed in Section IV and a summary with recommendations is provided in Section V.

\section{OUTPUT OF HPD AND VPD DEVICES}

The output of the NAVES II VPL was computed by MRC for two cases corresponding to a path over the ground with a conductivity and permittivity appropriate for $10 \%$ water content (labelled L01) and one over the sea with 
conductivity of $4 \mathrm{mhos} / \mathrm{m}$ and dielectric constant of 81 (labelled L02). Azimuthal directions that include paths over both ground and sea will yield signal strengths intermediate to the two cases considered. Calculations were provided in each case for fourteen elevation angles including $5,9,13,17,21,25,30,34,38,42,50,58,67$, and 79 degrees. We chose to work with the pulses generated for propagation both cver the ground and over the sea at three angles, namely, 17, 30, and 42 degrees. The temporal and spectral pulse shapes at $1000 \mathrm{~km}$ range for these six cases are shown in Figures $1 \mathrm{a}-\mathrm{f}(\mathrm{LO} 1)$ and $2 \mathrm{a}-\mathrm{f}(\mathrm{LO2})$. With the exception of minor bumps in the spectrum from 10-100 MHz of the L01_42 pulse (see Figure 1b), the spectral shape of these pulses can be characterized above $30 \mathrm{MHz}$ as a monotonically decreasing function of frequency with no particularly interesting or identifying features. This fact suggests that except for the consideration of optimizing signal-to-noise ratios including ionospheric effects, the selection of particular frequency channels above $30 \mathrm{MHz}$ is arbitrary. While optimizing signal strength favors the lower frequencies, minimizing ionospheric effects will favor the higher frequencies.

The output of the TACAMO HPD was computed by MRC for four elevation angles including 10,20,40, and 70 ivgrees and for four azimuthal directions measured with respert to the simulator arms, including $11.3,37.5,63.8$, and 90 degrees. We chose to work with two pulses generated for propagation at $20^{\circ}$ elevation and azimuthal angles with respect to the sinulator arms of $37^{\circ}$ and $90^{\circ}$ (desig. nated E20A37 and E20A90 respectively). Because of the four-fold azimuthal symmetry inherent to this configuration, calculations for the $37^{\circ}$ azimuth correspond to geographical az:muths of $41,116,221$, and 296 degrees while those for $90^{\circ}$ azimuth correspond to geographical azimuths of $169^{\circ}$ and $349^{\circ}$. The temporal and spectral p!!' : shapes projected back to one meter range for these two cases are shown in Figures 3a-b and $4 a-b$. The spectral shape of these signals shows an osciliatory :tructure that is associated with the interference of direct line of sight signal components and ground reflertions. These oscillations occur above $10 \mathrm{MHz}$ and have nul's at approximately 10 $\mathrm{MHz}$ intervals. This fact suggests that careful selertion of operating frequencies will be necessary for bandwidths less than $10 \mathrm{PiHz}$ in order to insure adequate signal-tonoise. We note that the significant structure in the spectrum of this signal precludes a continuous measurement of the chirp rate of the transionospheric signal thereby making it more difficult to obtaiit an accurate ionospheric TEC.

\section{IONOSPIERIC MODEL}

The i986 Intemational Reference Ionosphere (IRI;
Rawer et al., 1978a and b; Bilitza, 1986; Rawer and Bradley, 1987) is a computer program that generates vertical profiles of electron density, electron and ion temperatures, and positive ion composition for any given geographical location, time of day, season and solar activity. The electron density profile is computed by interpolating a series of tables developed from synoptic measurements obtained with ionosondes, topside sounders and incoherent scatter radars. The data base in some cases constitutes more than 20 years of measurements taken on an hourly basis. IRI therefore represents an excellent tool for estimating average ionospheric conditions for a wide range of geographical locations in the northern hemisphere.

The input parameters to IRI include the geographical location (north latitude and east longitude), the sunspot number (available from the Geomagnetic and Solar Data published monthly by the Journal of Geophysical Research), the month, time of day (hour), solar inclination (can be computed internally by IRI), lower and upper limits of the height profile, and the profile height resolution. The output includes plots and a listing of the ionospheric constituents and electron and ion temperatures as a function of height. The electron density profile can then be integrated to yield the total electron content (TEC).

This code was used to generate electron density profiles and TECs for the geographical location of the NAVES II VPD $\left(38^{\circ} 15^{\prime} \mathrm{N}, 76^{\circ} 20^{\prime} \mathrm{W}\right)$ and the solar activity projected for April, 1990. On the basis of the evolution over the past three years of solar cycle 22, the National Geophysical Data Center has predicted the sunspot number for April, 1990 to be $182 \pm 34$ at the $90 \%$ confidence level. We have generated the electron density profiles expected over Patuxent River, MD for a 24 hour period and for sunspot numbers of 150,182 , and 216 . These profiles were then integrated for elevation angles of $90,45,30$ and 15 degrees to obtain the corresponding TECs. Typical nighttime and daytime electron density profiles for a sunspot number of 182 are shown in Figures $5 a$ and b, respectively. The TECs as a function of the time of day for each of the sunspot numbers ar:d elevation angles discussed above are shown in Figures 6a-1. These calculations indicate an overall TEC range from approximatcly $1-30 \times 10^{17} \mathrm{~m}^{-2}$ and an average day to night contrast in 'TEC of approximately a factor of three.

\section{TRANSIONOSPHERIC PROPAGATION}

The transionospheric propagation code (TIPC; RousselDupre and Kelley, 1989) was used to calculate the transionospheric signals corresponding to the pulses discussed in Section II for TECs ranging from $0.0\left(001-20 \times 10^{17} \mathrm{~m}^{-2}\right.$. 
The result for the time domain signal L01_42.EVT from Savage and Carron and a TEC of $1 \times 10^{17} \mathrm{~m}^{-2}$ is shown in Figure 7 for a frequency range from $40-500 \mathrm{MHz}$. The short rise in signal strength observed at the end of the pulses in these figures is a result of aliasing and should be ignored. Note that the signal strength does not vary substantially over the $7 \mu$ s length of the pulses. This result illustrates that ionospheric dispersion has reduced the amplitude of the low frequency components of the signal such that they are approximately equal to that of the high frequency components.

The transionospheric time domain signals corresponding to a TEC of $1 \times 10^{17} \mathrm{~m}^{-2}$ are shown for the TACAMO HPD E20A37 and E20A90 pulses in Figures 8a-b for a frequency range from $37-500 \mathrm{MHz}$. Note that the strong oscillations in signal strength correspond to the arrival of individual frequency packets seen in the original signal spectrum, high frequencies arriving first. The strong variation in signal power versus frequency indicated in these results suggests that selection of operating frequencies would affect both signal-to-noise for detection and the measurement of TEC.

TIPC can also simulate the detection of signals by specified receivers. Eight receivers with central frequencies of $40,80,120$, and $200 \mathrm{MHz}$ and bandwidths of 20 and $5 \mathrm{MHz}$ were modeled. The envelopes of the detected transionospheric signal for the VPD L02_17.EVT pulse are shown in Figures $9 \mathrm{a}-\mathrm{h}$ for the 5 and $20 \mathrm{MHz}$ bandwidth receivers centered at $120 \mathrm{MHz}$ and for TECs of $.01,1,5$ and $20 \times 10^{17} \mathrm{~m}^{-2}$. Similar results are shown in Figures $10 \mathrm{a}-\mathrm{h}$ for the HPD E20A37 pulse. For low TECs the filtered transionospheric signal has the shape essentially of the envelope of the impulse response of the filter. At high TECs the ionospheric dispersion dominates over the filter response and defines the shape of the detected signal.

The maximum RMS power density (watts $/ \mathrm{m}^{2}$ ) measured in cach of these receivers at $1000 \mathrm{~km}$ range is plotted as a function of TEC. (note that $1 \times 10^{13} \mathrm{~cm}^{-2}=1 \times 10^{17} \mathrm{~m}^{-2}$ ) for cach of the NAVES II VPD pulses discussed in Scction II (L01 42.EVT, LO1_30.EVT, L02_42.EVT, L02_30.EVT, L02_17.EVT). The following figures give the responses to these signals at the indicated center frequencics: Figures 11a-1 (200 MHz receiver); 12a-l (120) $\mathrm{MHz}$ recei, $\mathrm{r}) ; 13 \mathrm{a}-\mathrm{l}(80 \mathrm{MHz}$ receiver); $14 \mathrm{a}-\mathrm{l}(40 \mathrm{MHz}$ receiver). Note that for large TEC the power varies inversely with TEC (i.e., $\alpha$ 1/TEC) as expected. This fact can be used to extrapolate the results for TECs larger than those presented. To obtain the power at a range of $R$ meters, multiply the value determined from the plots by $10^{12} / \mathrm{R}^{2}$.

Similar results were obtained for each of the TACAMO HPD pulses discussed in Section II: (E20A37 and E20A90). The following figures give the responses to these signals at the indicated center frequencies: Figures $15 \mathrm{a}-\mathrm{d}(200 \mathrm{MHz}$ receiver); $16 \mathrm{a}-\mathrm{d}(120 \mathrm{MHz}$ receiver) $17 \mathrm{a}-\mathrm{d}(80 \mathrm{MHz}$ receiver); $18 \mathrm{a}-\mathrm{d}(40 \mathrm{MHz}$ receiver). To obtain the power at a range of $R$ meters from these figures, multiply the value determined from the plots by $1 / R^{2}$. Note that this normalization differs from that used for the VPD pulses.

\section{SUMMARY}

The spectral shape of the computed VPD pulses can be characterized above $30 \mathrm{MHz}$ as a monotonically decreasing function of frequency with no particularly interesting or identifying features. The radiated power density in various spectral bands is summarized in Figures $19 \mathrm{a}$ and $\mathrm{b}$ for paths over the ground (LOI) and over the sea (L(2), respectively. For the elevation angles studied, the difference between the two paths is small (less than a factor of two in power density) and shows up primarily at low elevation angles $\left(17^{\circ}\right)$ and low frequencies $(<80 \mathrm{MHz})$. The ratio of power density cornputed for a $20 \mathrm{MHz}$ bandwidth receiver to that for a $5 \mathrm{MHz}$ bandwidth receiver is approximately a factor of ten over the spectral range studied. Note that the source does not appear impulsive to receivers with band widths greater than or equal to $20 \mathrm{MH} \%$, but that for narrower band widths it is reasonable to assume that the power density increases as the bandwidth squared. The spectral shape of the TACAMO HPD signals exhibits an oscillatory structure that is associated with the interference of direct line of sight signal components and ground reflections. These oscillations occur above $10 \mathrm{MHz}$ and have nulls at approximately $10 \mathrm{MHz}$ intervals. This fact suggests that careful selection of operating frequencics will be necessary for bandwidths less than $10 \mathrm{MHz}$ in order to insure adequate signal-to-noise. The significant structure in the spectrum of this signal will make it more difficult to obtain an accurate ionospheric TEC. The radiated power density in various spectral bands is summarized in Figure 20 for two azimuthal directions $\left(37^{\circ}\right.$ and $90^{\circ}$ ) measured relative to the axis of the simulator. As expected the power ciensities are higher across the spectral range at an arimuth of $90^{\circ}$.

The dominant effect of a deterministic ionosphere is to disperse the frequency content of an EMP in time with the high frequency components arriving first. The transionospheric signal computed for the VPD is stretched out over $7 \mu$ s in time for a TEC of $1 \times 10^{17} \mathrm{~m}^{-2}$ with an amplitude that does not vary substantially with time (or frequency). This result illustrates that ionospheric dispersion has reduced the amplitude of the low frequency components of the signal such that it is approximately equal to that of the high frequency components. As a result, no optimum bandwidth exists for the VPD pulse assuming that the background noise is flat ('white') across the bandwidth. Re- 
ceiver frequencies should be selected in spectral regions with minimum background noise. Similar results apply for the HPD pulse except for the additional amplitude modulation introduced by interference effects.

The maximum RMS power density (watts $/ \mathrm{m}^{2}$ ) measured in each of eight receivers is plotted as a function of
TEC in Figures 11-14 for each of the NAVES II VPD pulses and in Figures 15-18 for each of the TACAMO HPD pulses. A listing of the pulses, receivers and associated bandwidths, and corresponding figures is provided in Table I for convenience.

TABLE 1. PLOTS OF RMS POWER DENSITY VS. TEC

\begin{tabular}{|c|c|c|c|c|c|}
\hline Pulse Type & $\begin{array}{c}\text { Elevation } \\
\left({ }^{\circ}\right)\end{array}$ & $\begin{array}{c}\text { Azimuth } \\
\left({ }^{\circ}\right)\end{array}$ & $\begin{array}{l}\text { Receiver } \\
\text { Frequency } \\
\text { (MHz) }\end{array}$ & $\begin{array}{l}\text { Bandwidth } \\
(\mathrm{MHz})\end{array}$ & $\begin{array}{l}\text { Figure } \\
\text { Number }\end{array}$ \\
\hline VPD & 42 & Ground & 200 & 20 & $11 \mathrm{a}$ \\
\hline VPD & 42 & Ground & 200 & 5 & $11 \mathrm{~b}$ \\
\hline VPD & 30 & Ground & 200 & 20 & $11 \mathrm{c}$ \\
\hline VPD & 30 & Ground & 200 & 5 & $11 d$ \\
\hline VPD & 17 & Ground & 200 & 20 & $11 \mathrm{c}$ \\
\hline VPD & 17 & Ground & 200 & 5 & $11 \mathrm{f}$ \\
\hline VPD & 42 & Sea & 200 & 20 & $11 \mathrm{~g}$ \\
\hline VPD & 42 & Sea & 200 & 5 & $11 \mathrm{~h}$ \\
\hline VPD & 30 & Sea & 200 & 20 & $11 i$ \\
\hline VPD & 30 & Sea & 200 & 5 & $11 \mathrm{j}$ \\
\hline VPD & 17 & Sea & 200 & 20 & $11 \mathrm{k}$ \\
\hline VPD & 17 & Sea & 200 & 5 & 111 \\
\hline VPD & 42 & Ground & 120 & 20 & $12 a$ \\
\hline VPD & 42 & Ground & 120 & 5 & $12 \mathrm{~b}$ \\
\hline VPD & 30 & Ground & 120 & 20 & $12 c$ \\
\hline VPD & 30 & Ground & 120 & 5 & $12 \mathrm{~d}$ \\
\hline VPD & 17 & Ground & 120 & 20 & $12 \mathrm{e}$ \\
\hline VPD & 17 & Ground & 120 & 5 & $12 f$ \\
\hline VPD & 42 & Sea & 120 & 2.0 & $12 \mathrm{~g}$ \\
\hline VPD & 42 & Sea & 120 & 5 & $12 \mathrm{~h}$ \\
\hline VPD & 30 & Sea & 120 & 20 & $12 \mathrm{i}$ \\
\hline VPD & 30 & Sea & 120 & 5 & $12 \mathrm{j}$ \\
\hline VPD & 17 & Sea & 120 & 20 & $12 \mathrm{k}$ \\
\hline VPD & 17 & Sea & 120 & 5 & 121 \\
\hline VPD & 42 & Ground & 80 & 20 & $13 a$ \\
\hline VPD & 42 & Ground & 80 & 5 & $13 b$ \\
\hline VPD & 30 & Ground & 80 & 20 & $13 \mathrm{c}$ \\
\hline VPD & 30 & Ground & 80 & 5 & $13 d$ \\
\hline VPD & 17 & Ground & 80 & 20 & $13 \mathrm{e}$ \\
\hline VPD & 17 & Ground & 80 & 5 & $13 \mathrm{f}$ \\
\hline VPD & 42 & Sea & 80 & 20 & $13 \mathrm{~g}$ \\
\hline VPD & 42 & Sea & 80 & 5 & $13 \mathrm{~h}$ \\
\hline VPD & 30 & Sea & 80 & 20 & $13 \mathrm{i}$ \\
\hline VPD & 30 & Sea & 80 & 5 & $13 j$ \\
\hline VPD & 17 & Sea & 80 & 20 & $13 \mathrm{k}$ \\
\hline VPD & 17 & Sea & 80 & 5 & 131 \\
\hline
\end{tabular}


TABLE 1. CONT.

\begin{tabular}{|c|c|c|c|c|c|}
\hline Pulse Type & $\begin{array}{c}\text { Elevation } \\
\left({ }^{\circ}\right)\end{array}$ & $\begin{array}{c}\text { Azimuth } \\
\left({ }^{\circ}\right)\end{array}$ & $\begin{array}{l}\text { Receiver } \\
\text { Frequency } \\
\text { (MHz) }\end{array}$ & $\begin{array}{c}\text { Bandwidth } \\
\text { (MHz) }\end{array}$ & $\begin{array}{c}\text { Figure } \\
\text { Number }\end{array}$ \\
\hline VPD & 42 & Ground & 40 & 20 & $14 a$ \\
\hline VPD & 42 & Ground & 40 & 5 & $14 b$ \\
\hline VPD & 30 & Ground & 40 & 20 & $14 \mathrm{c}$ \\
\hline VPD & 30 & Ground & 40 & 5 & $14 d$ \\
\hline VPD & 17 & Ground & 40 & 20 & $14 \mathrm{e}$ \\
\hline VPD & 17 & Ground & 40 & 5 & $14 \mathrm{f}$ \\
\hline VPD & 42 & Sea & 40 & 20 & $14 \mathrm{~g}$ \\
\hline VPD & 42 & Sea & 40 & 5 & $14 \mathrm{~h}$ \\
\hline VPD & 30 & Sea & 40 & 20 & $14 \mathrm{i}$ \\
\hline VPD & 30 & Sea & 40 & 5 & $14 \mathrm{j}$ \\
\hline VPD & 17 & Sea & 40 & 20 & $14 \mathrm{k}$ \\
\hline VPD & 17 & Sea & 40 & 5 & 141 \\
\hline HPD & 20 & 37 & 200 & 20 & $15 \mathrm{a}$ \\
\hline HPD & 20 & 90 & 200 & 5 & $15 b$ \\
\hline HPD & 20 & $37^{\circ}$ & 200 & 20 & $15 \mathrm{c}$ \\
\hline HPD & 20 & 90 & 200 & 5 & $15 \mathrm{~d}$ \\
\hline HPD & 20 & 37 & 120 & 20 & $16 a$ \\
\hline HPD & 20 & 90 & 120 & 5 & $16 \mathrm{~b}$ \\
\hline HPD & 20 & 37 & 120 & 20 & $16 \mathrm{c}$ \\
\hline HPD & 20 & 90 & 120 & 5 & $16 \mathrm{~d}$ \\
\hline HPD & 20 & 37 & 80 & 20 & $17 \mathrm{a}$ \\
\hline HPD & 20 & 90 & 80 & 5 & $17 \mathrm{~b}$ \\
\hline HPD & 20 & 37 & 80 & 20 & $17 \mathrm{c}$ \\
\hline HPD & 20 & 90 & 80 & 5 & $17 d$ \\
\hline HPD & 20 & 37 & 40 & 20 & $18 \mathrm{a}$ \\
\hline HPD & 20 & 90 & 40 & 5 & $18 \mathrm{~b}$ \\
\hline HPD & 20 & 37 & 40 & 20 & $18 \mathrm{c}$ \\
\hline HPD & 20 & 90 & 40 & 5 & $18 \mathrm{~d}$ \\
\hline
\end{tabular}

\section{ACKNOWLEDGEMENTS}

The author would like to thank Dr. Stephen Knox for helpful discussions and a critical review of this document.

\section{REFERENCES}

Bilitza, D., 1986, "IRI: Recent Developments," Radio Sci., 21, 343.

Rawer, K., D. Bilitza and S. Ramakrishnan, 1978a, Rev. of

Geophys. and Spa.Phys., 16, No. 2, 177.
Rawer, K., S Ramakrishnan, and D. Bilitza, 1978b, "IRI 1978," International Union of RadioScience (URSI), Brussels, 75 pages.

Rawer, K. and P. A. Bradley 1987, editors of "International Reference Ionosphere-Status 1986/87," Advances in Spa. Res., 7, No. 6, 129 pages.

Roussel-Dupre, R. and Kelley, T. A. "Transionospheric Propagation Code (TIPC)," LAMS Report in press, Los Alamos National Laboratory, Los Alamos, New Mexico. 


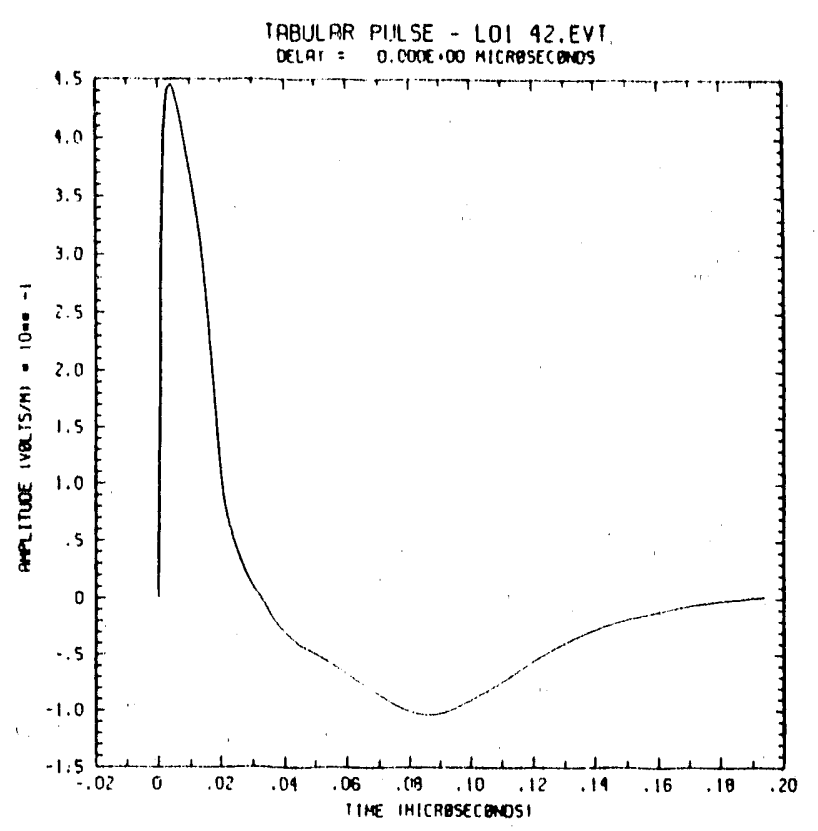

$1 \mathrm{a}$

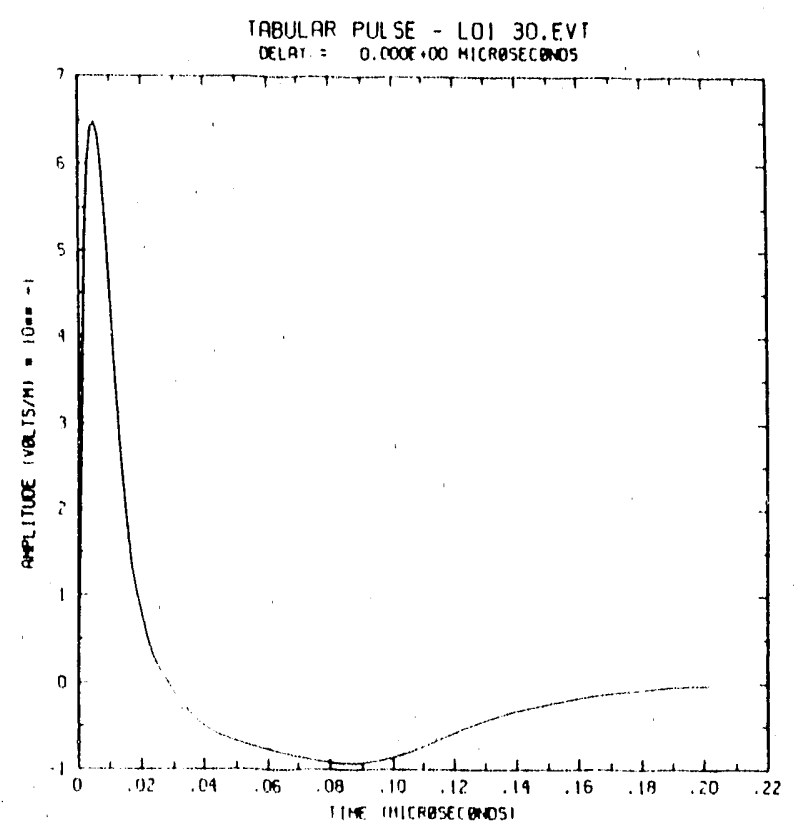

$1 \mathrm{c}$

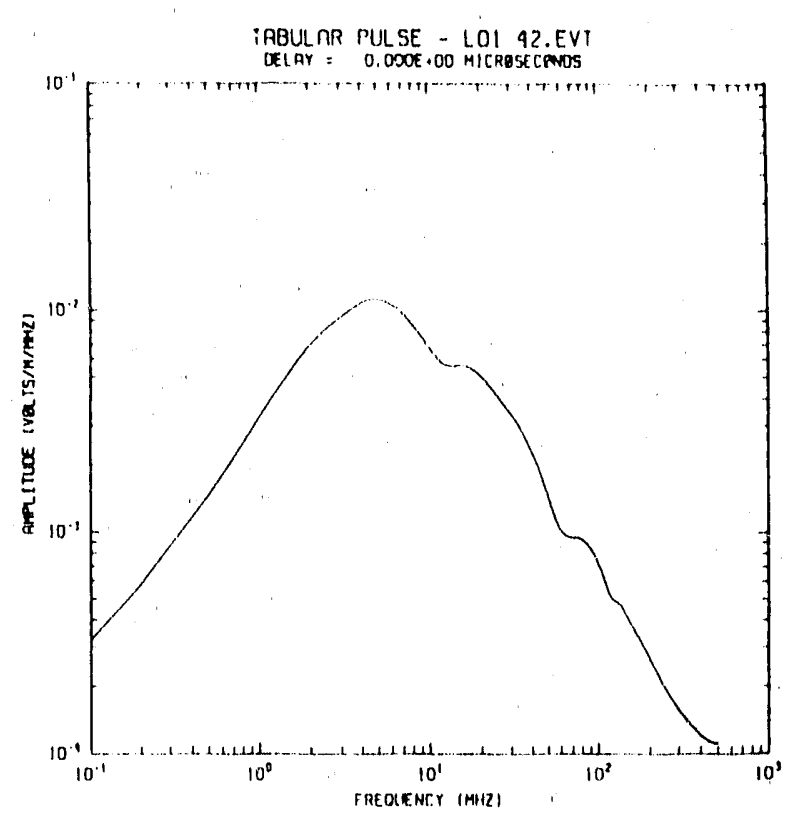

$1 \mathrm{~b}$

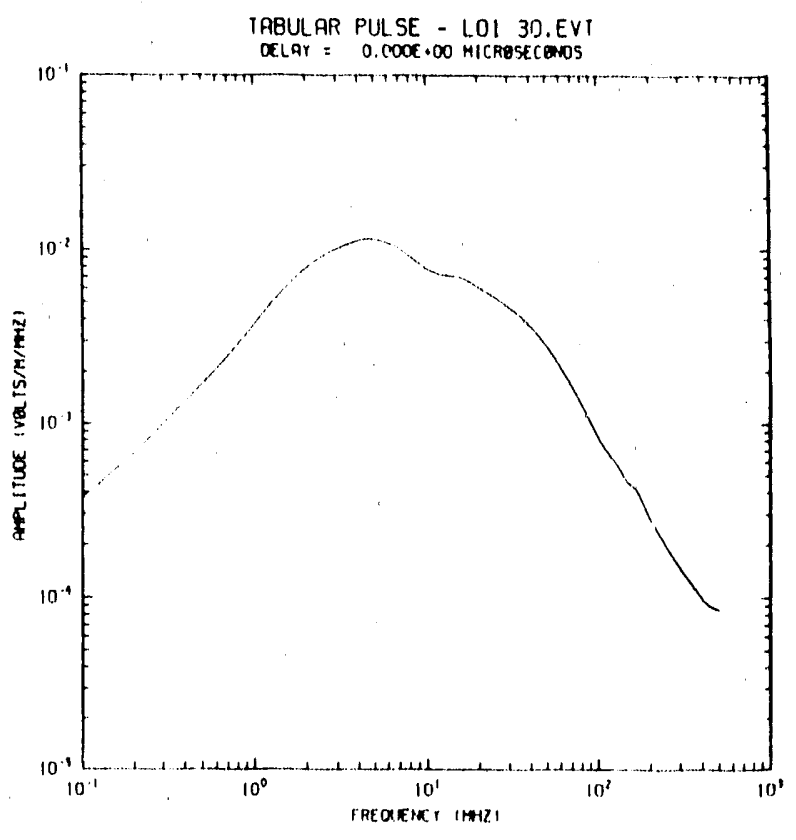

$1 d$

Figures la-d: Plots of the temporal and spectral VPD L01 pulse shapes at $1000 \mathrm{~km}$ range for elevation angles of $17^{\circ}$ (1a and $b$ ), and $30^{\circ}(1 \mathrm{c}$ and $\mathrm{d})$. 


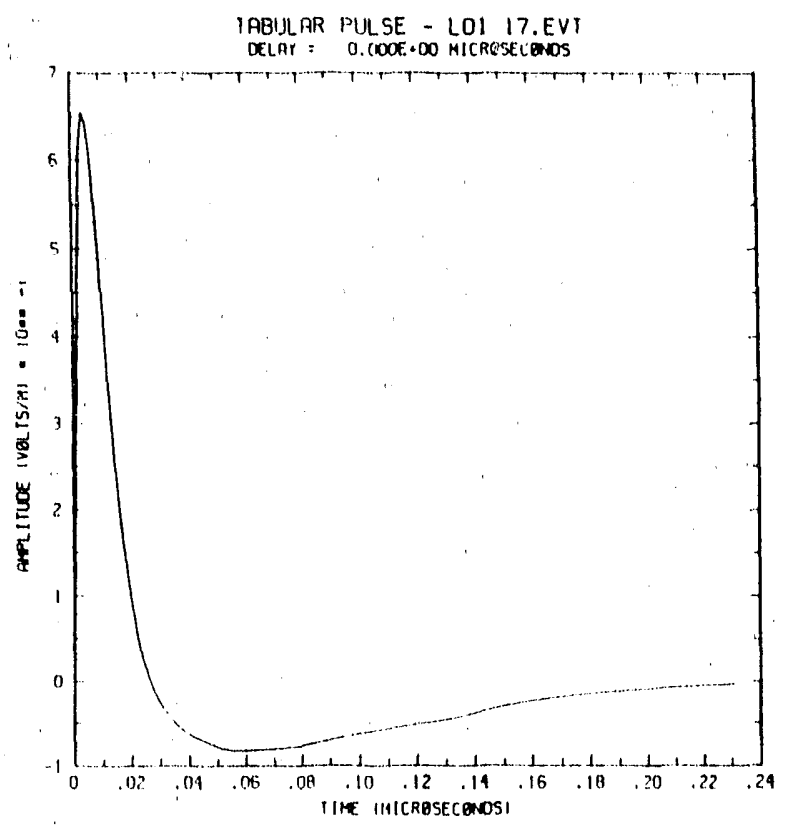

le

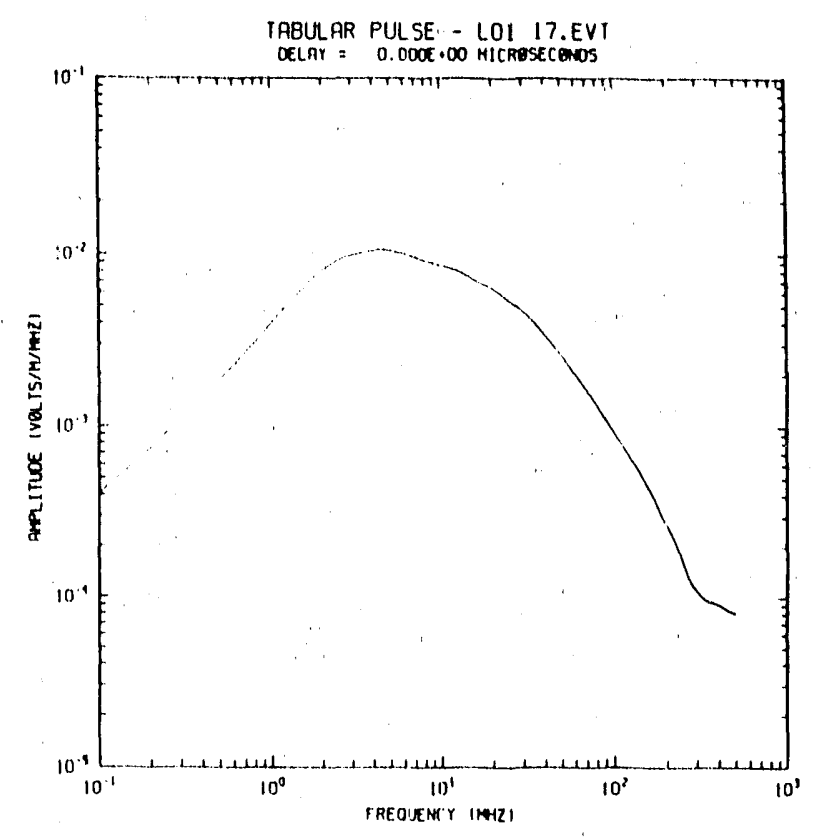

If

Figures 1e-f: Plots of the temporal and spectral VPD L01 pulse shapes at $1000 \mathrm{~km}$ range for elevation angle of $42^{\circ}$ (1c and $\mathrm{f}$.

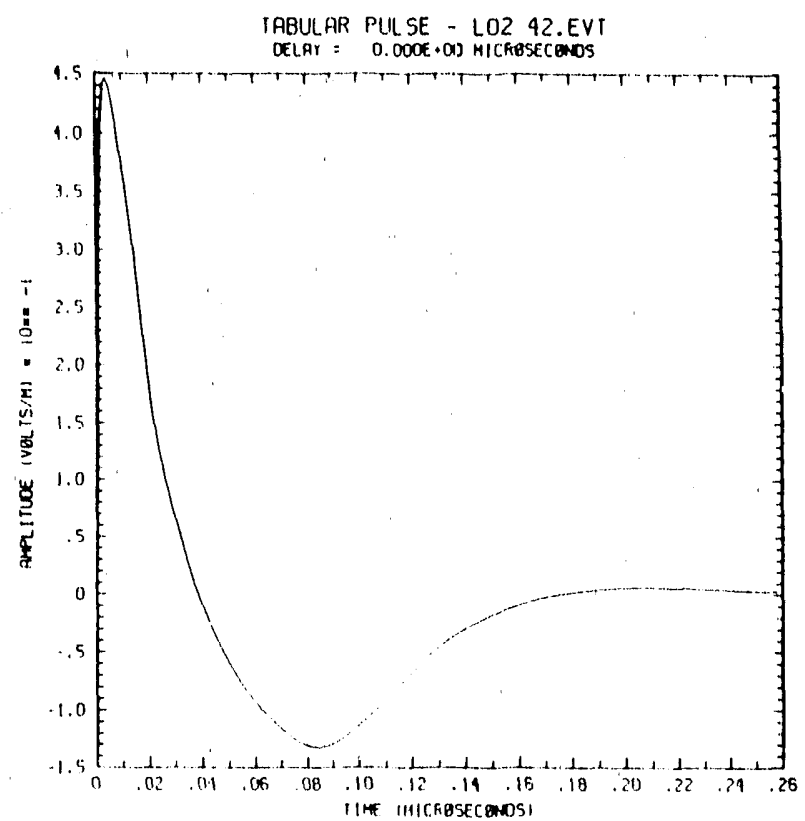

$2 \mathrm{a}$

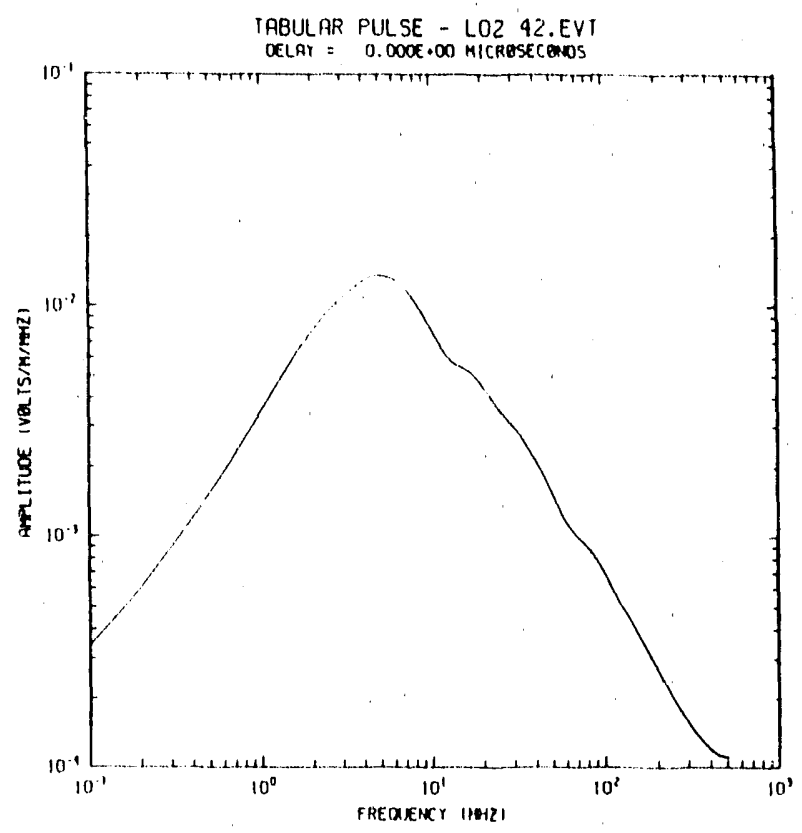

$2 b$

Figures 2a-b: Plots of the temporal and spectral VPD L02 pulse shapes at $1000 \mathrm{~km}$ range for clevation angles of $17^{\circ}(2 \mathrm{a}$ and b). 


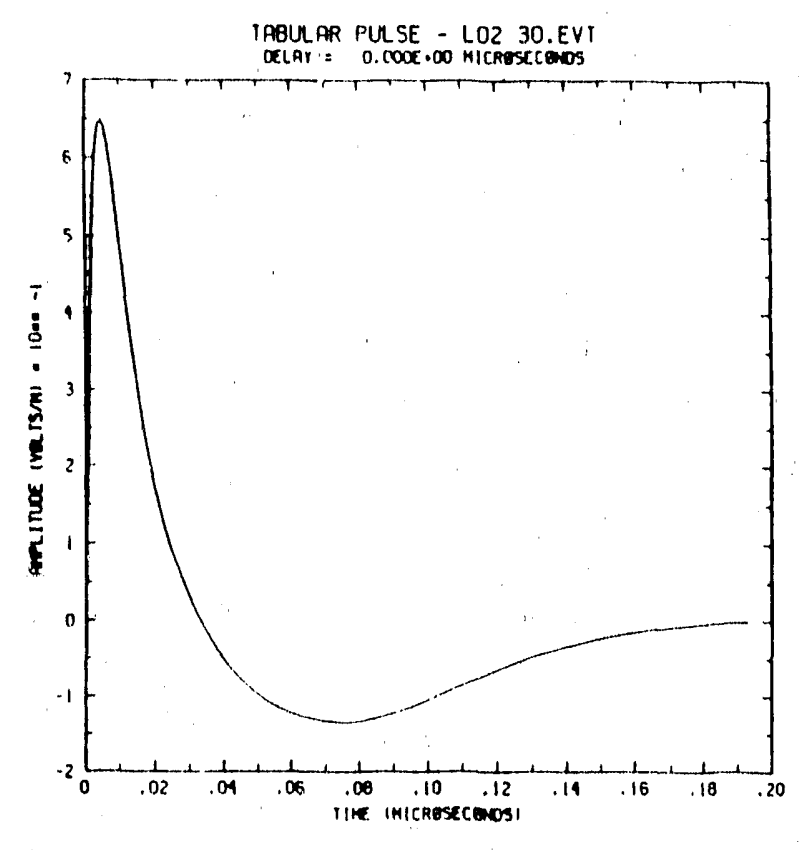

2c

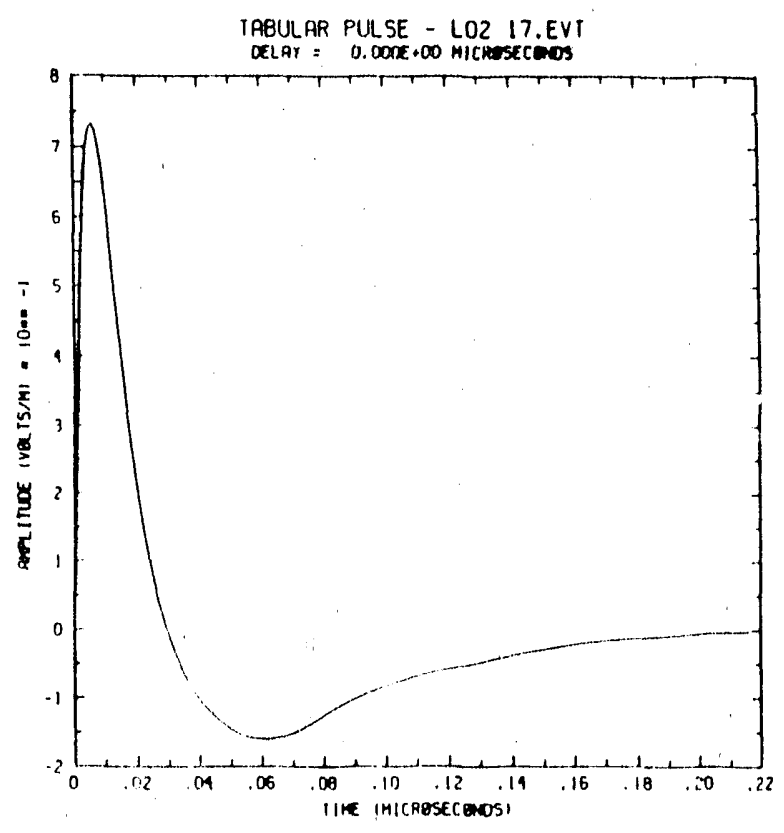

$2 \mathrm{c}$

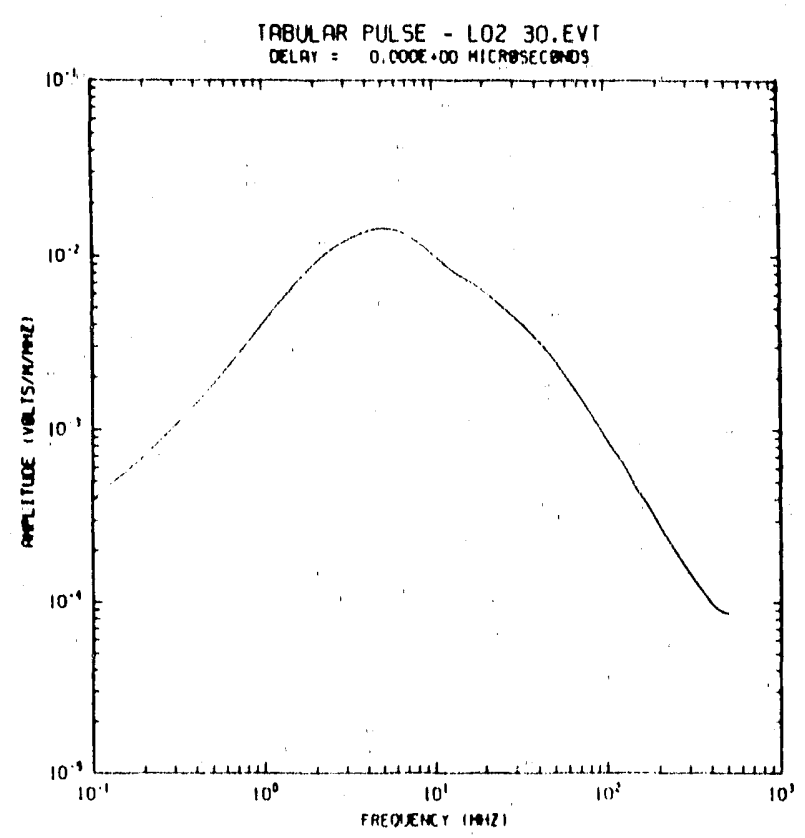

$2 d$

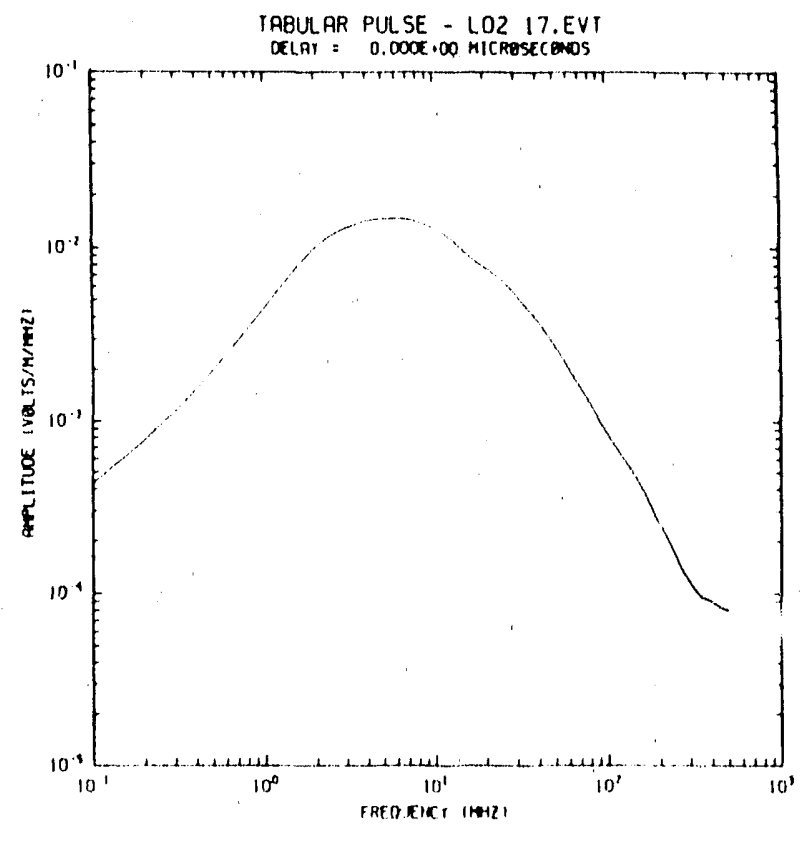

$2 f$

Figures 2c-e: Plots of the temporal and spectral VPD LO2 pulse shapes at $1(0)(0) \mathrm{km}$ range for elevation angles of 3()$^{\circ}(2 \mathrm{c}$ and $\mathrm{d})$, and $42^{\circ}(2 \mathrm{e}$ and $\mathrm{f})$. 


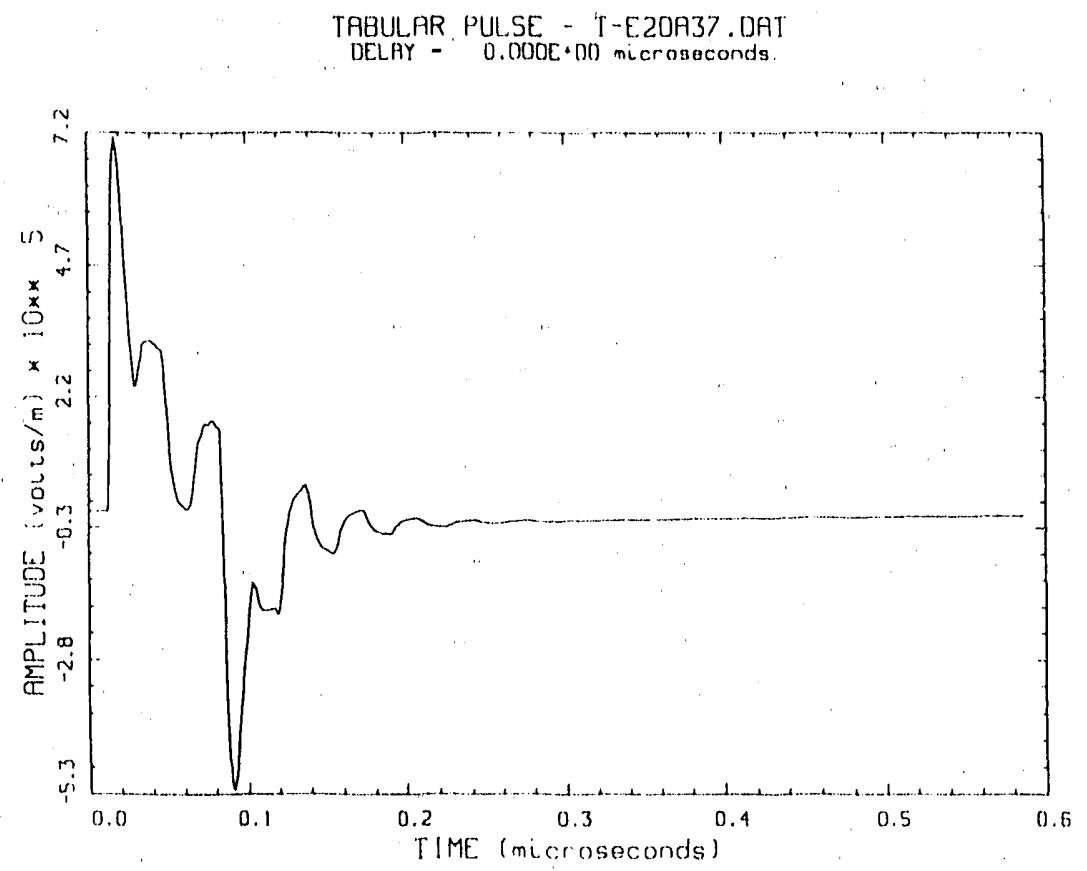

3a

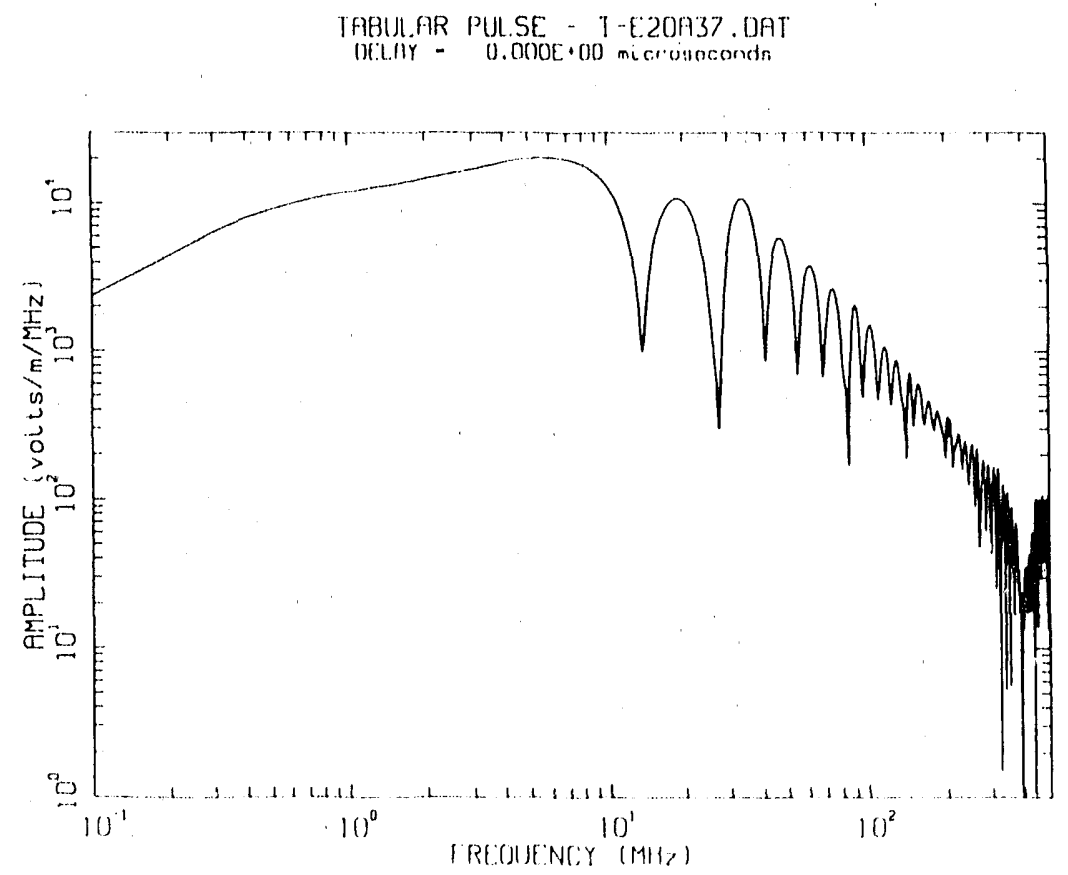

$3 b$

Figures 3a-b: Plots of the temporal (a) and spectral (b) HPD pulse shapes at $1 \mathrm{~m}$ range for an clevation angle of $20^{\circ}$ and an azimuthal direction measureit with respect to the simulator arms of $37^{\circ}$. 


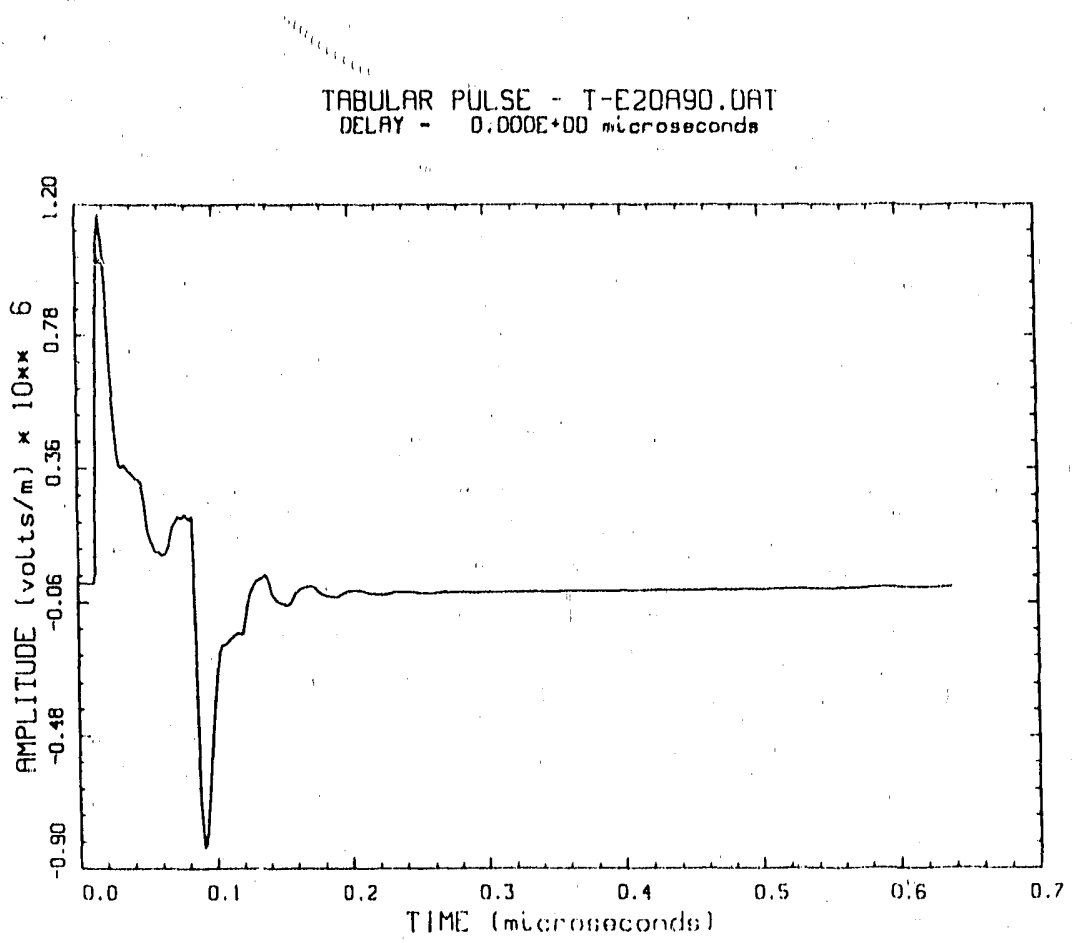

$4 \mathrm{a}$

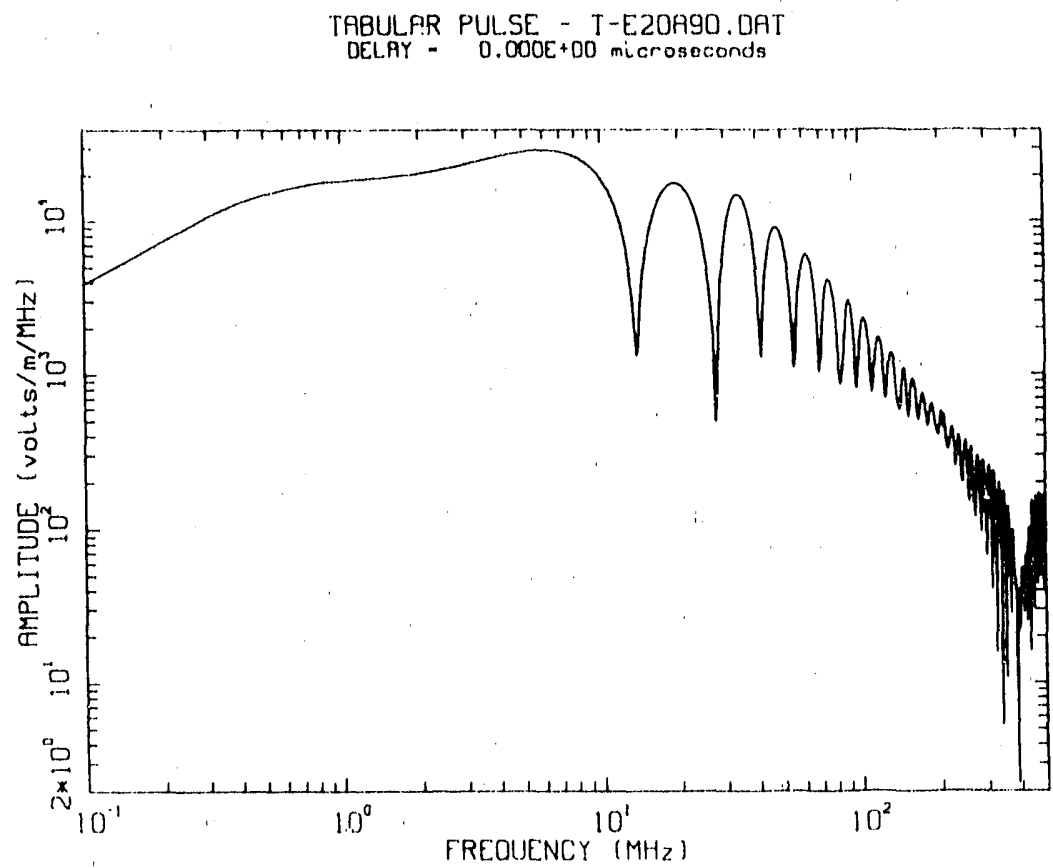

$4 \mathrm{~b}$

Figures 4a-b: Plots of $4 \mathrm{e}$ temporal (a) and spectral (b) HPD pulse shapes at $1 \mathrm{~m}$ range for an elevation angle of $20^{\circ}$ and an azimuthal direction measured with respect to the simulator arms of $90^{\circ}$. 


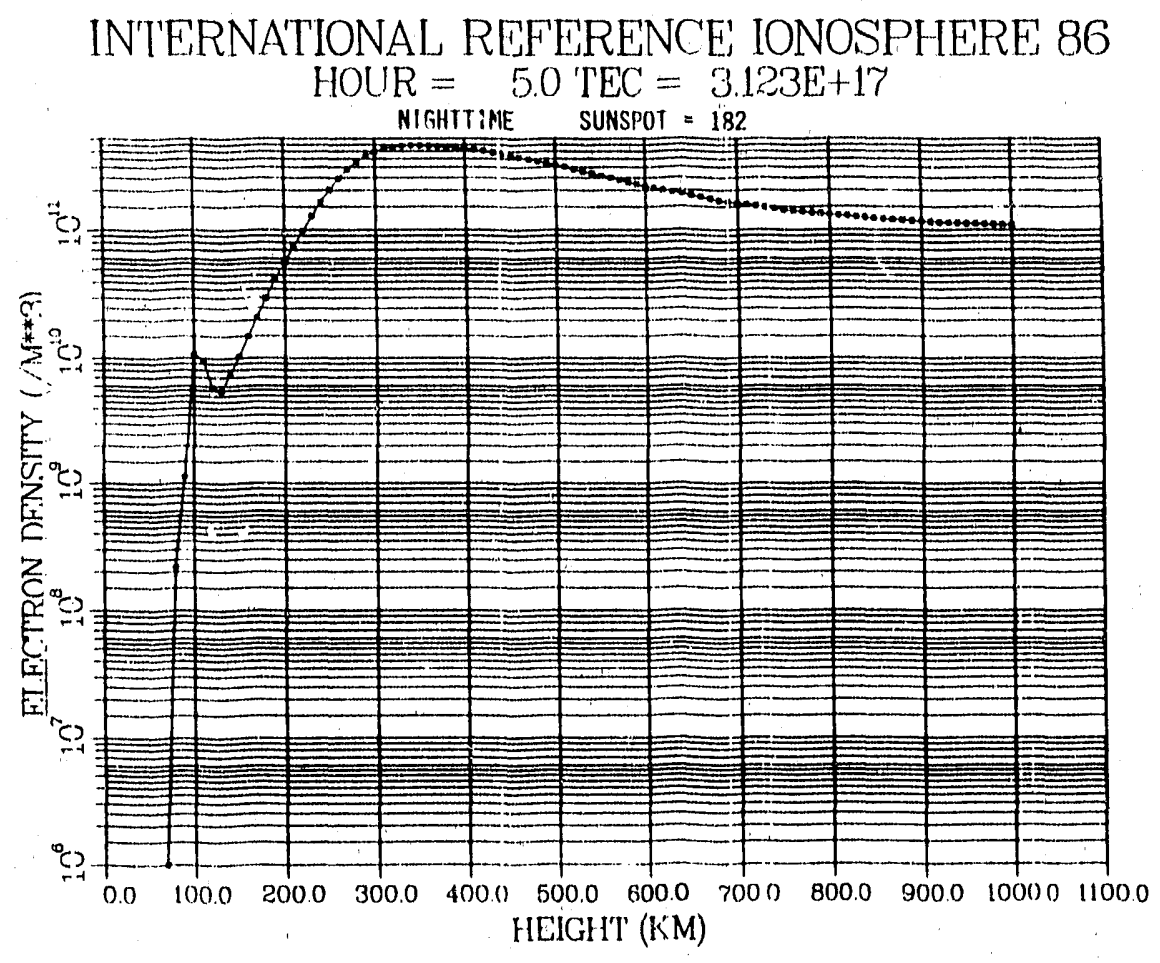

$5 a$

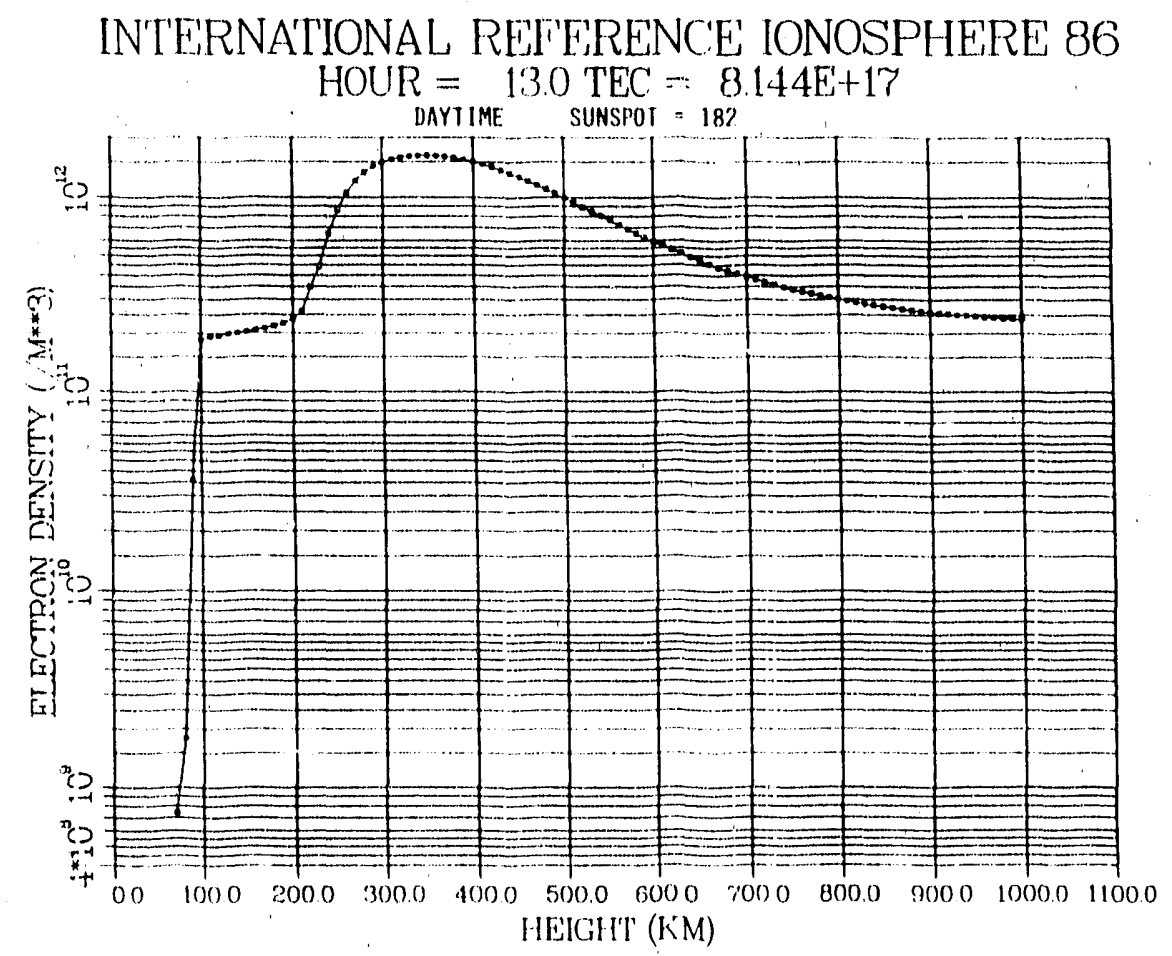

$5 b$

Figures 5a-b: Typical nighttime (a) and daytime (b) electron density profiles over Patuxent River, MD for a sunspet number of 182 . 


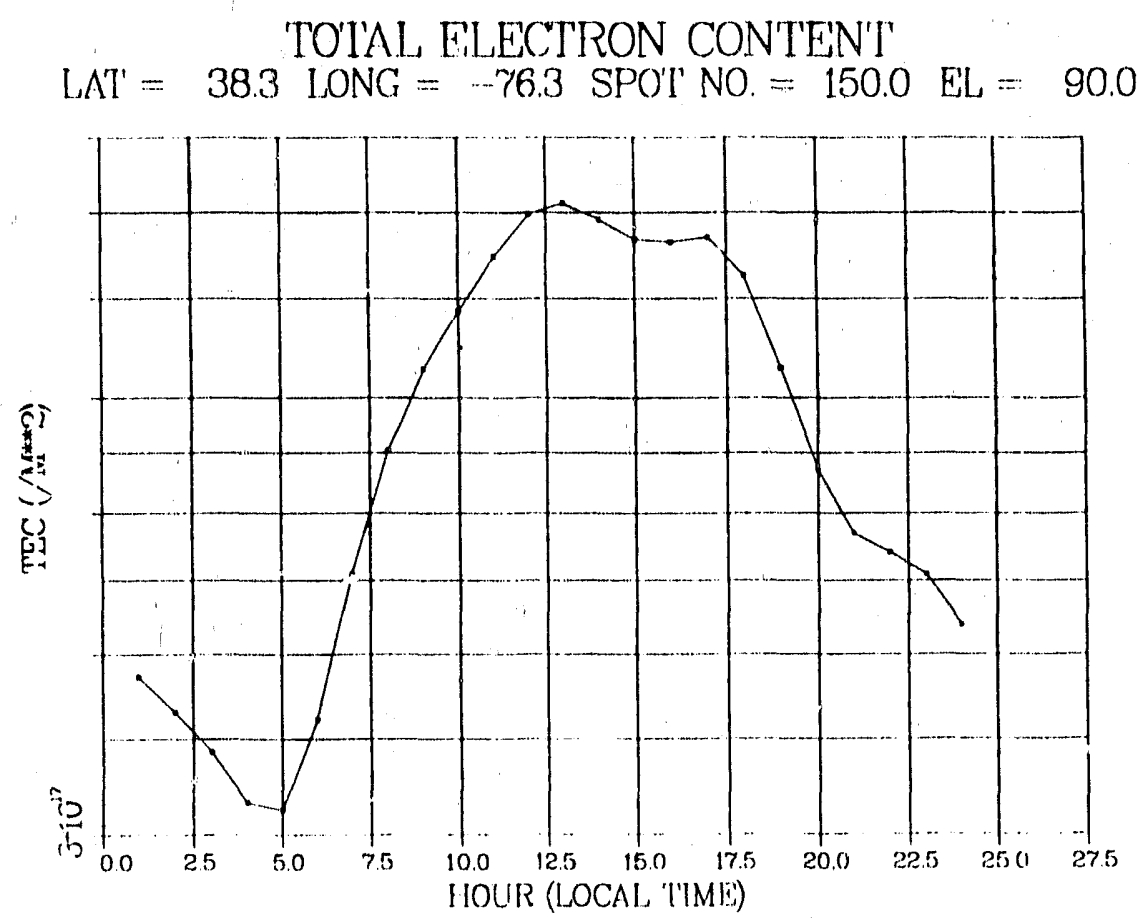

$6 a$

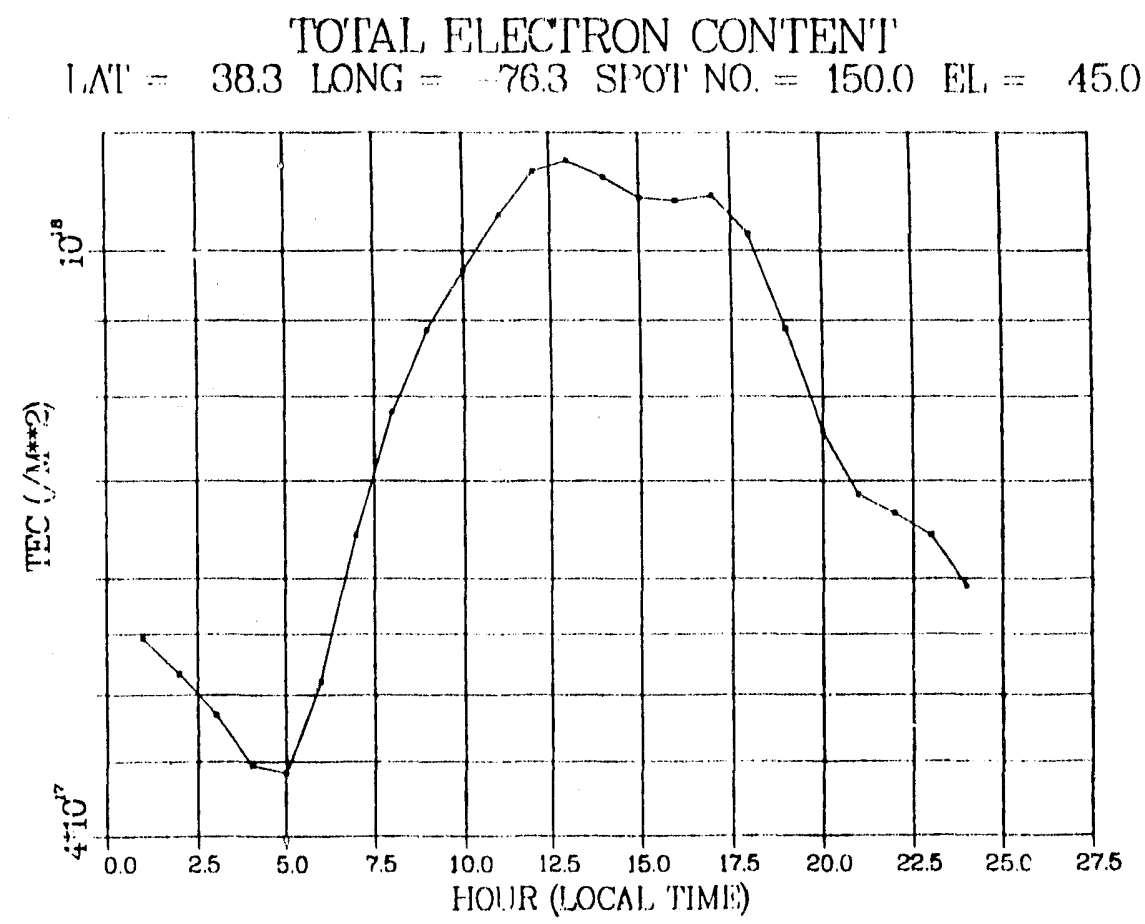

$6 \mathrm{~b}$

Figures 6a-b: Plots of the TEC as a function of the time of day for sunspot numbers and elevation angles of $150,90^{\circ}$ (a); and $150,45^{\circ}(\mathrm{b})$. 
'T'O'IAI, F'LE'CIIRON CON'IEN'I'

I.A' -38.3 LONG $=76.3$ SPO'I NO $=150.0$ EL $=30.0$

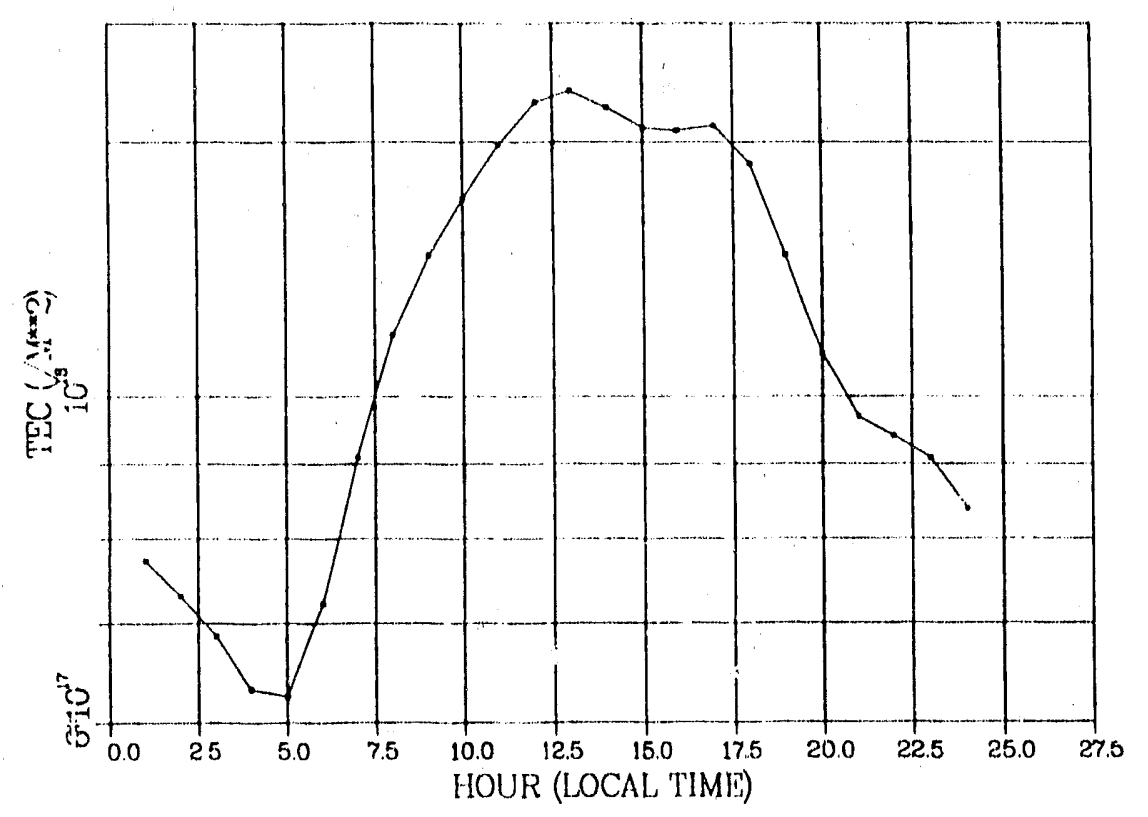

$6 c$

'TO'TAL, FLECITRON CON'TE'N'I'

$I_{1} \mathrm{~N}^{\prime}=38.3 \mathrm{LONG}=-76.3 \mathrm{SP}\left(\mathrm{O}^{\prime} \mathrm{T} \mathrm{NO}=150.0 \mathrm{EI}=15.0\right.$

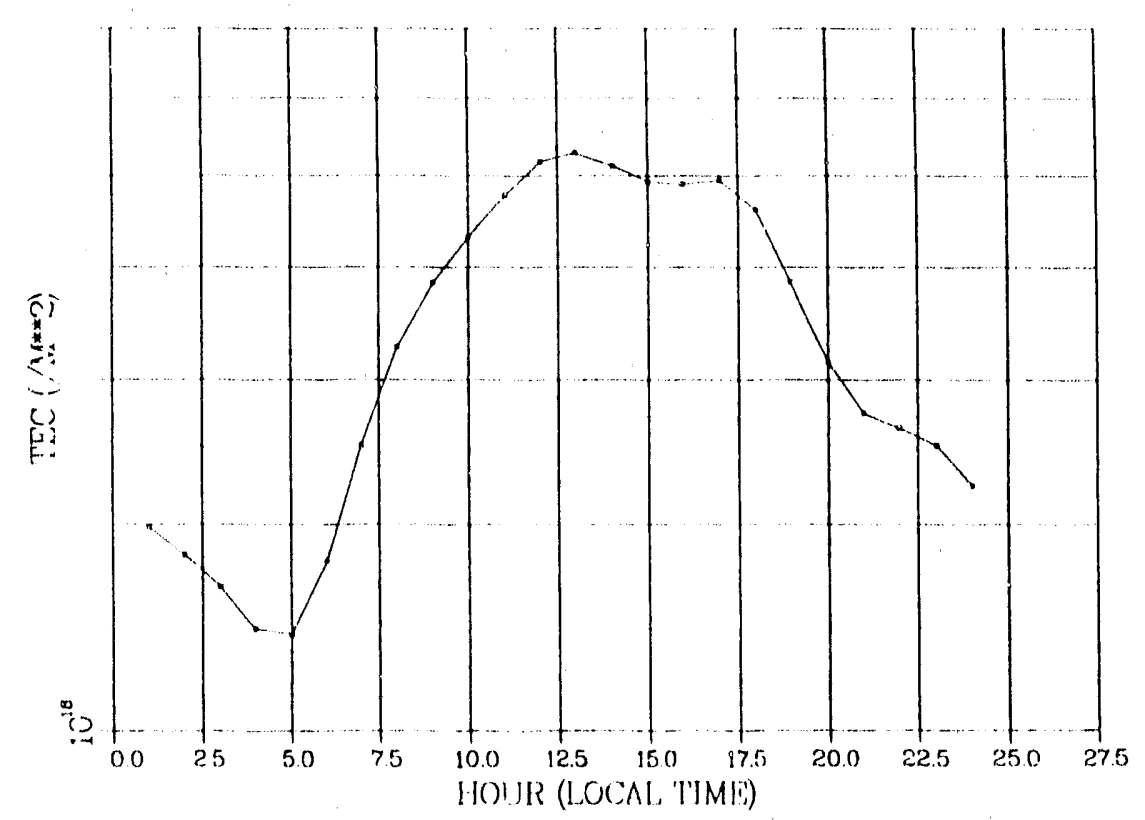

$6 d$

Figures $6 \mathrm{c}-\mathrm{d}$ : Plots of the TEC as a function of the time of day for sunspot numbers and elevation angles of $150,30^{\circ}(\mathrm{c})$; and $150,15^{\circ}(\mathrm{d})$. 
TOTAL ELECTRON CONTENT

$\mathrm{LAT}=39.3 \mathrm{LONG}=-76.3 \mathrm{SPOT}$ NO $=182.0 \mathrm{EL}==90.0$

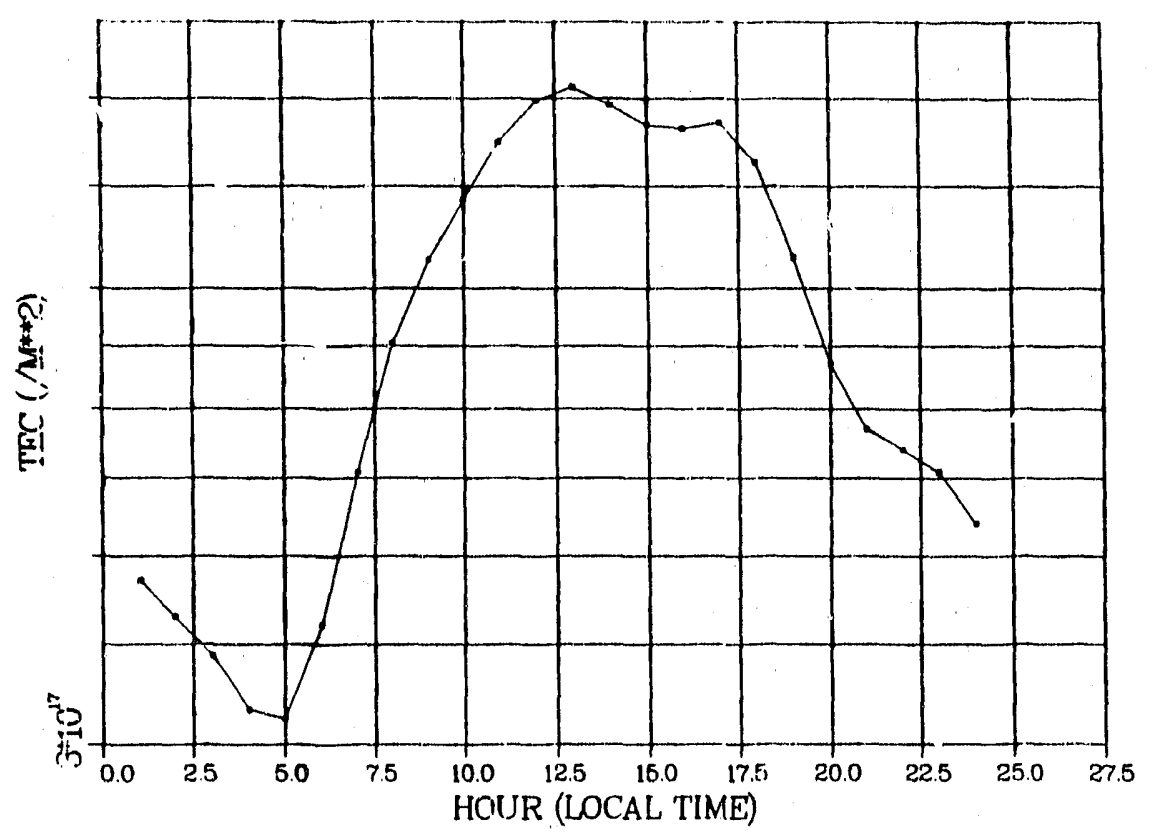

$6 e$

TOTAL ELECTRON CONTENT

$\triangle \mathrm{AT}=38.3$ LONG $=-76.3$ SPOT NO $=182.0 \quad \mathrm{E} \mathrm{L}=45.0$

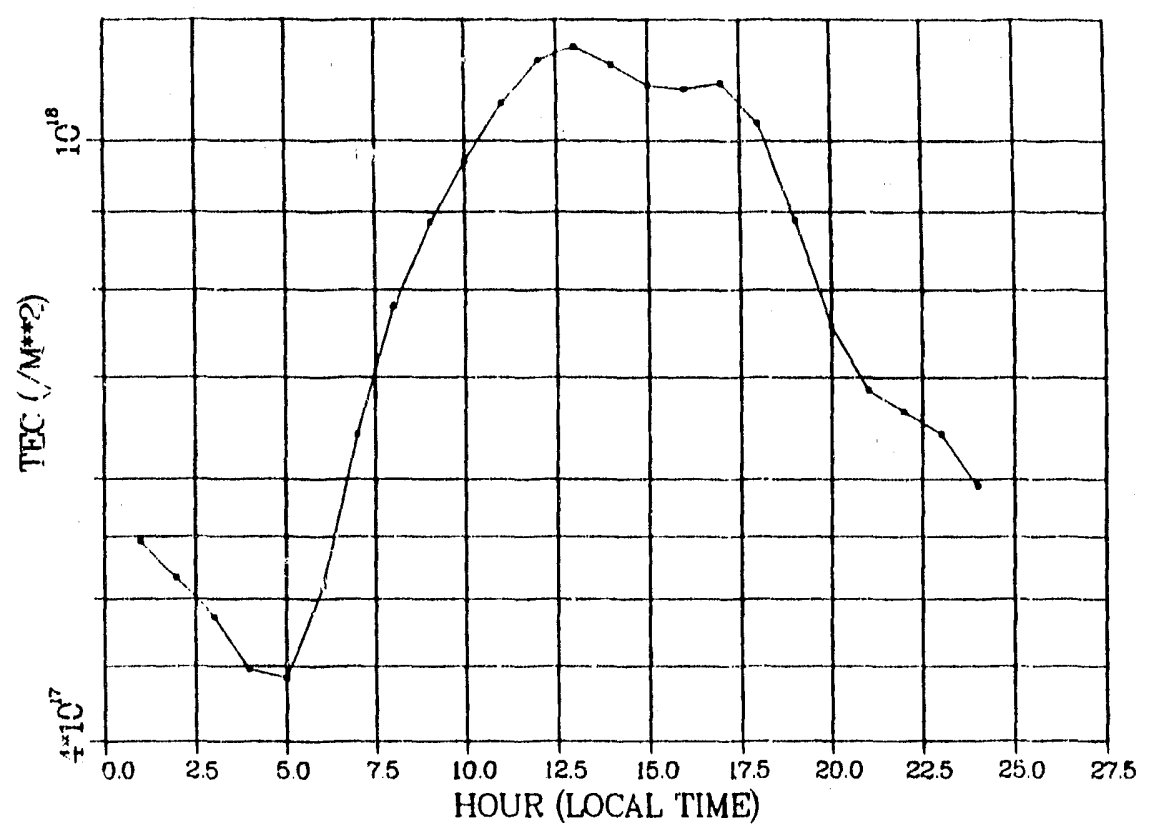

$6 f$

Figures $6 \mathrm{e}-\mathrm{f}$ : Plots of the TEC as a function of the time of day for sunspot numbers and elevation angles of $182,90^{\circ}$ (e); and $182,45^{\circ}(\mathrm{f})$. 

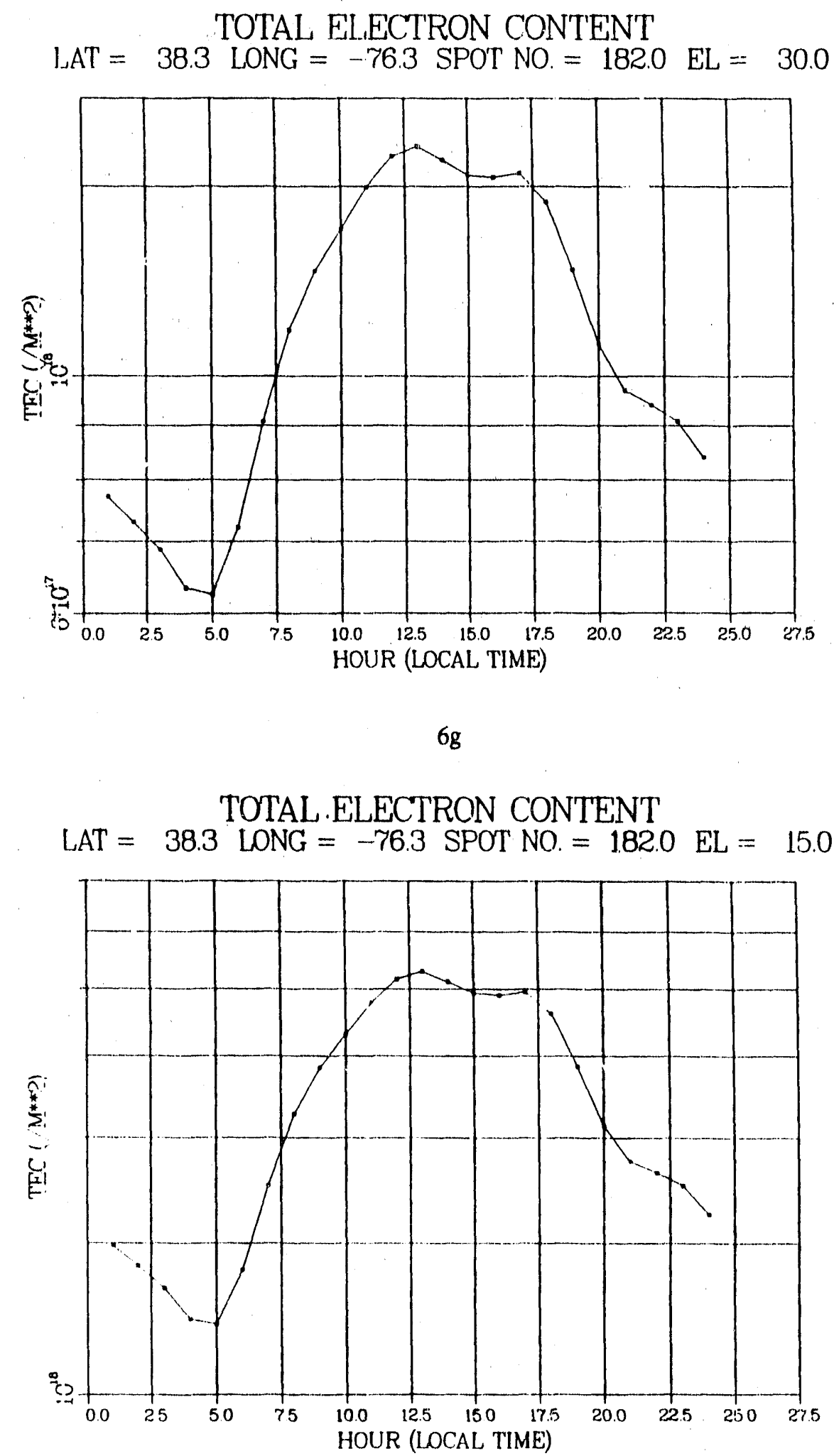

$6 \mathrm{~h}$

Figures $6 \mathrm{~g}-\mathrm{h}$ : Plots of the TEC as a function of the time of day for sunspot numbers and elevation angles of $182,30^{\circ}(\mathrm{g})$; and $182,15^{\circ}(\mathrm{h})$. 


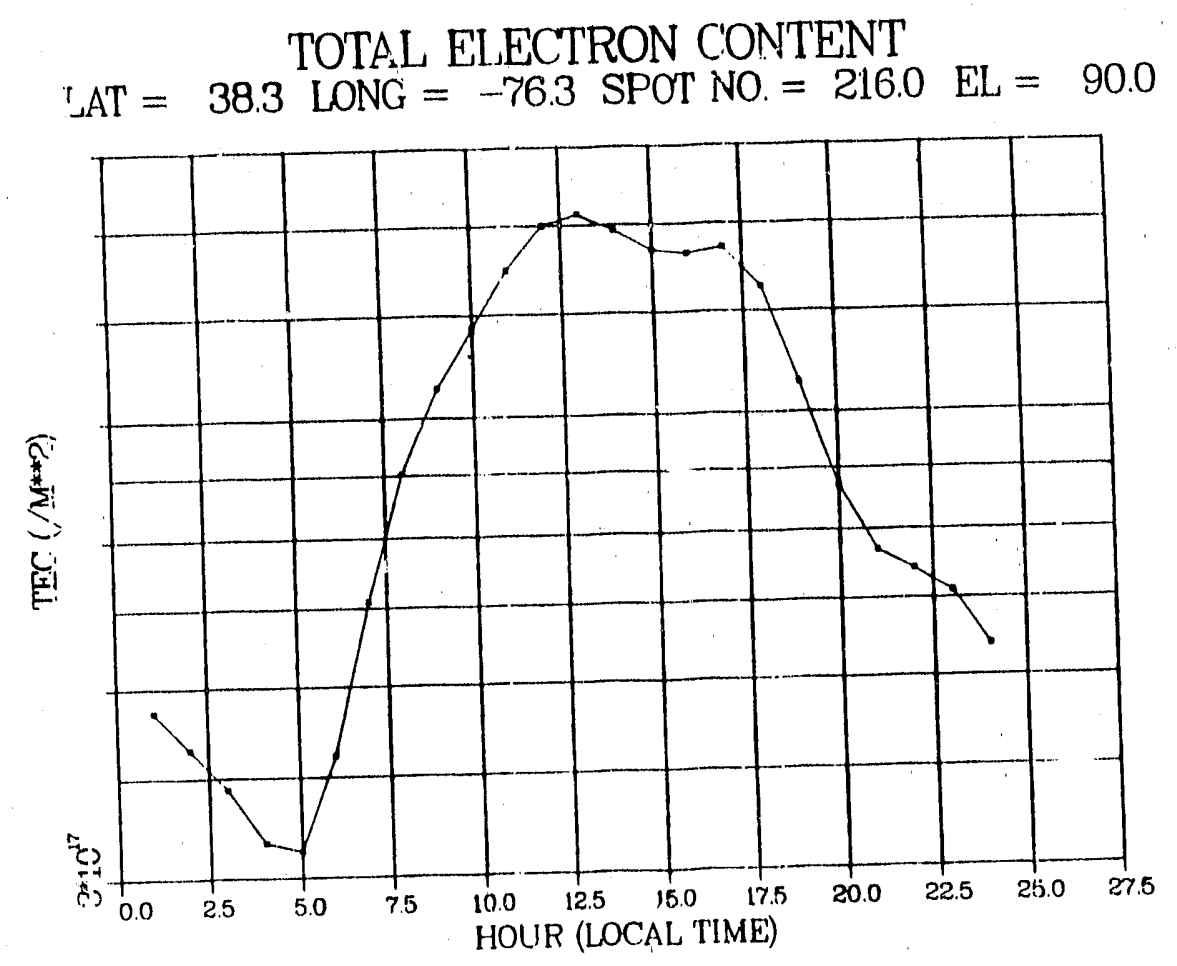

$6 i$

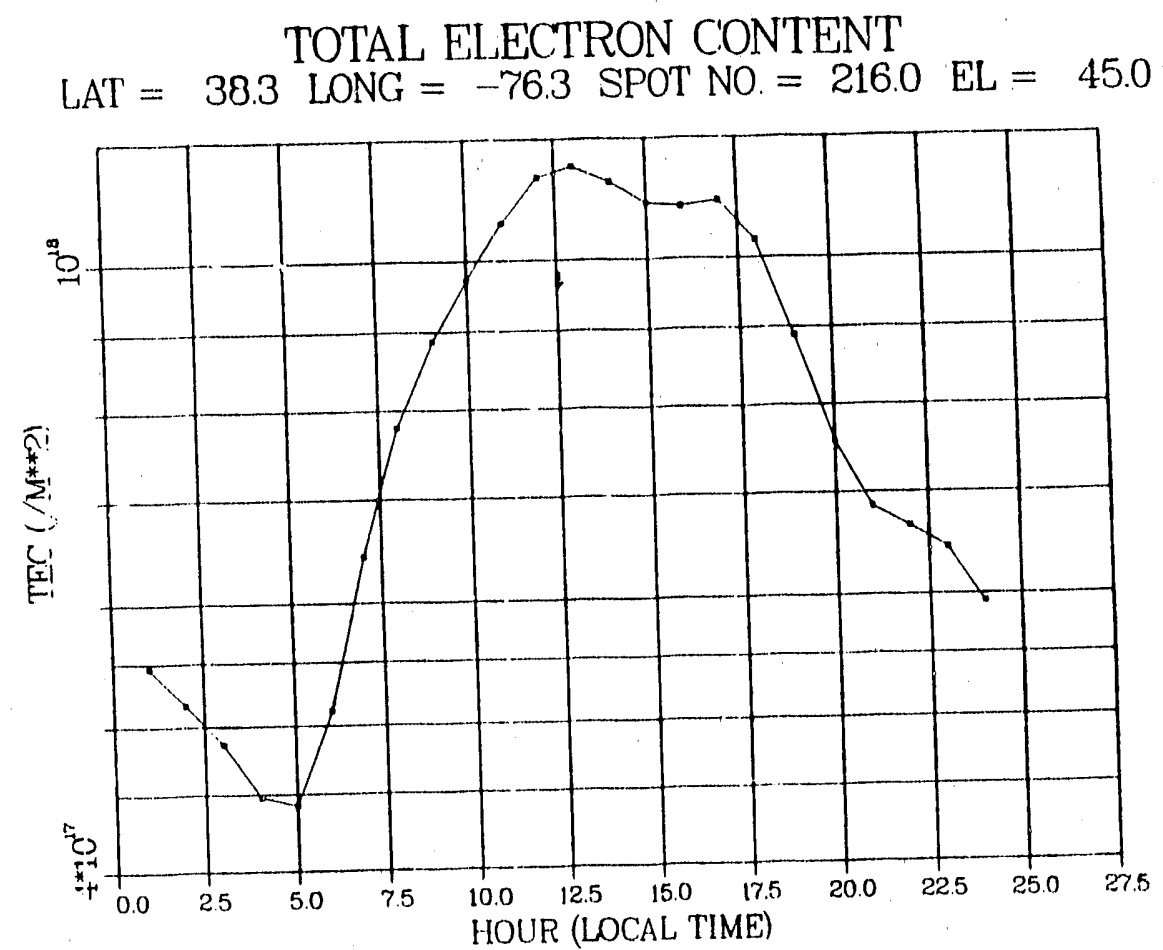

$6 j$

Figures 6i-j: Plots of the TEC as a function of the time of day for sunspot numbers and elevation angles of $216,90^{\circ}$ (i); and $216,45^{\circ}(\mathrm{j})$. 

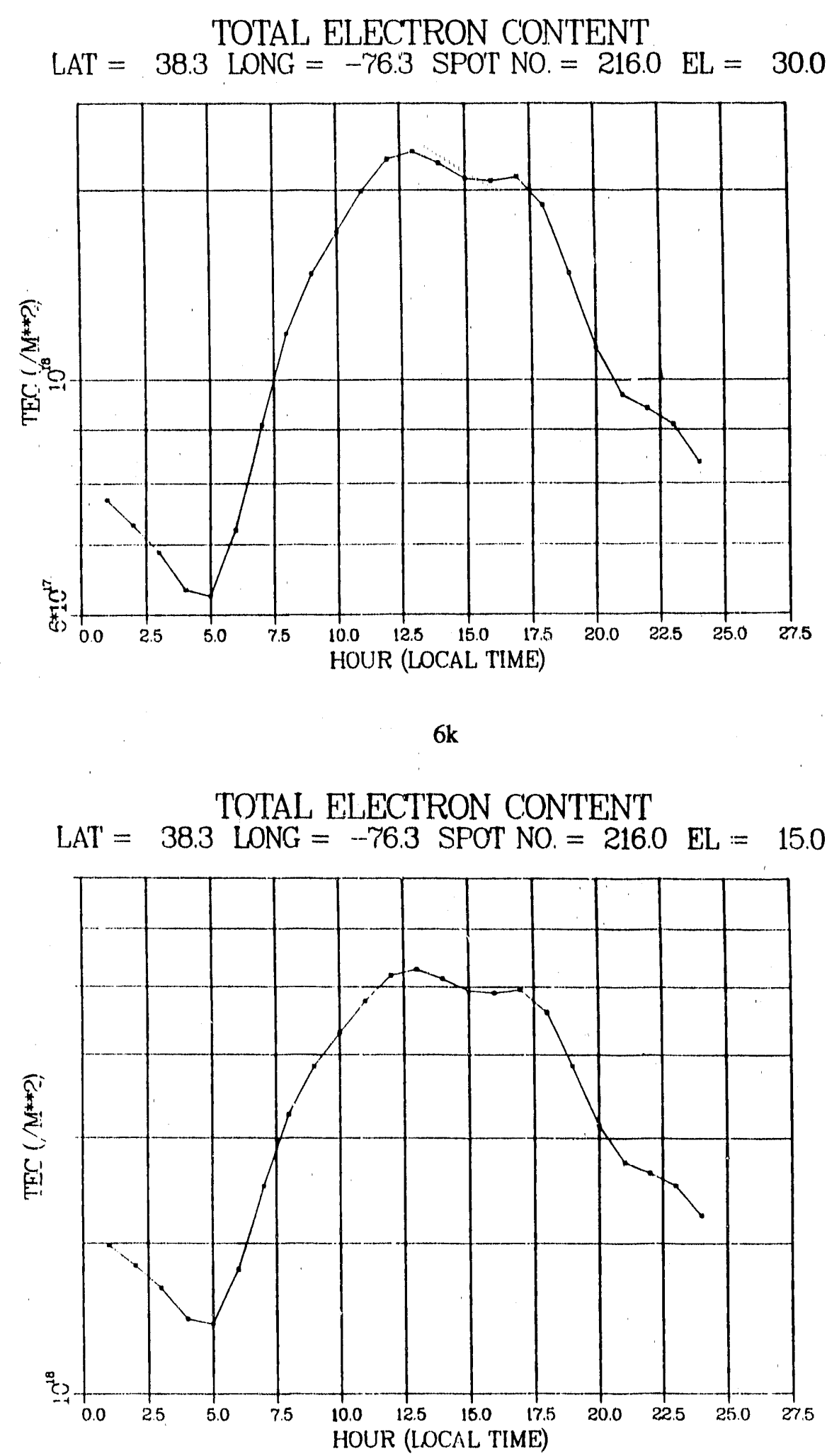

61

Figures $6 \mathrm{k}-1$ : Plots of the TEC as a function of the time of day for sunspot numbers and elevation angles of $216,30^{\circ}(\mathrm{k})$; and $216,15^{\circ}(1)$. 
TRANS IONOSPIHERIC PULSE - TEC $=1.0000(10 * 13 / C M * 2)$ FREO RANGE 40.0 TO 500:0 MHz

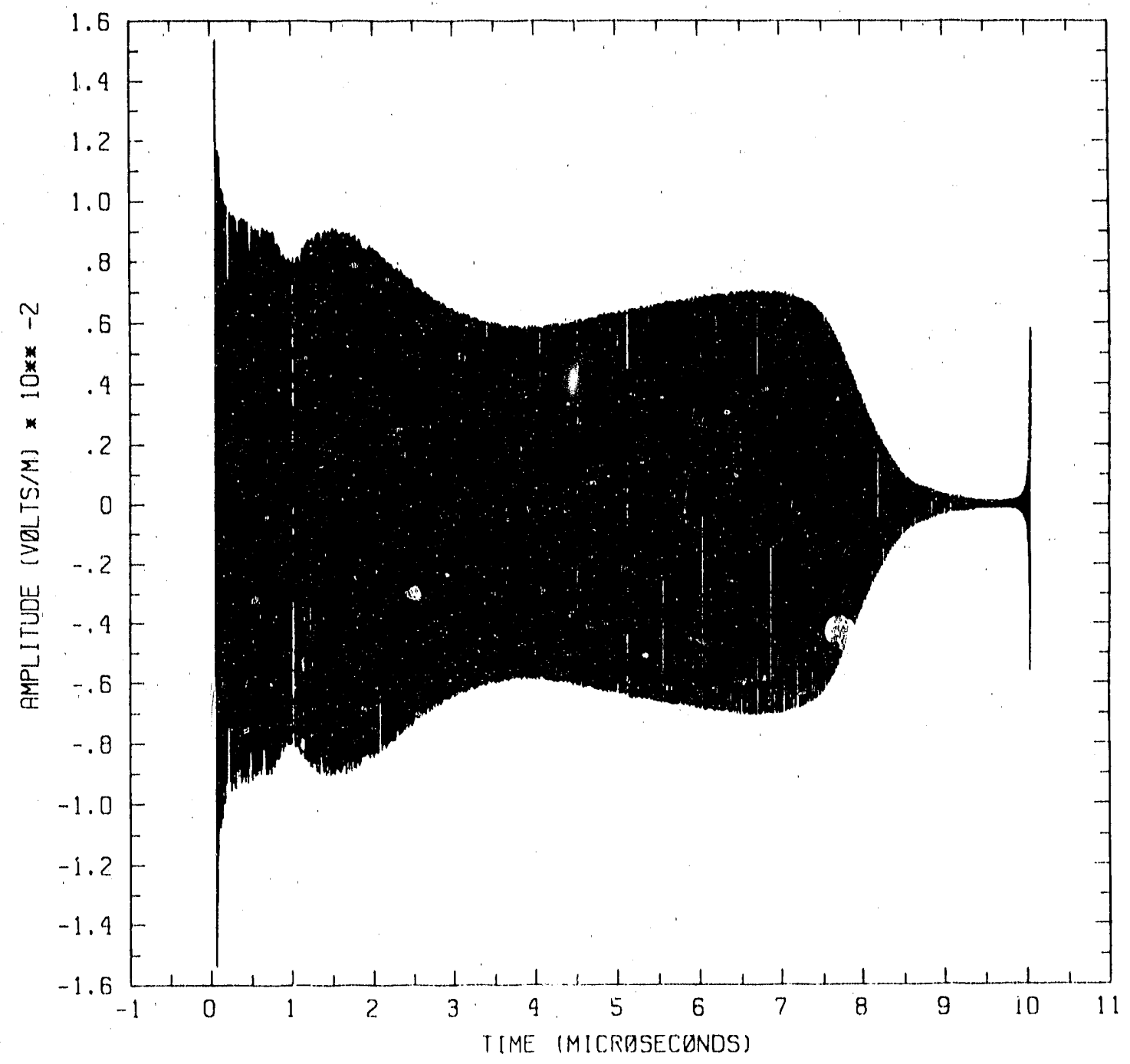

Figure 7: Transionospheric signal for the VPD L01 pulse at $42^{\circ}$ clevation and for a TEC of $1 \times 10^{17} \mathrm{~m}^{-2}$. Only frequencies in the range of $40-500 \mathrm{MHz}$ are included in this plot. 
TRANS IONOSPHERIC PULSE. - TEC - $1.0000(10 \times * 13 / \mathrm{cm} * * 2)$

FREO RFINGE: $\quad 36.5$ TO $500.0 \mathrm{MHZ}$

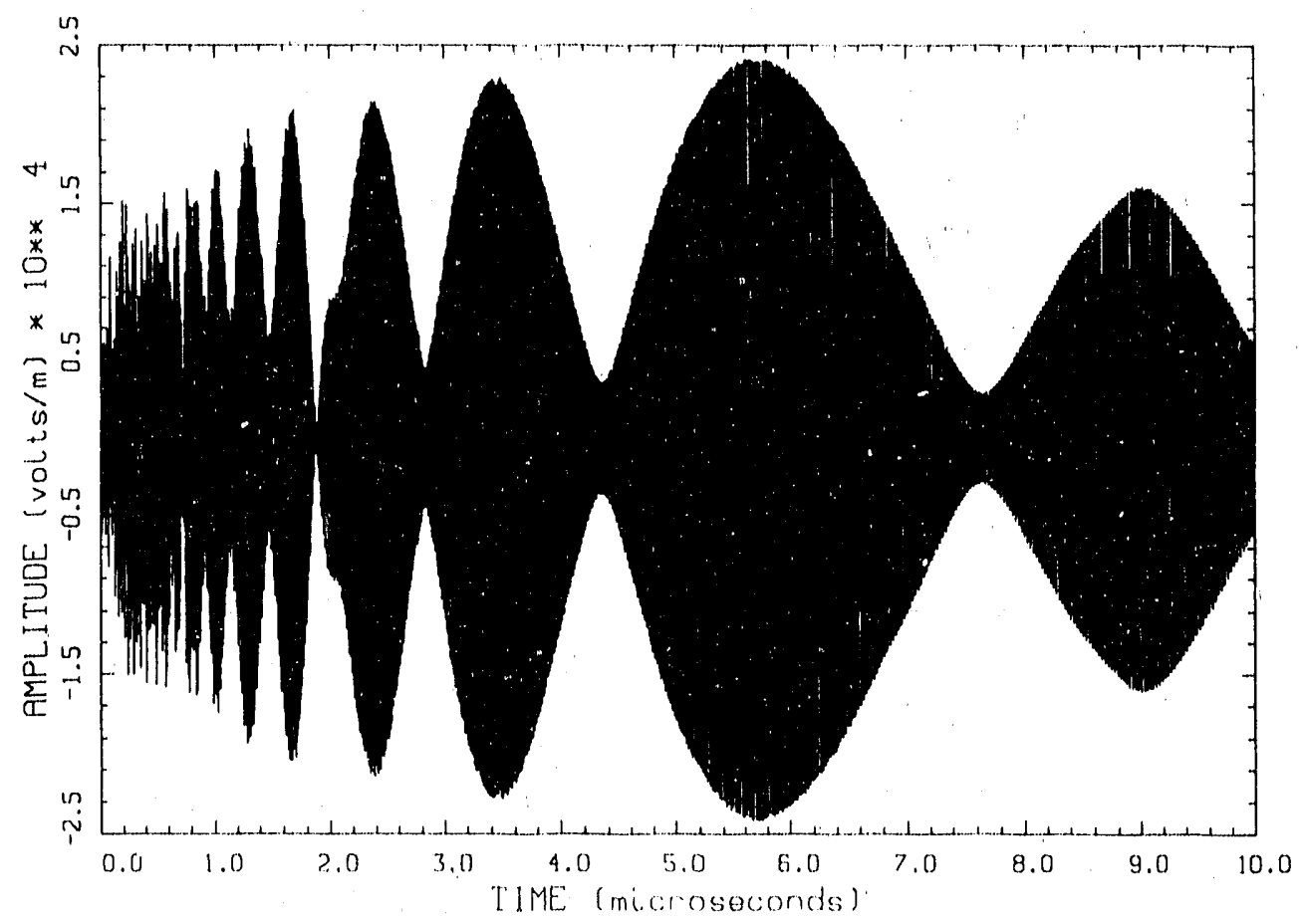

$8 \mathrm{a}$

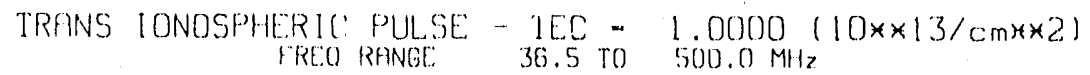

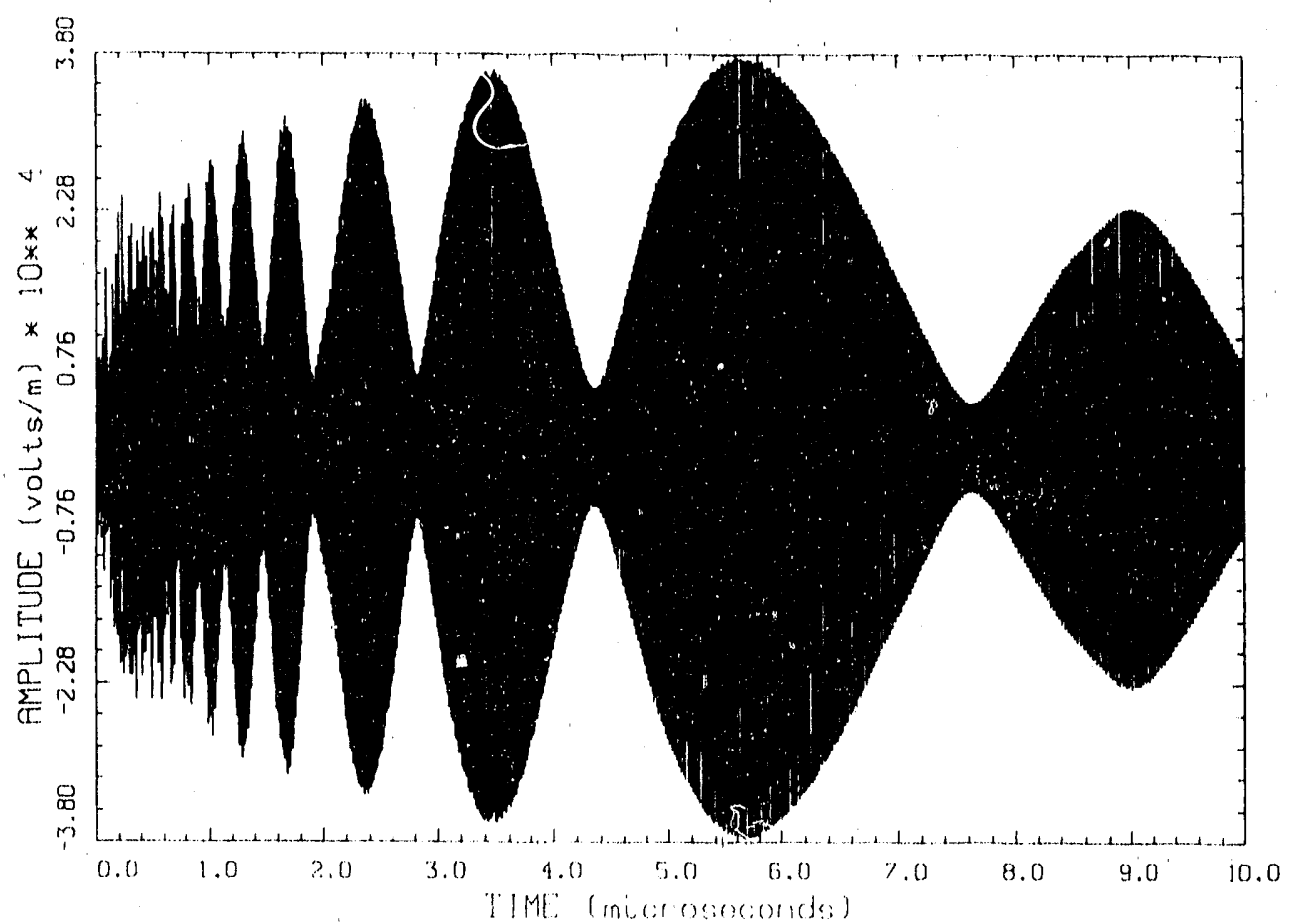

$8 \mathrm{~b}$

Figures 8a-b: Transionospheric signals for the HPD pulses at $20^{\circ}$ elevation, $37^{\circ}$ azimuth (a) and $20^{\circ}$ elevation, 9()$^{\circ}$ azimuth (b), for a TEC of $1 \times 10^{17} \mathrm{~m}^{2}$. Only frequencies in the range of $37-500 \mathrm{MHz}$ are included in these plots. 


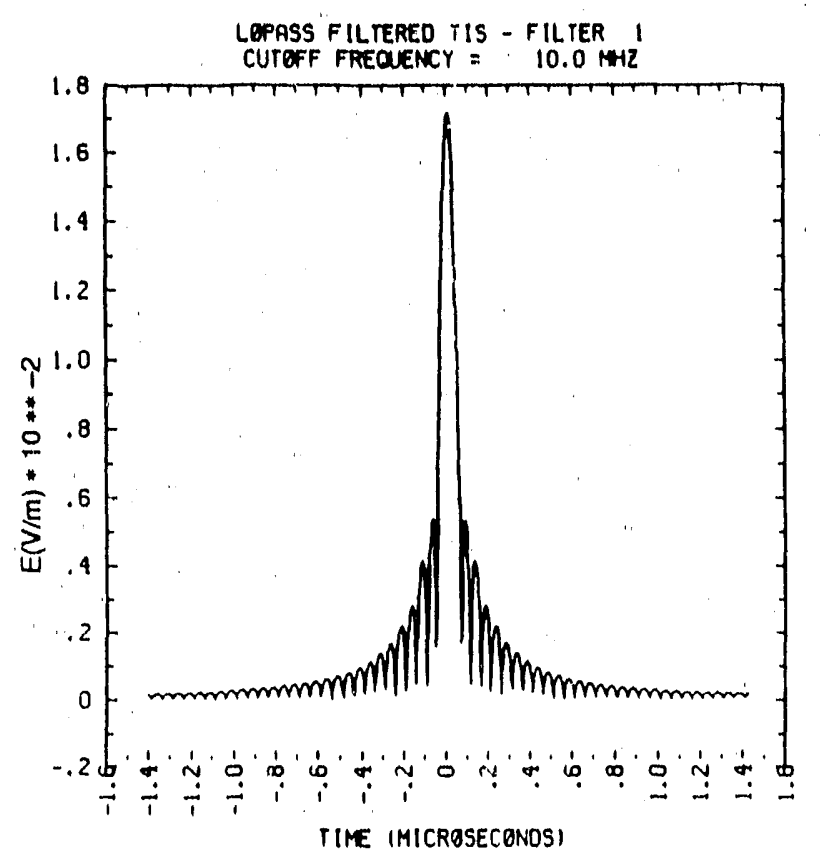

$9 \mathrm{a}$

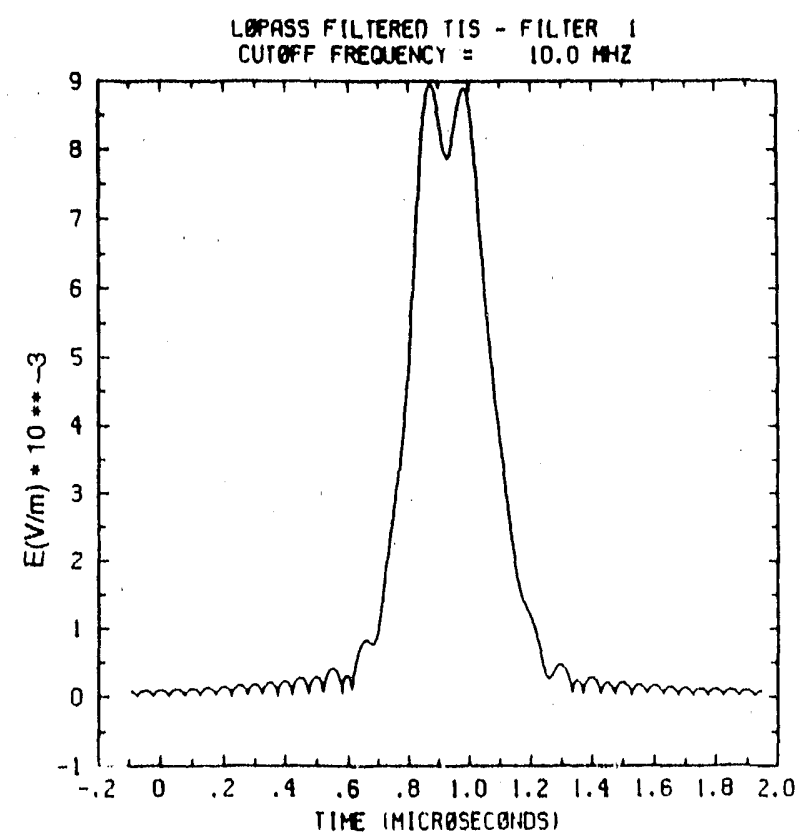

$9 \mathrm{c}$

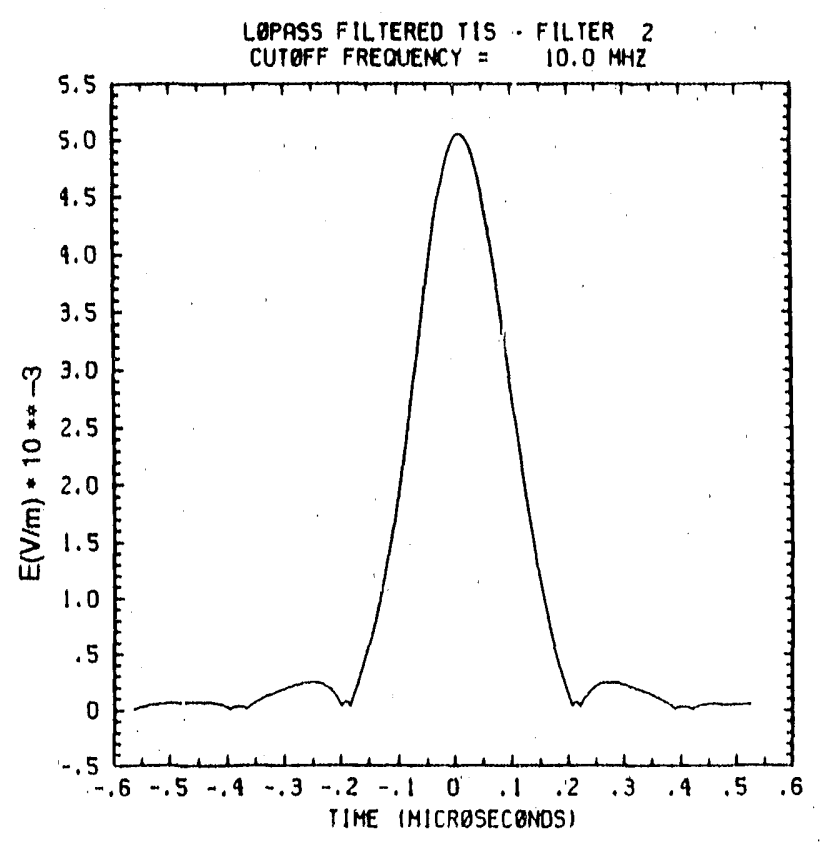

$9 \mathrm{~b}$

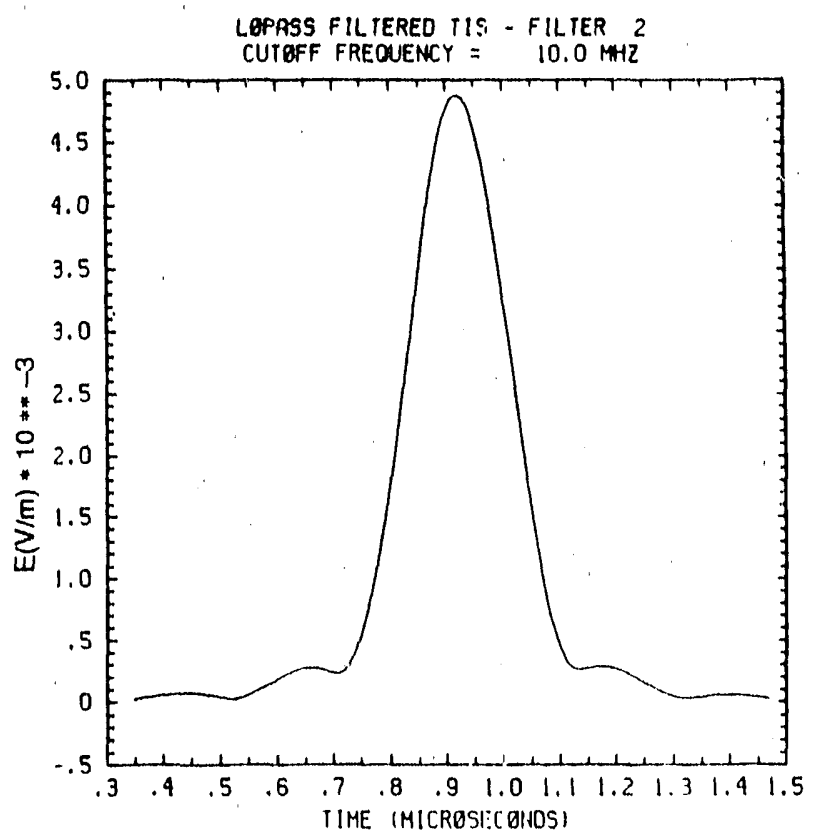

$9 \mathrm{~d}$

Figures 9a-d: Envelopes of the detected transionospheric signal for the VPD L02 pulse at $17^{\circ}$ elevation for the 5 and 20 $\mathrm{MHz}$ bandwidth receivers centered at $120 \mathrm{MHz}$ and for TECS of $0.01 \times 10^{17} \mathrm{~m}^{-2}(\mathrm{a}$ and $\mathrm{b}), 1.0 \times 10^{17} \mathrm{~m}^{-2}(\mathrm{c}$ and $\mathrm{d})$, 


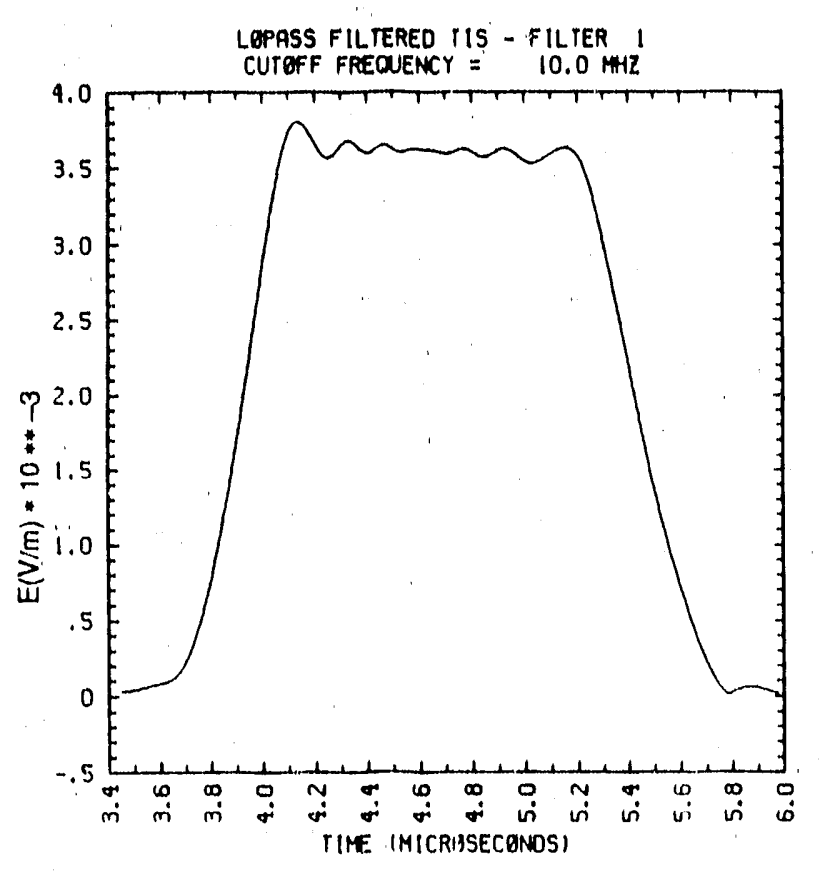

$9 \mathrm{c}$

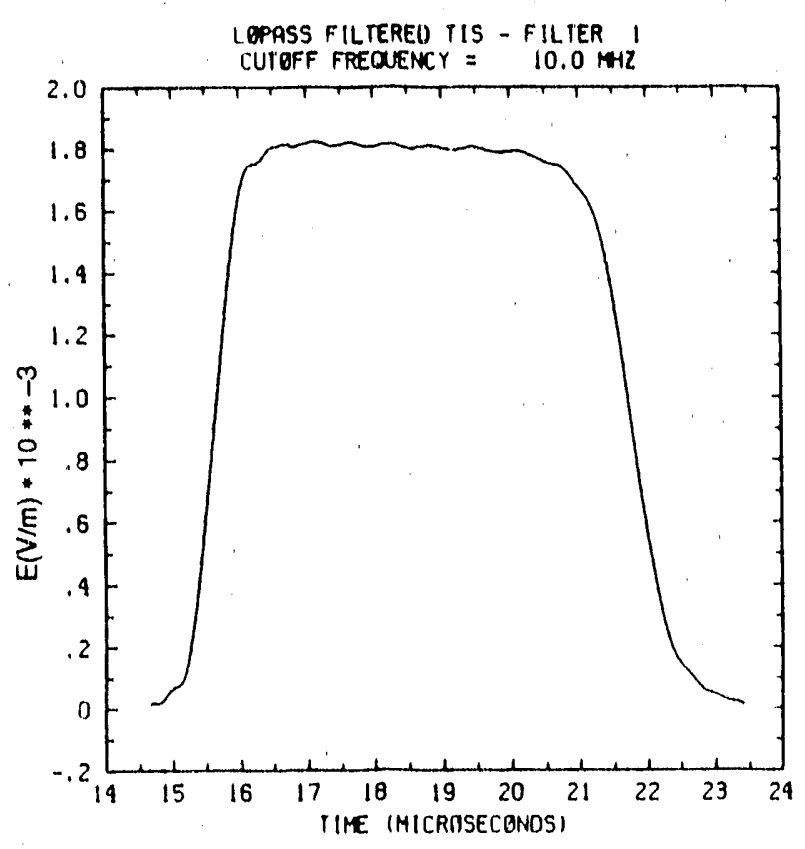

$9 \mathrm{~g}$

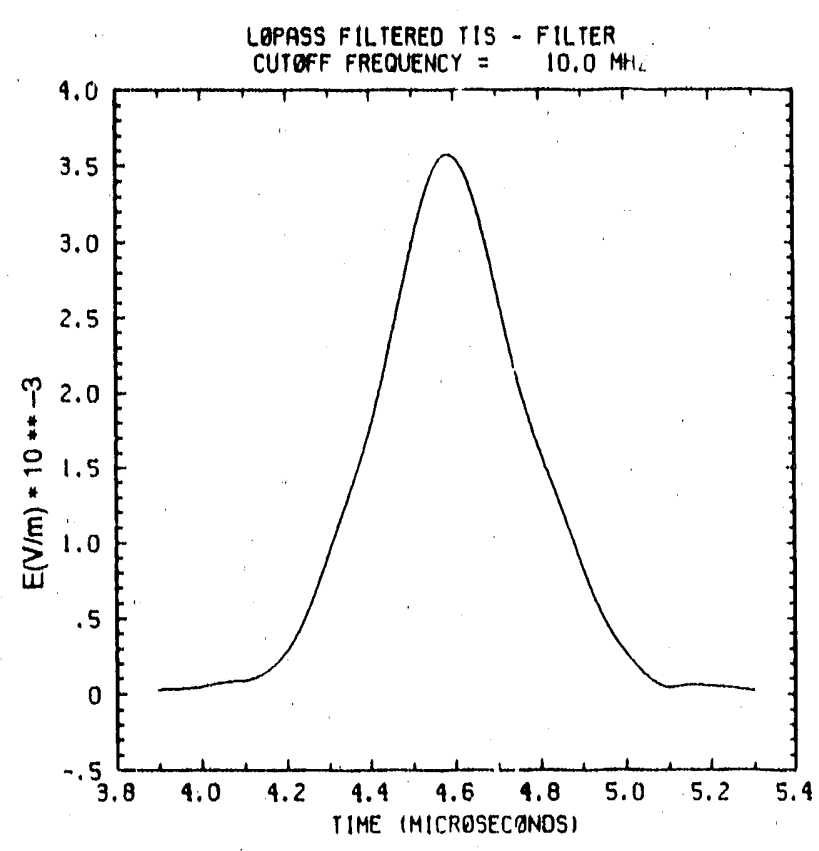

9f

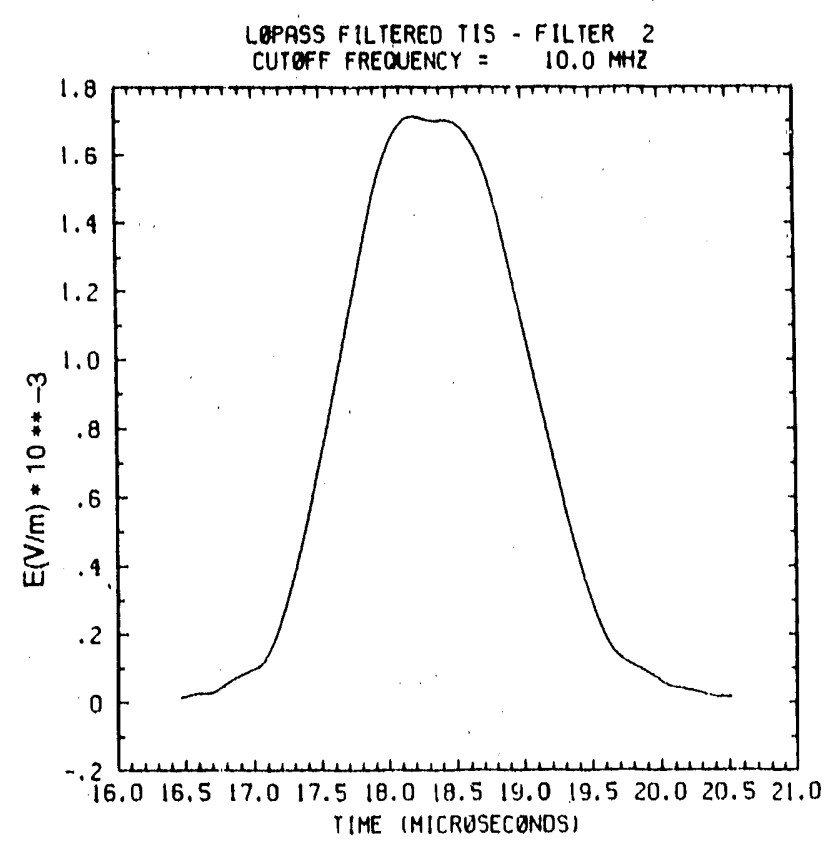

9h

Figures 9e-h: Envelopes of the detected transionospheric signal for the VPD L.02 pulse at $17^{\circ}$ elevation for the 5 and 20 MHz bandwidth receivers centered at $120 \mathrm{MHz}$ and for TECs of $5.0 \times 10^{17} \mathrm{~m}^{2}(\mathrm{c}$ and $\mathrm{f})$, and $20.0 \times 10^{17} \mathrm{~m}^{-2}(\mathrm{~g}$ and $\mathrm{h})$. 


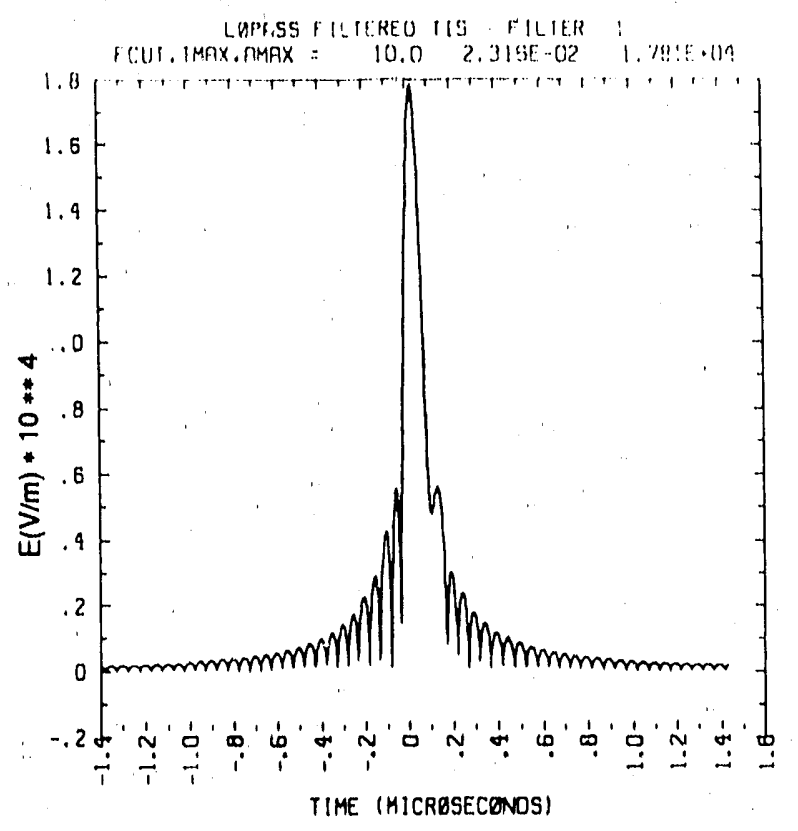

$10 a$

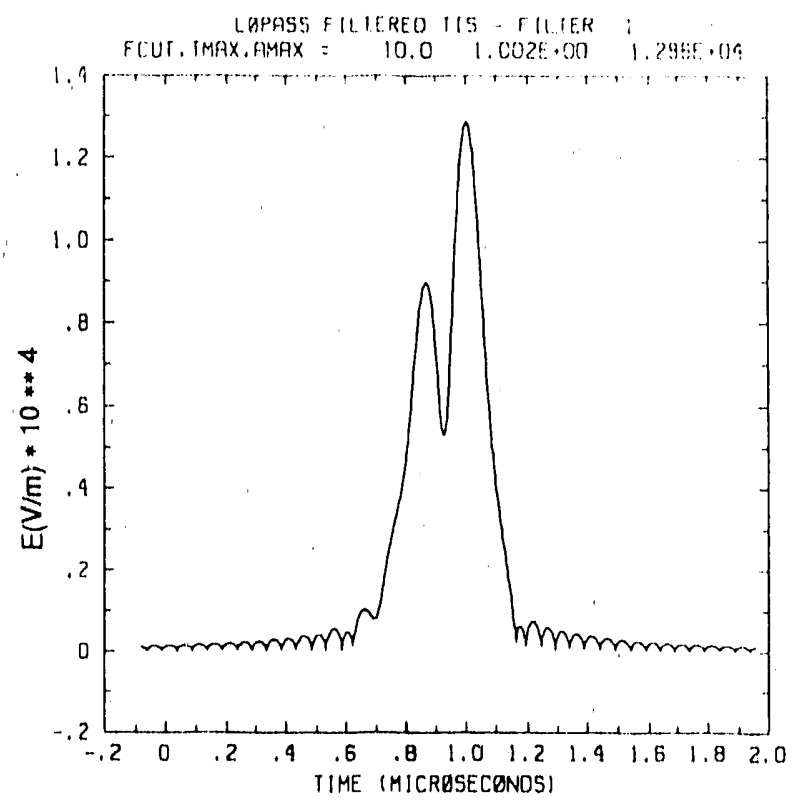

$10 \mathrm{c}$

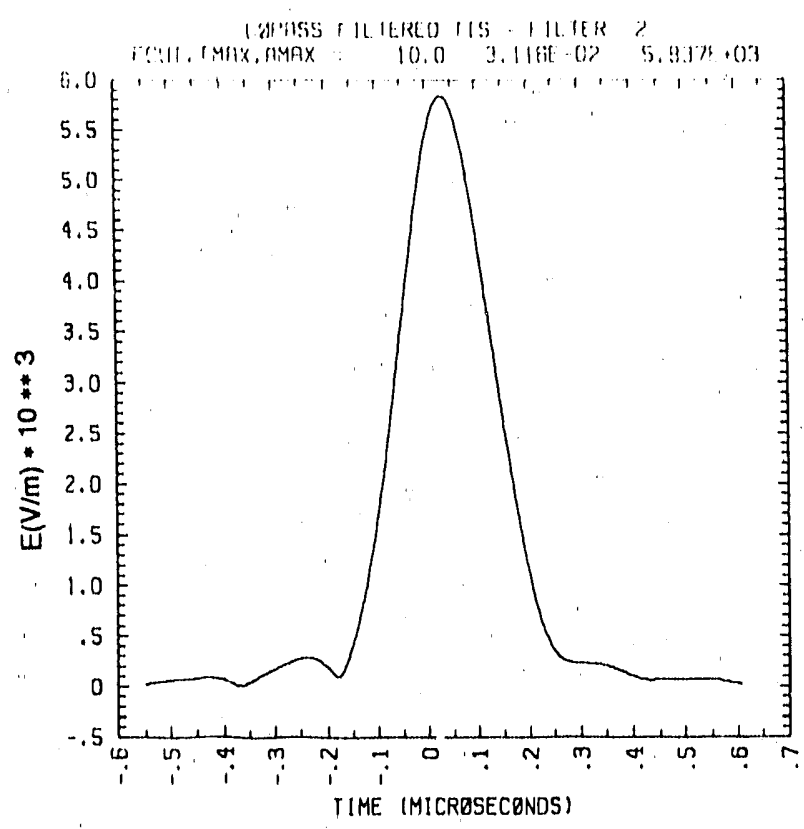

$10 \mathrm{~b}$

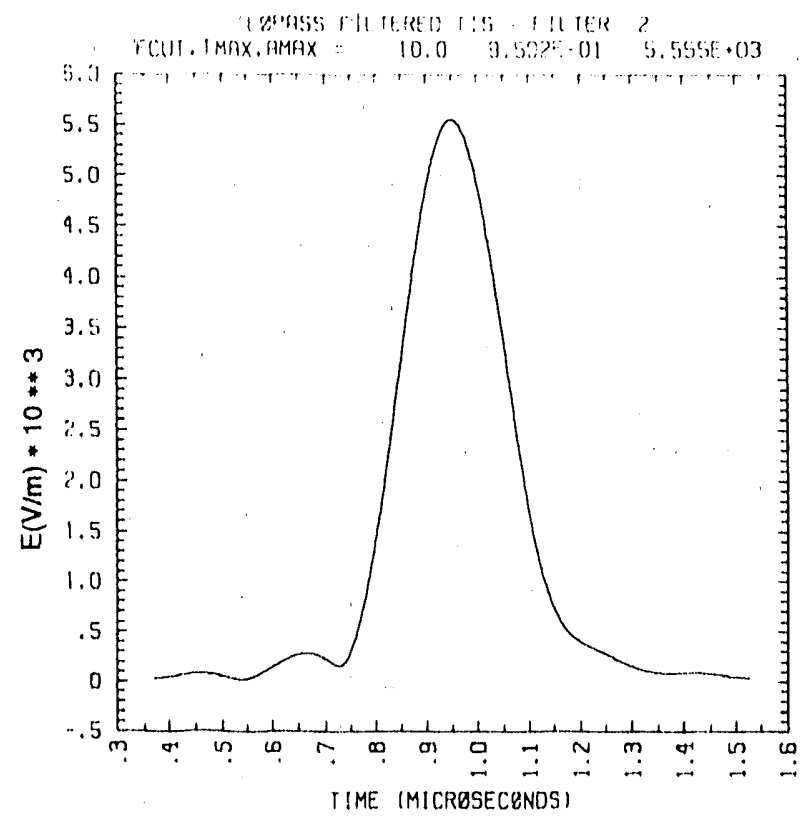

$10 \mathrm{~d}$

Figures 10a-d: Envelopes of the detected transionospheric signal for the HPD pulse at $20^{\circ}$ elevation and $37^{\circ}$ azimuth for the 5 and $20 \mathrm{MHz}$ bandwidth receivers centered at $120 \mathrm{MHz}$ and for TECs of $\left(0.01 \times 10^{17} \mathrm{~m}^{-2}(\mathrm{a}\right.$ and $\mathrm{b}), 1.0 \times 10^{17} \mathrm{~m}^{-2}(\mathrm{c}$ and $\mathrm{d}$ ). 


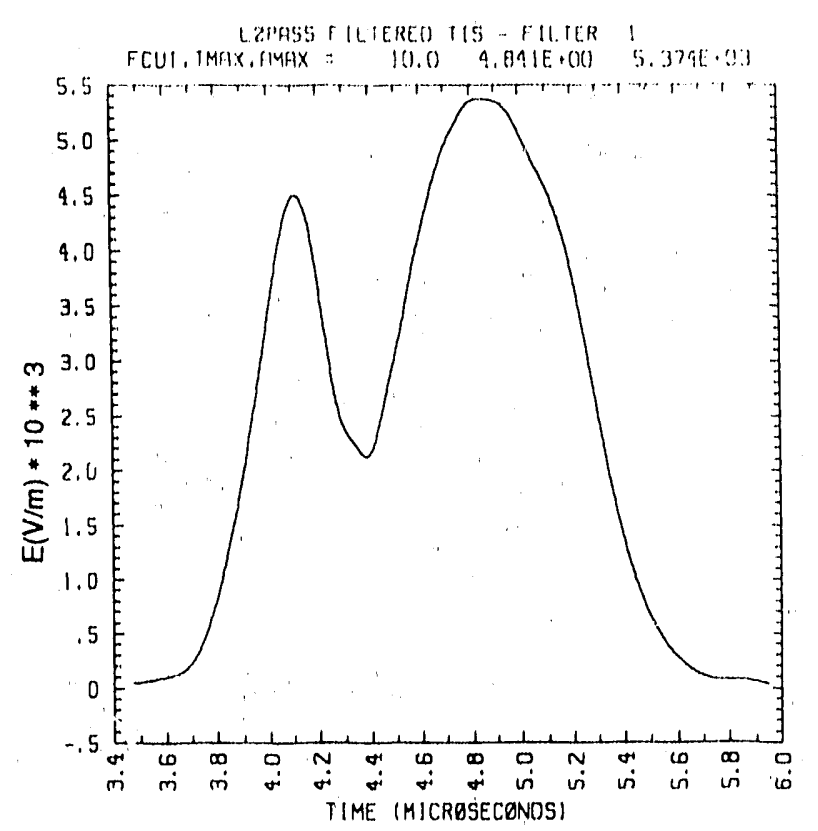

$10 \mathrm{e}$

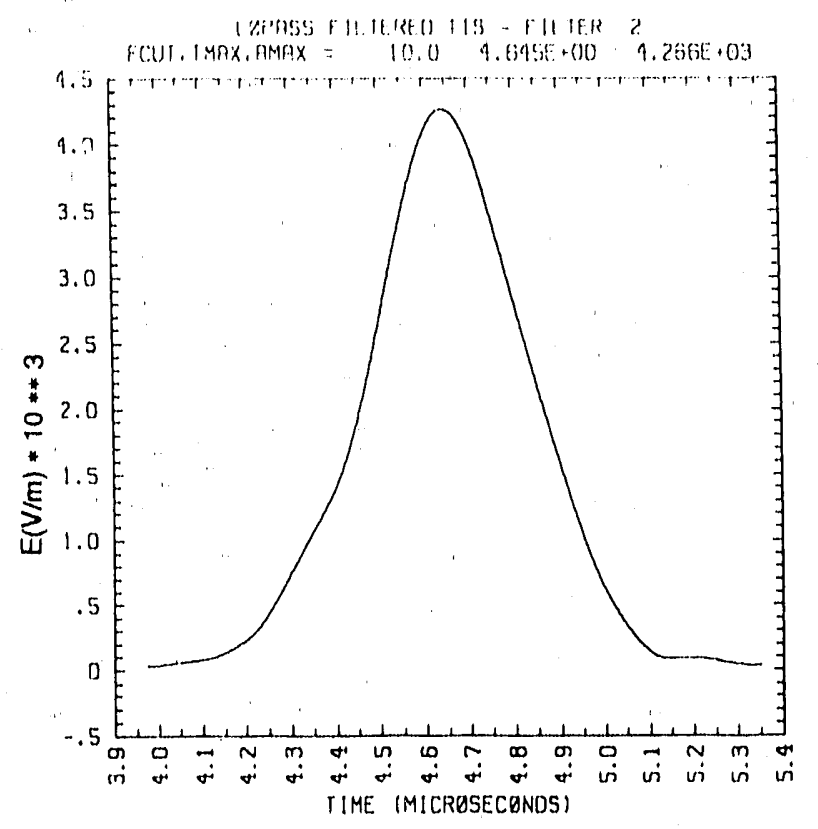

$10 \mathrm{f}$

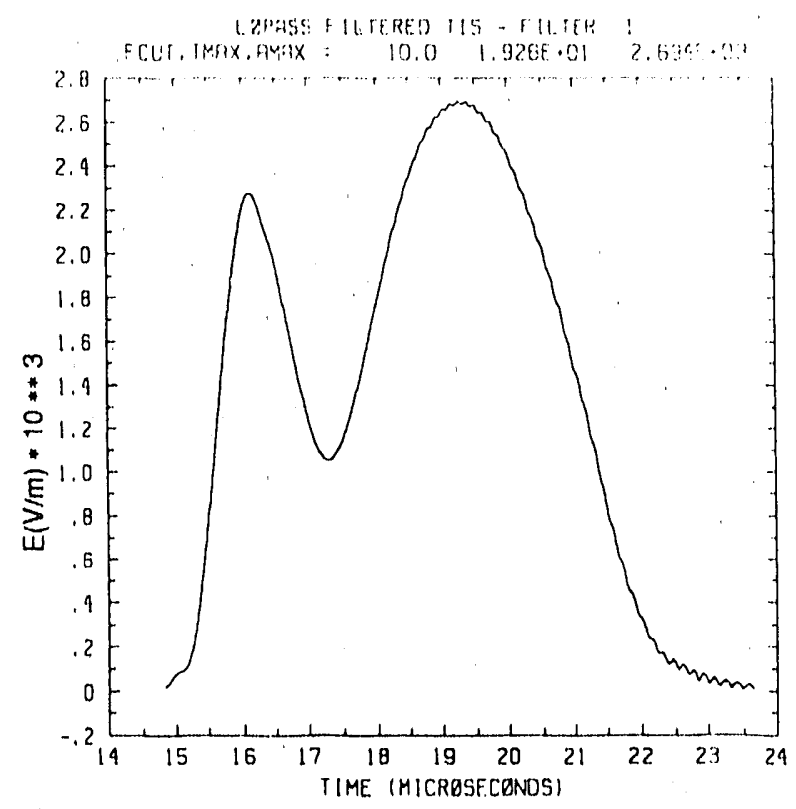

$\log$

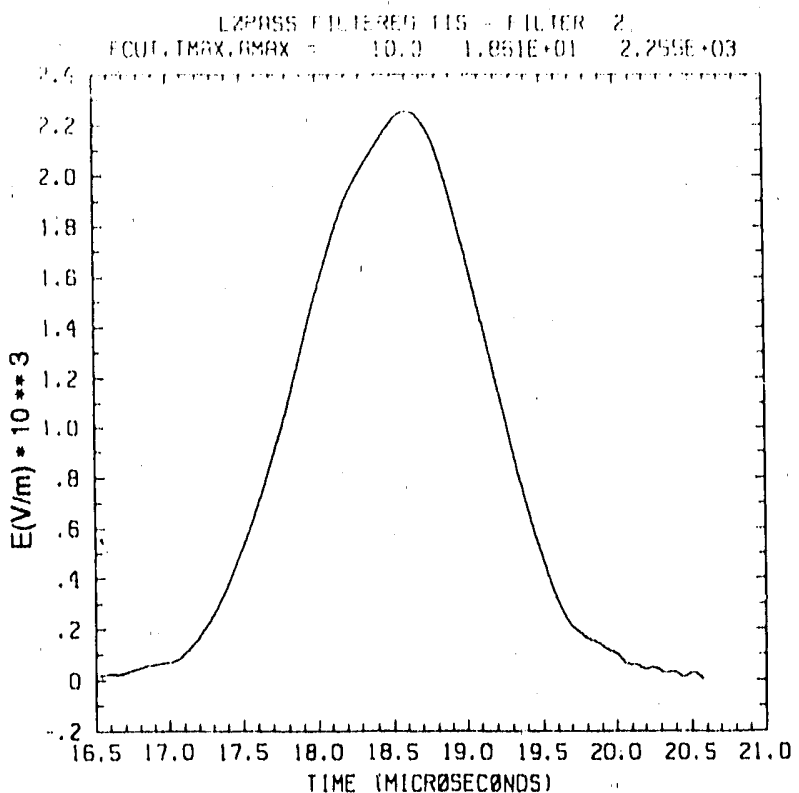

$10 h_{1}$

Figures 10e-h: Envelopes of the detected transionospheric signal for the HPD pulse at $20^{\circ}$ elevation and $37^{\circ}$ arimuth for the 5 and $20 \mathrm{MHz}$ bandwidth receivers centered at $120 \mathrm{MHz}$ and for TECs of $5.0 \times 10^{17} \mathrm{~m}^{-2}(\mathrm{c}$ and $\mathrm{f})$, and $20.0 \times 10^{17} \mathrm{~m}^{2}$. ( $g$ and $h$ ). 


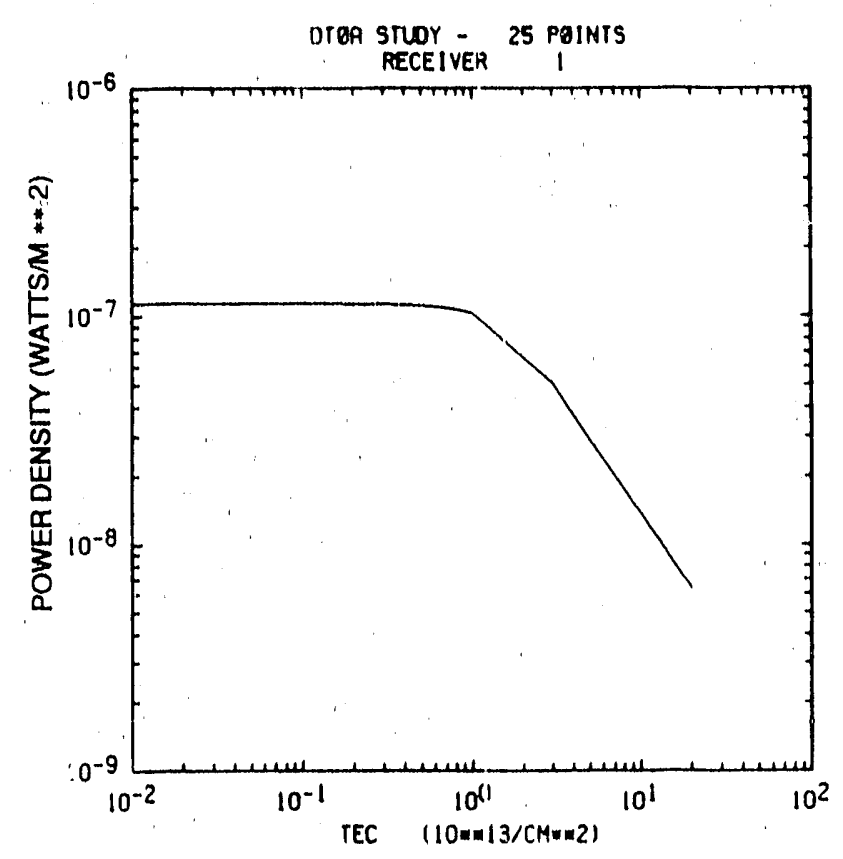

$11 \mathrm{a}$

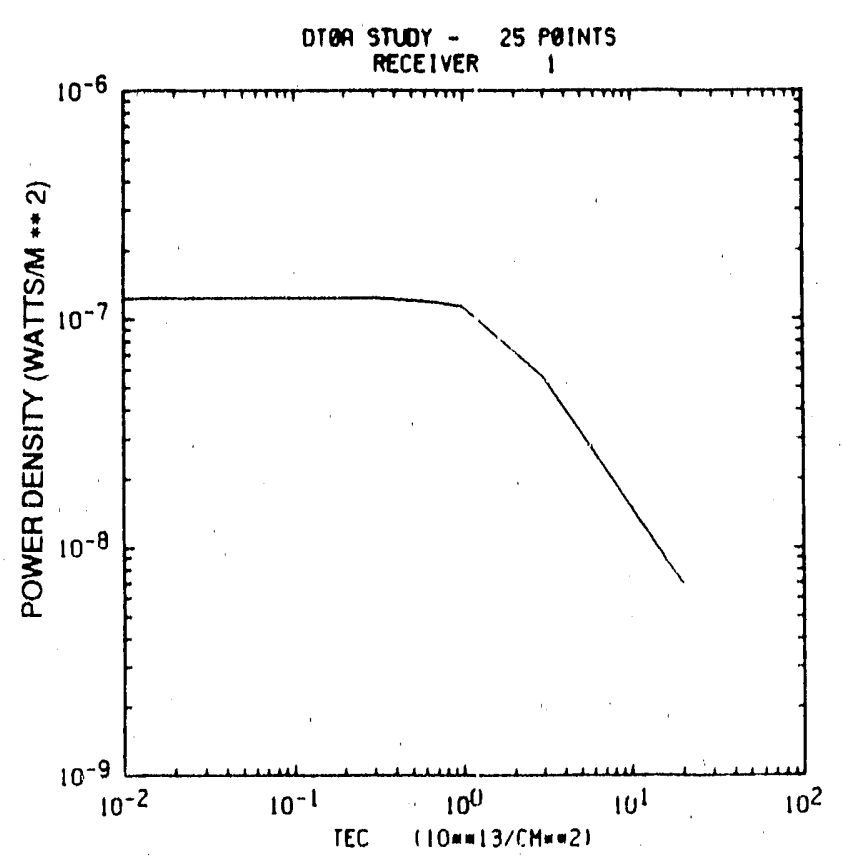

$11 \mathrm{c}$

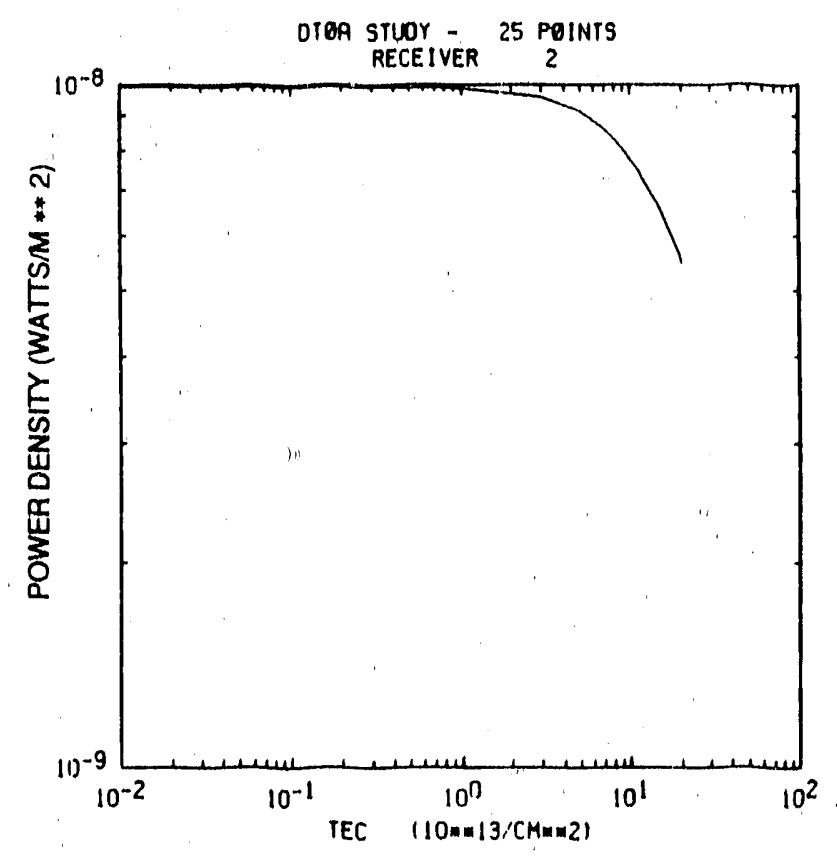

$11 \mathrm{~b}$

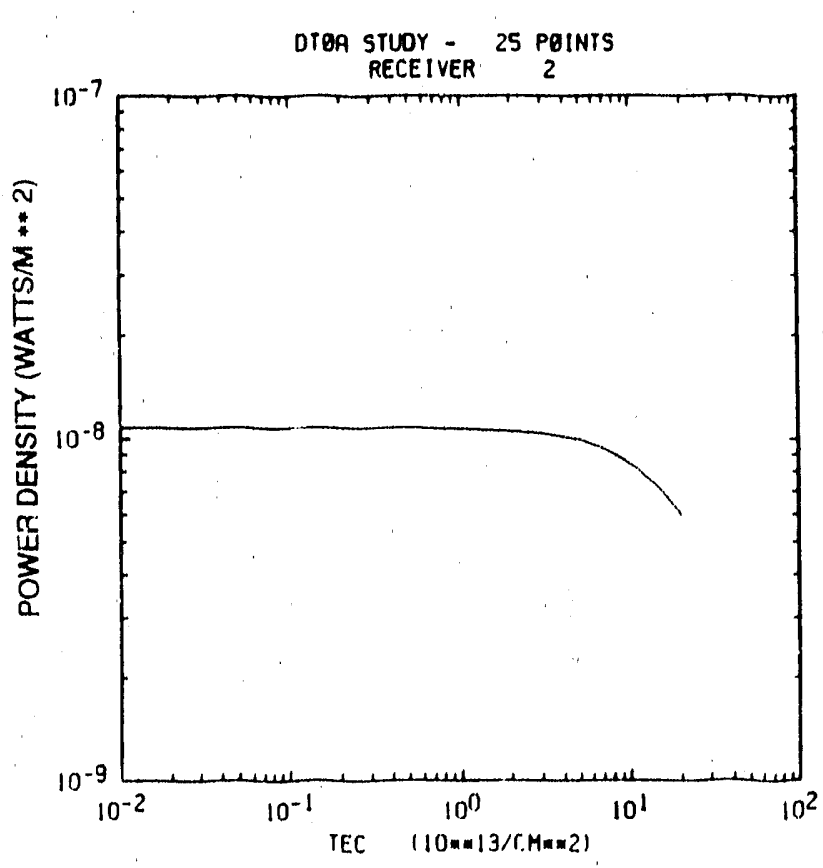

ild

Figures 11a-d: Maximum RMS power density (watts/ $\mathrm{m}^{2}$ ) at $1000 \mathrm{~km}$ range, measured in the 5 and $20 \mathrm{MHz}$ bandwidth receivers centered at $200 \mathrm{MHz}$ for the VPD L01 pulse at $42^{\circ}$ elevation (a and b); LO1 pulse at $30^{\circ}$ clevation (c and d). L() 1 pulse at $17^{\circ}$ clevation (e and f); LO2 pulse at $42^{\circ}$ elevation ( $\mathrm{g}$ and $\mathrm{h}$ ); L02 pulse at $30^{\circ}$ clevation ( $\mathrm{i}$ and $\mathrm{j}$ ); and L02 pulse at $17^{\circ}$ clevation ( $k$ and 1 ). 


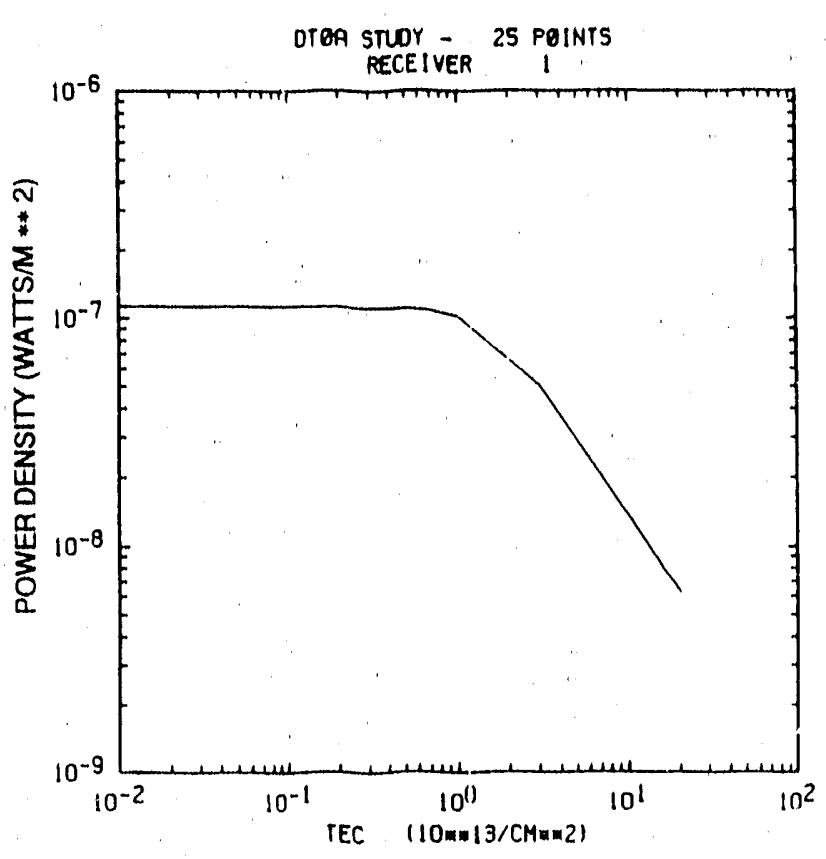

$11 \mathrm{e}$
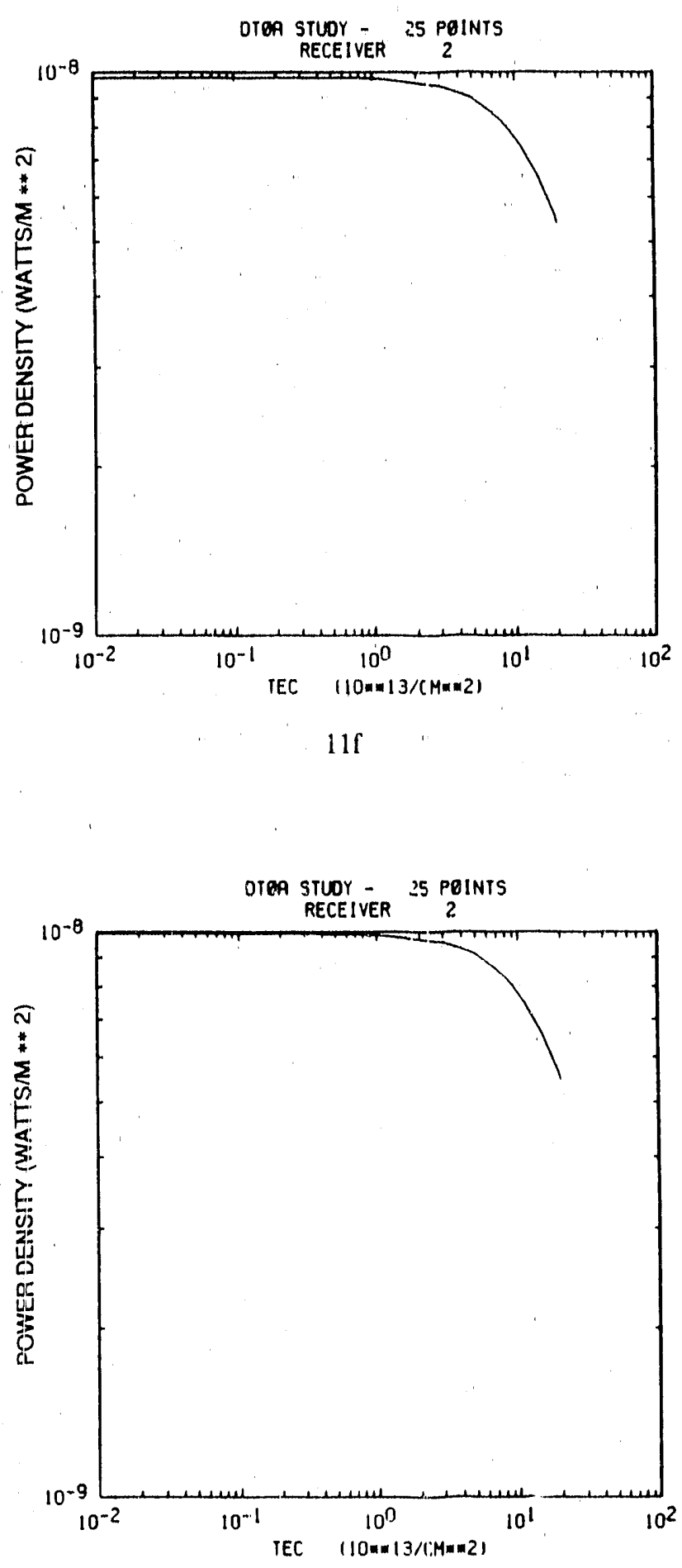

$11 \mathrm{~h}$

Figures 11e-h: Maximum RMS power density (watts/ $\mathrm{m}^{2}$ ) at $1000 \mathrm{~km}$ range, measured in the 5 and $20 \mathrm{MH} x$ bandwidth receivers centered at $200 \mathrm{MHz}$ for the VPD L01 pulse at $17^{\circ}$ elevation (e and $\mathrm{f}$ ); LO2 pulse at $42^{\circ}$ clevation ( $\mathrm{g}$ and $\mathrm{h}$ ), LO2 pulse at $30^{\circ}$ elevation ( $\mathrm{i}$ and $\mathrm{j}$ ); and $\mathrm{L} 02$ pulse at $17^{\circ}$ elevation ( $\mathrm{k}$ and $\mathrm{l}$ ). 


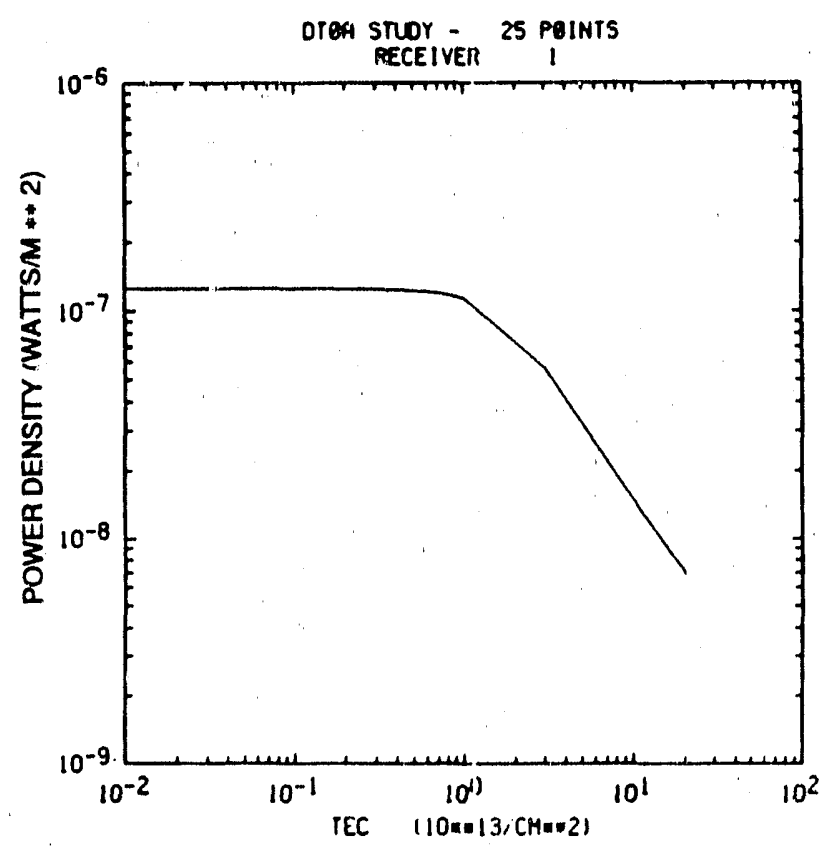

$11 \mathrm{i}$

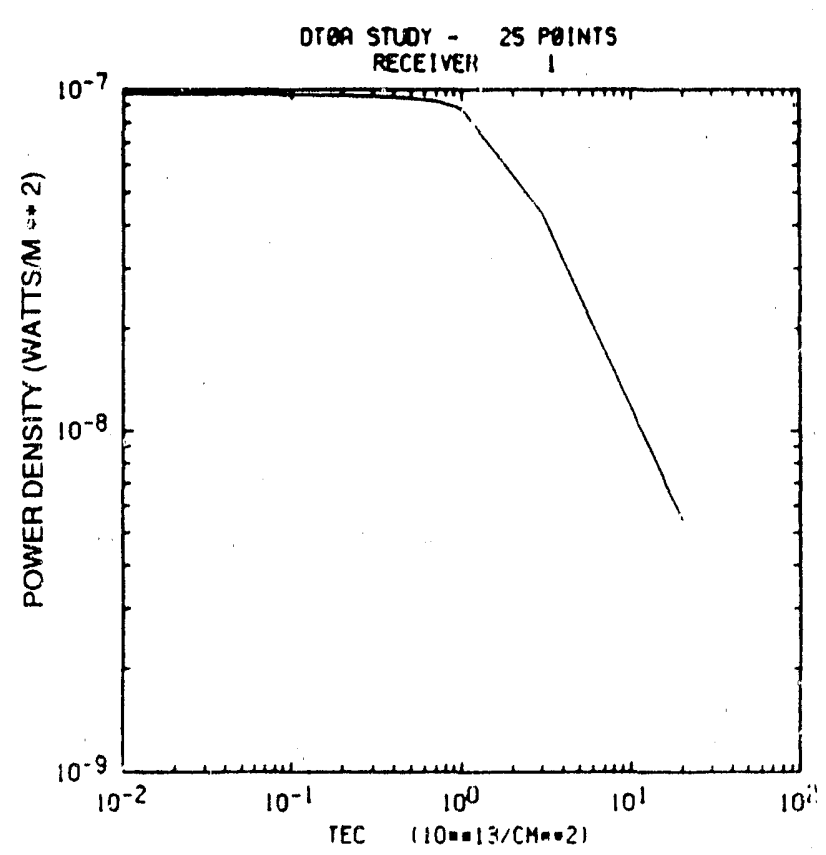

$11 \mathrm{k}$

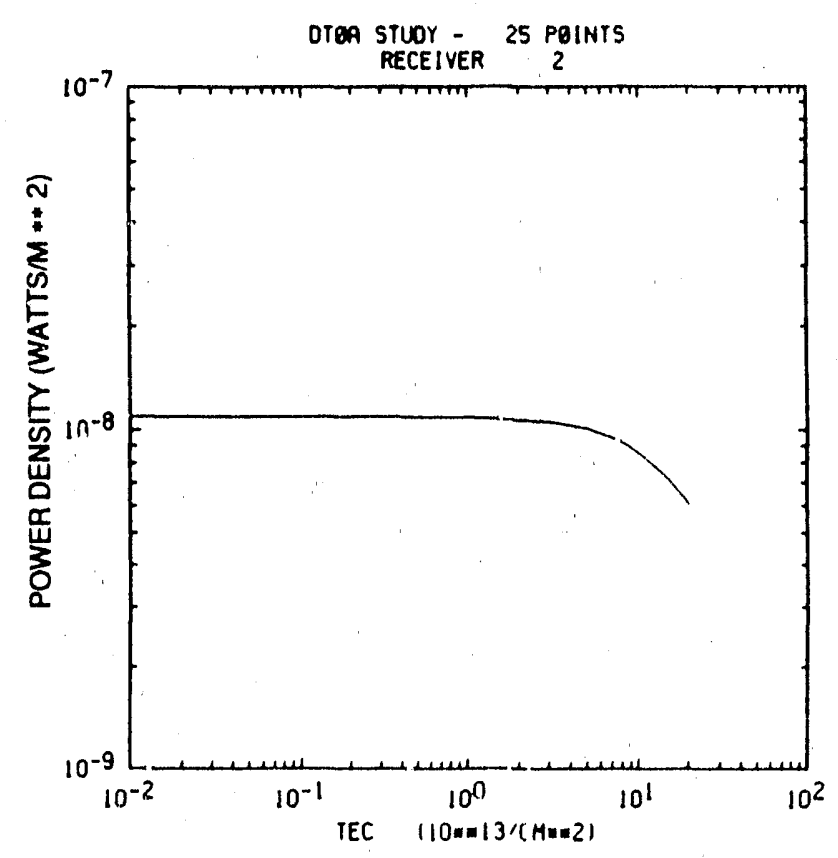

$11 \mathrm{j}$

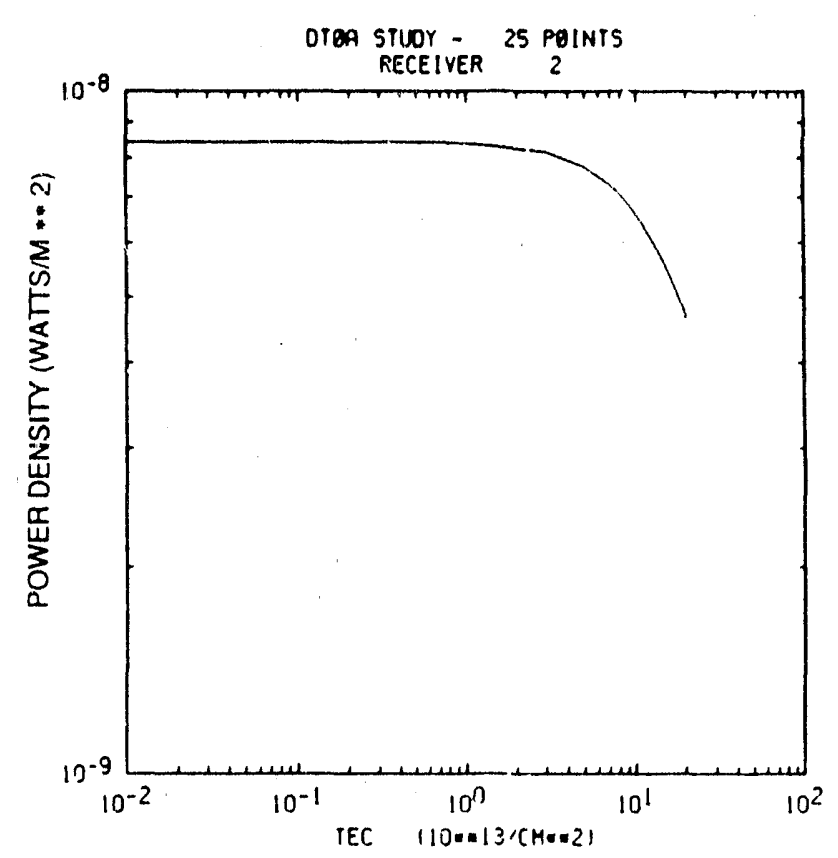

111

Figures 11i-l: Maximum RMS power density (watts $/ \mathrm{m}^{z}$ ) at $1000 \mathrm{~km}$ range, measured in the 5 and $20 \mathrm{MH}$. bandwidth receivers centered at $200 \mathrm{MHz}$ for the $\mathrm{L} 02$ pulse at $30^{\circ}$ elevation ( $i$ and $j$ ); and L02 pulse at $17^{\circ}$ clevation ( $k$ and !). 


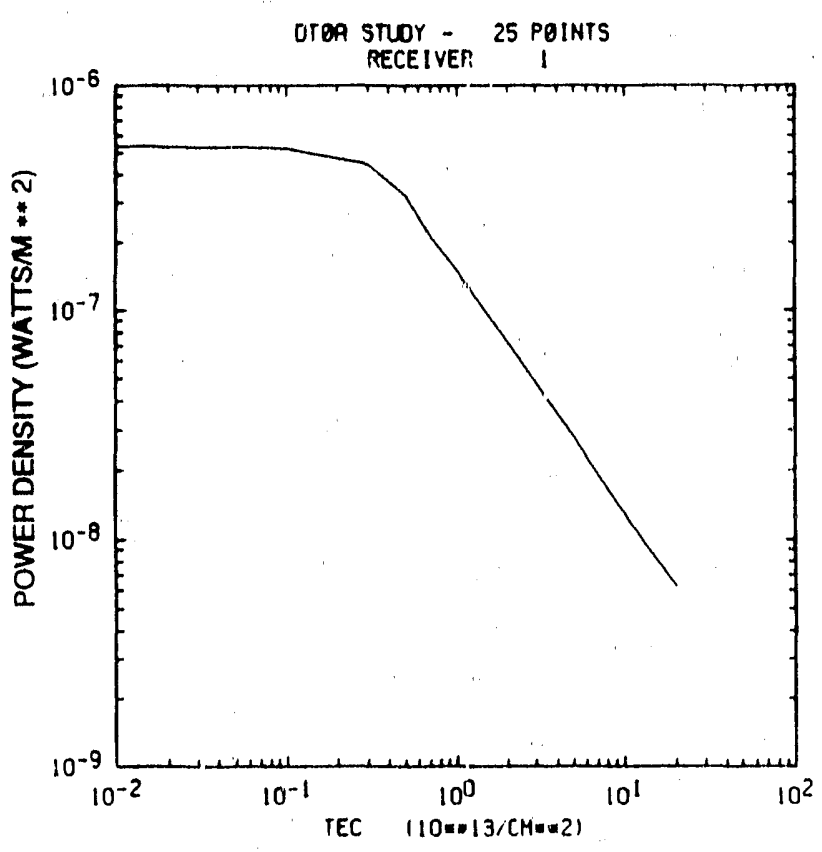

$12 \mathrm{a}$

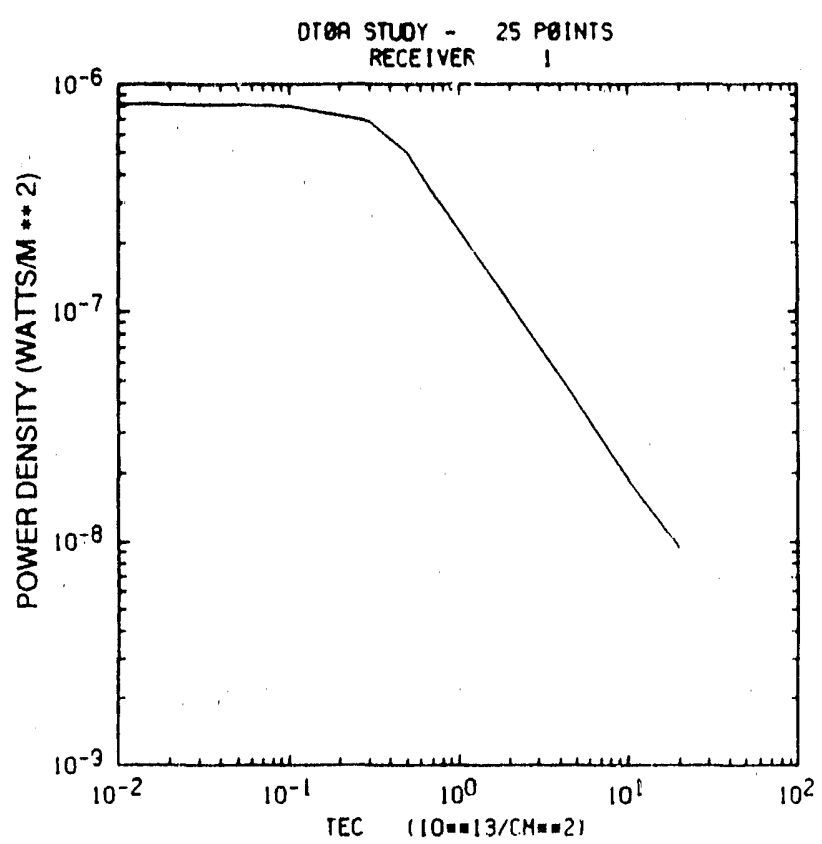

$12 \mathrm{c}$

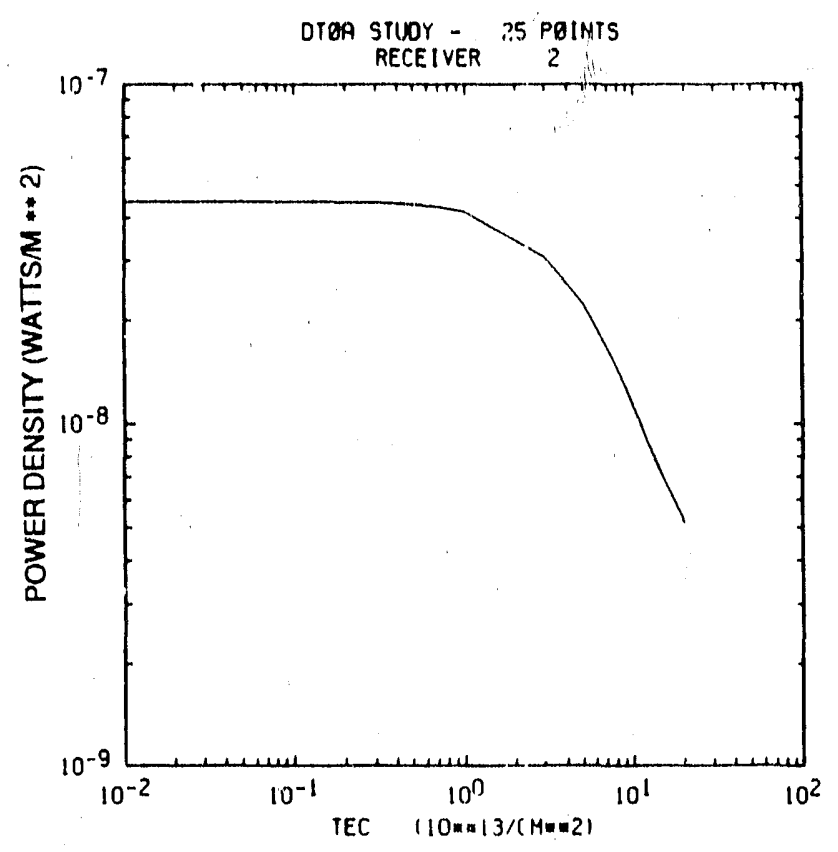

$12 b$

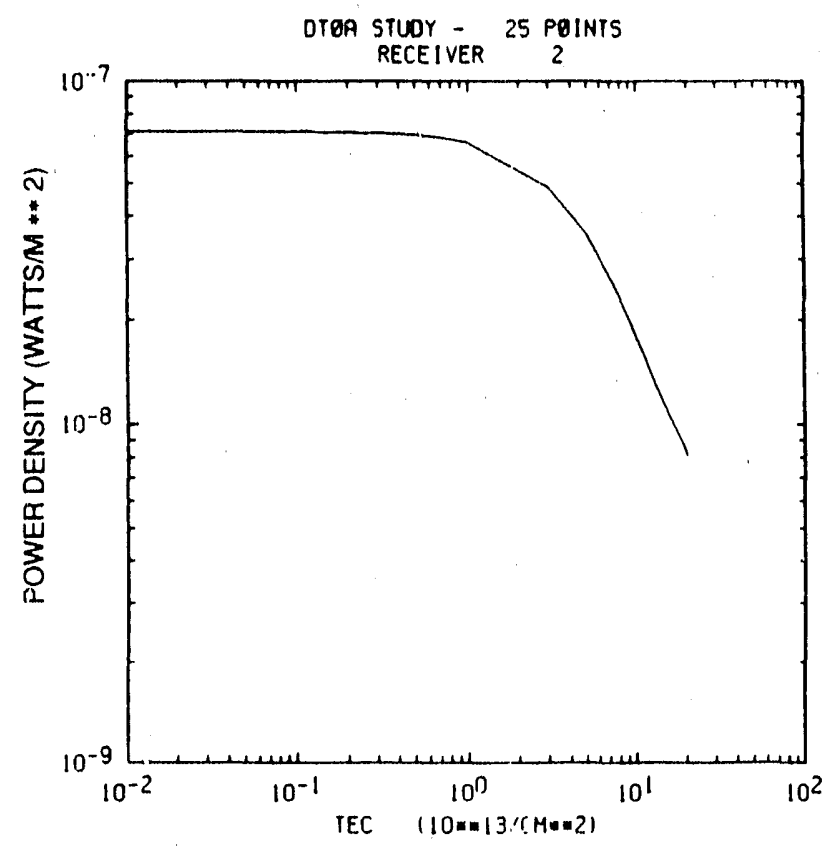

Figures 12a-d: Maximum RMS power density (watts/ $\mathrm{m}^{2}$ ) at $1000 \mathrm{~km}$ range, measured in the 5 anci $20 \mathrm{MHz}$ bandwidth receivers centered at $120 \mathrm{MHz}$ for the VPD L01 pulse at $42^{\circ}$ elevation ( $\mathrm{a}$ and $\mathrm{b}$ ); L01 pulse at $30^{\circ}$ elevation (c and d); L01 pulse at $17^{\circ}$ elevation (e and $\mathrm{f}$ ); $\mathrm{L} 02$ pulse at $42^{\circ}$ elevation ( $\mathrm{g}$ and $\mathrm{h}$ ); LO2 pulse at $30^{\circ}$ elevation ( $\mathrm{i}$ and $\left.\mathrm{j}\right)$; and $\mathrm{L} 02$ pulse at $17^{\circ}$ elevation ( $k$ and $\left.l\right)$. 


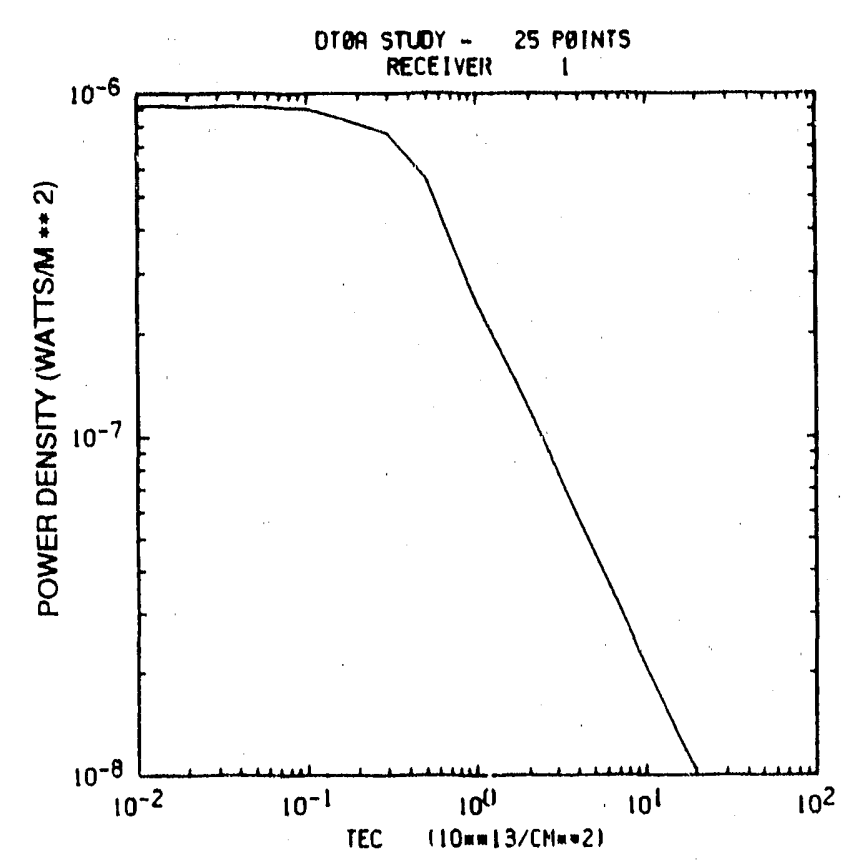

$12 \mathrm{e}$

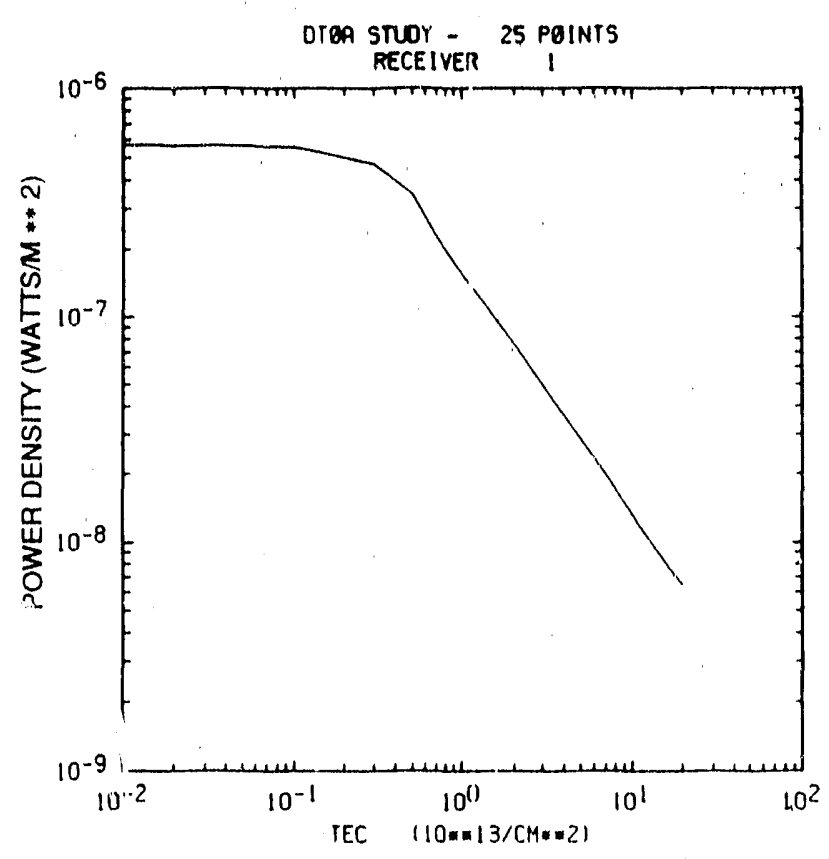

$12 \mathrm{~g}$

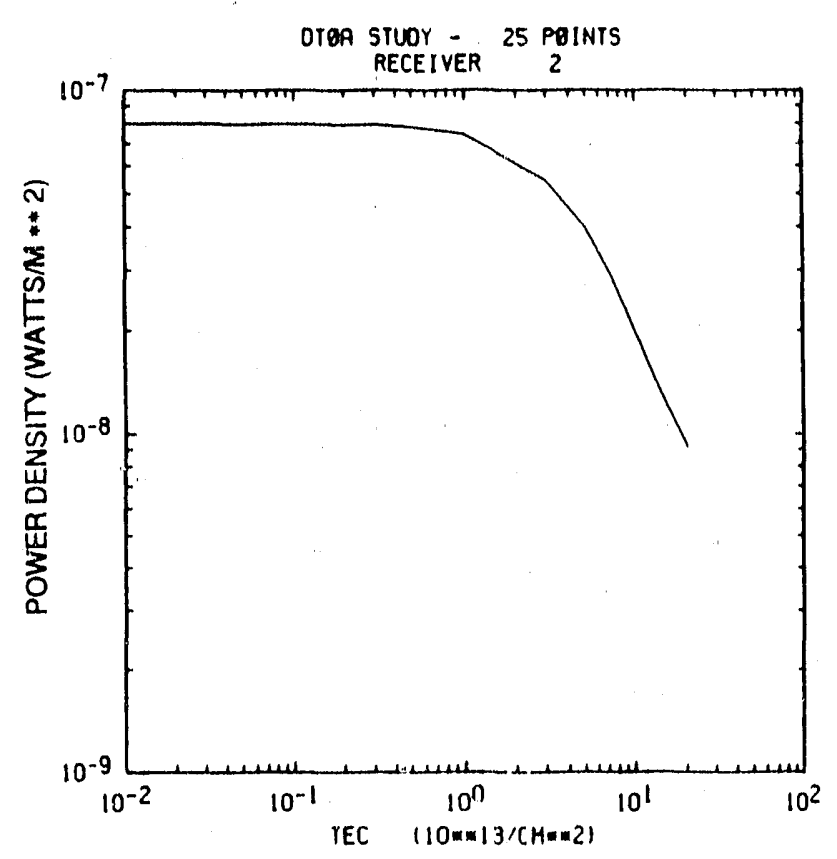

$12 \mathrm{f}$

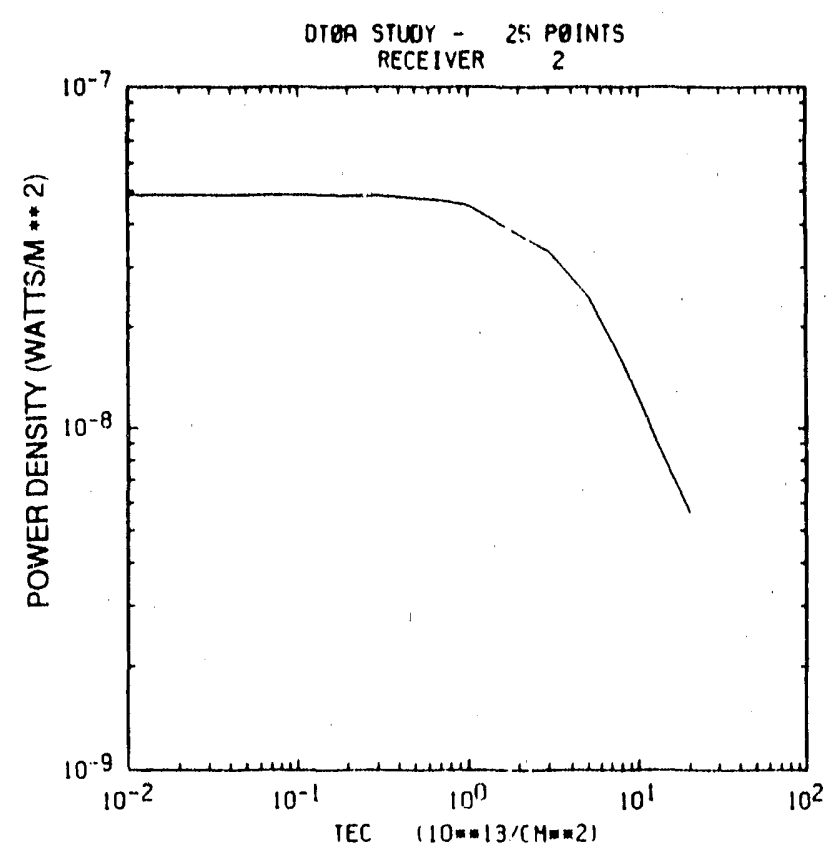

$12 \mathrm{~h}$

Figures 12e-h: Maximum RMS power density (watts/ $\mathrm{m}^{2}$ ) at $1000 \mathrm{~km}$ range, measured in the 5 and $20 \mathrm{MHz}$ bandwidth receivers centered at $120 \mathrm{MHz}$ for the L01 pulse at $17^{\circ}$ elevation (e and $\mathrm{f}$; L02 pulse at $42^{\circ}$ elevation ( $\mathrm{g}$ and $\mathrm{h}$ ). 


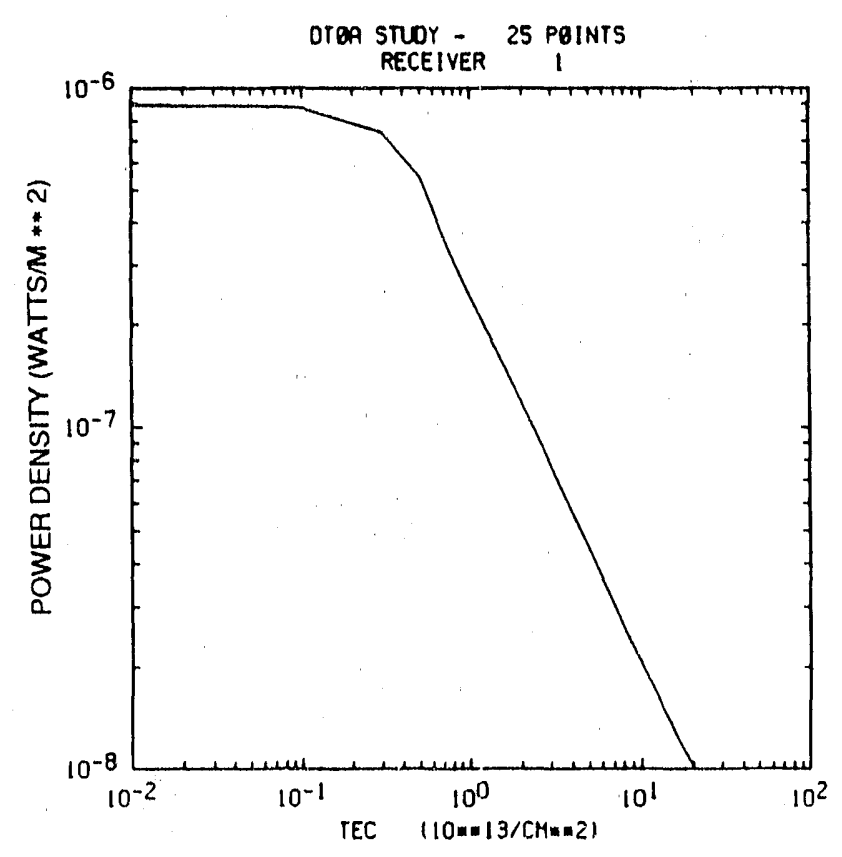

$12 \mathrm{i}$

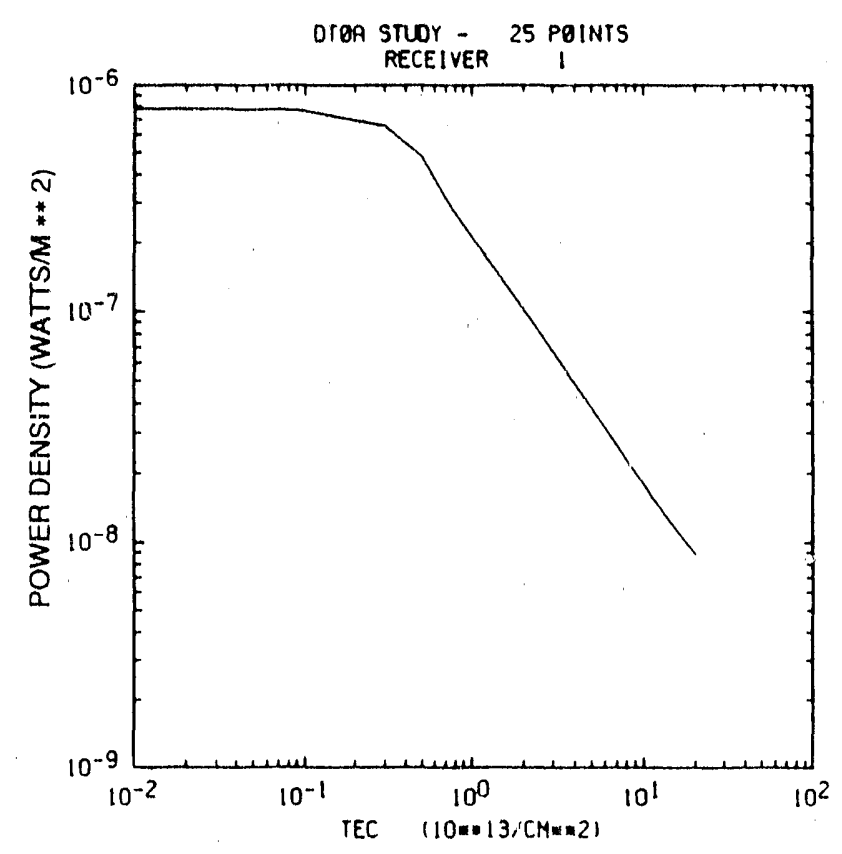

$12 k$

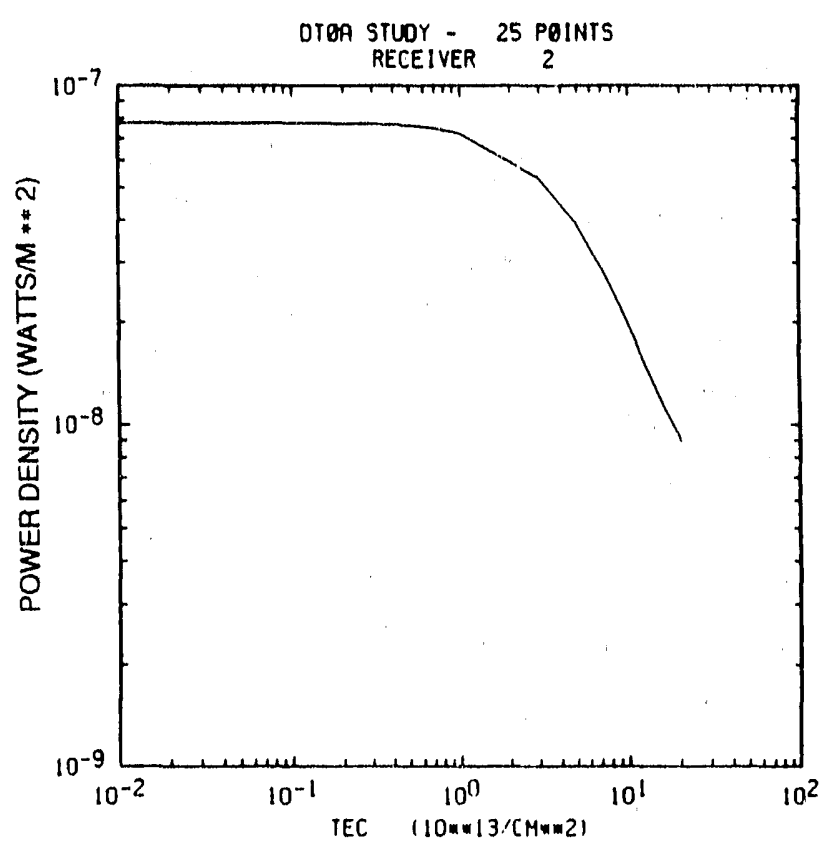

$12 \mathrm{j}$

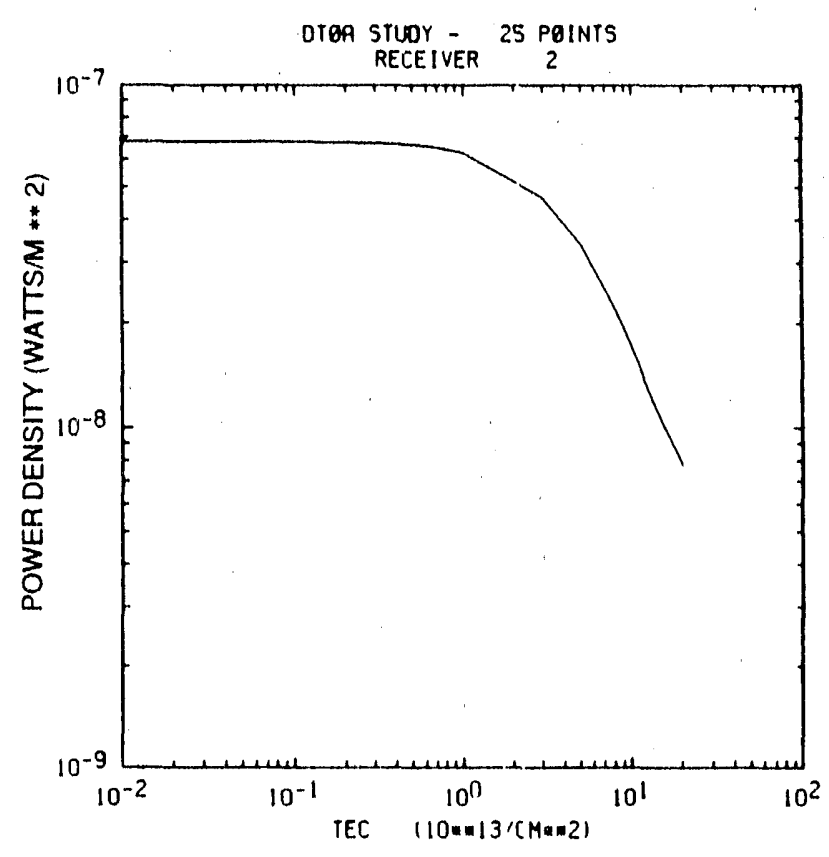

121

Figures 12i-l: Maximum RMS power dersity (watts $/ \mathrm{m}^{2}$ ) at $1000 \mathrm{~km}$ range, measured in the 5 and $20 \mathrm{MHz}$ bandwidth receivers centered at $120 \mathrm{MHz}$ for the $\mathrm{L} 02$ pulse at $30^{\circ}$ elevation ( $\mathrm{i}$ and $\mathrm{j}$ ); and $\mathrm{L} 02$ pulse at $17^{\circ}$ clevation ( $\mathrm{k}$ and $\mathrm{l}$ ). 


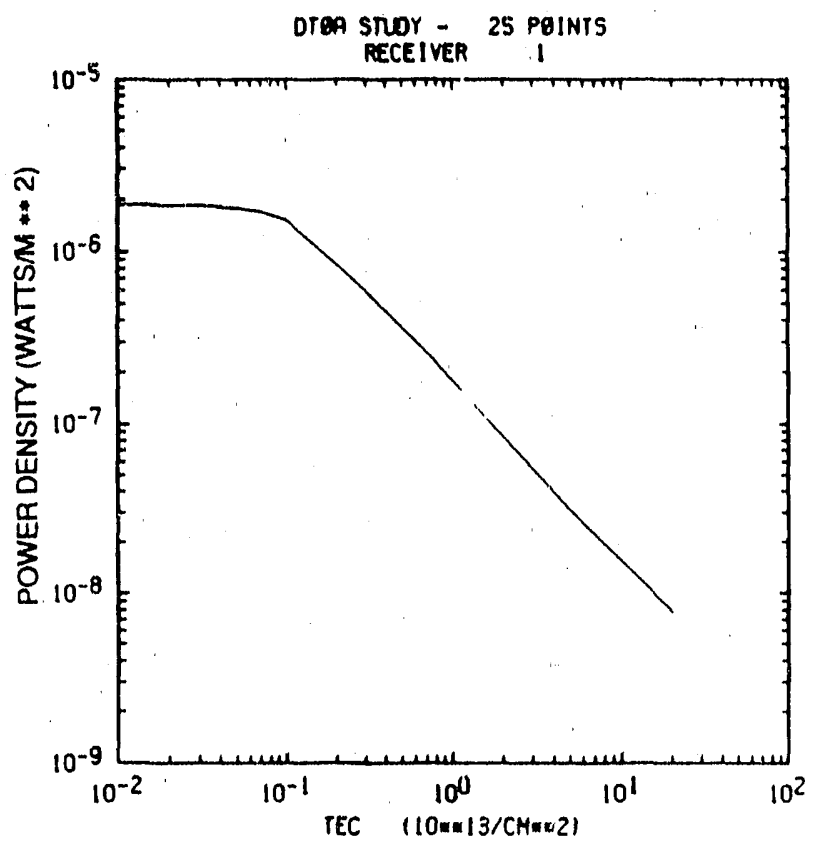

$13 a$

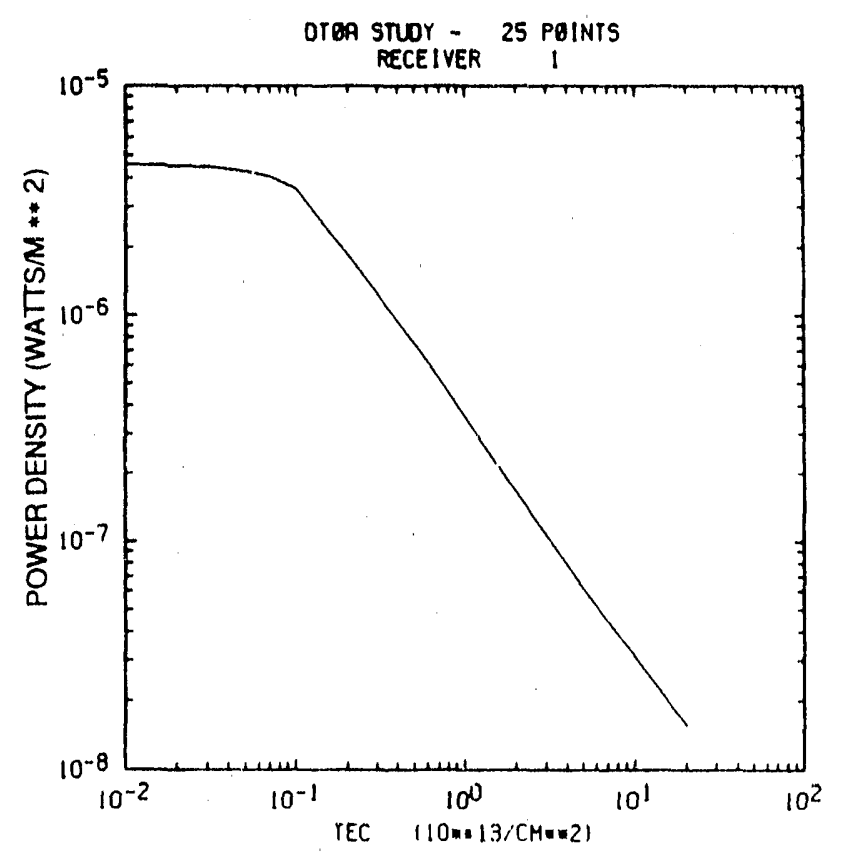

$13 \mathrm{c}$

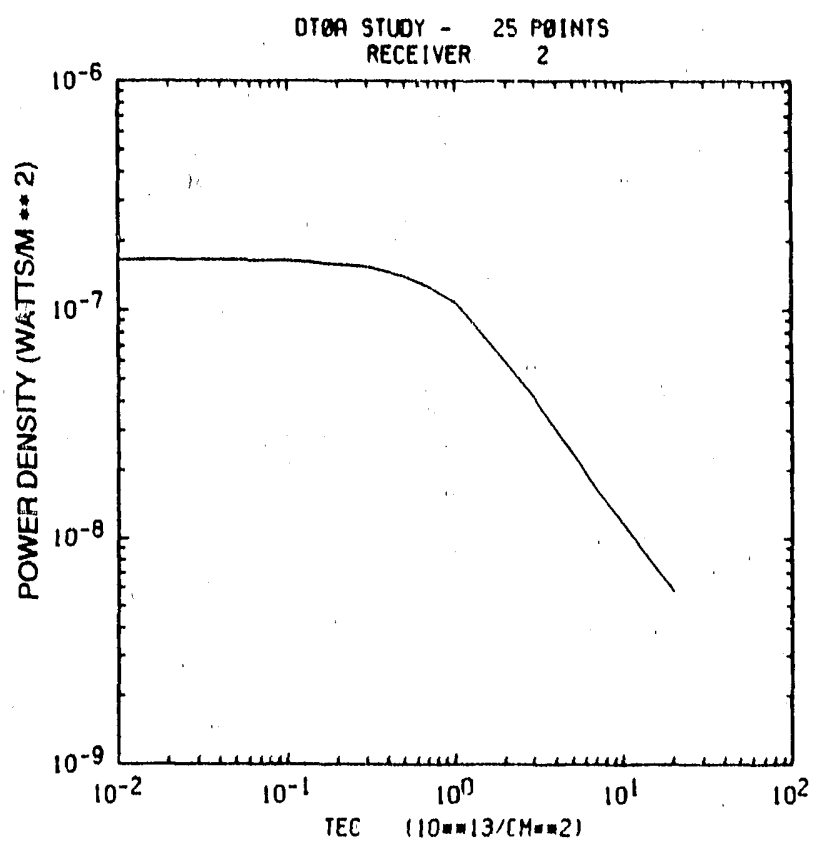

$13 b$

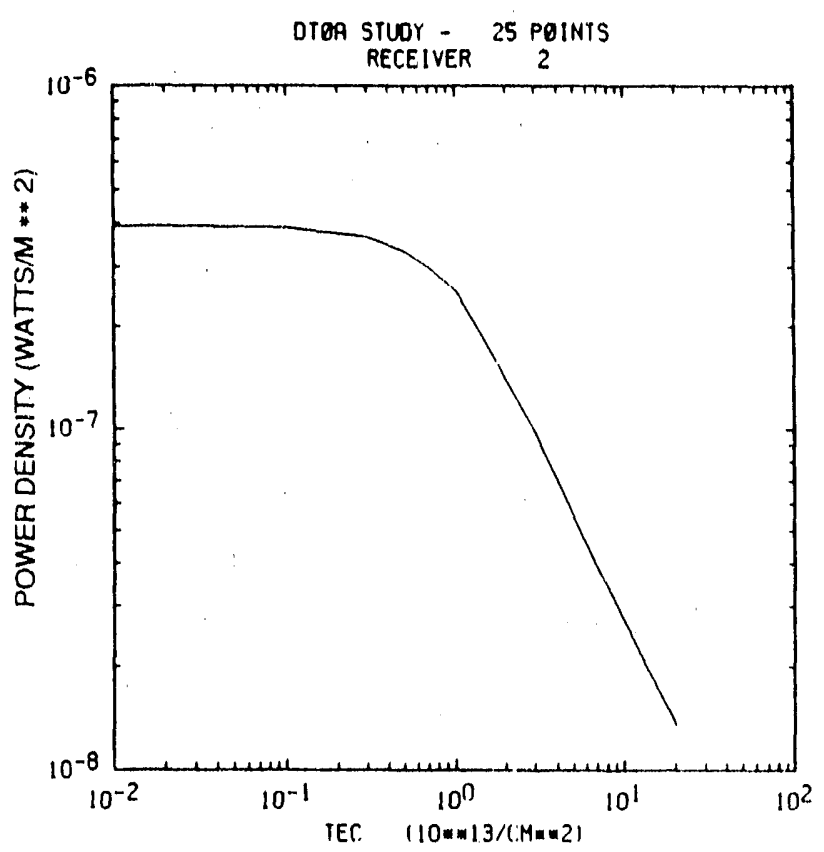

$13 d$

Figures 13a-d: Maximum RMS power density $\left(\mathrm{Watts} / \mathrm{m}^{2}\right)$ at $1000 \mathrm{~km}$ range, measured in the 5 and $20 \mathrm{MHz}$ bandwidth receivers centered at $80 \mathrm{MHz}$ for the VPD L01 pulse at $42^{\circ}$ elevation (a and b); L01 pulse at $30^{\circ}$ elevation (c and d). 


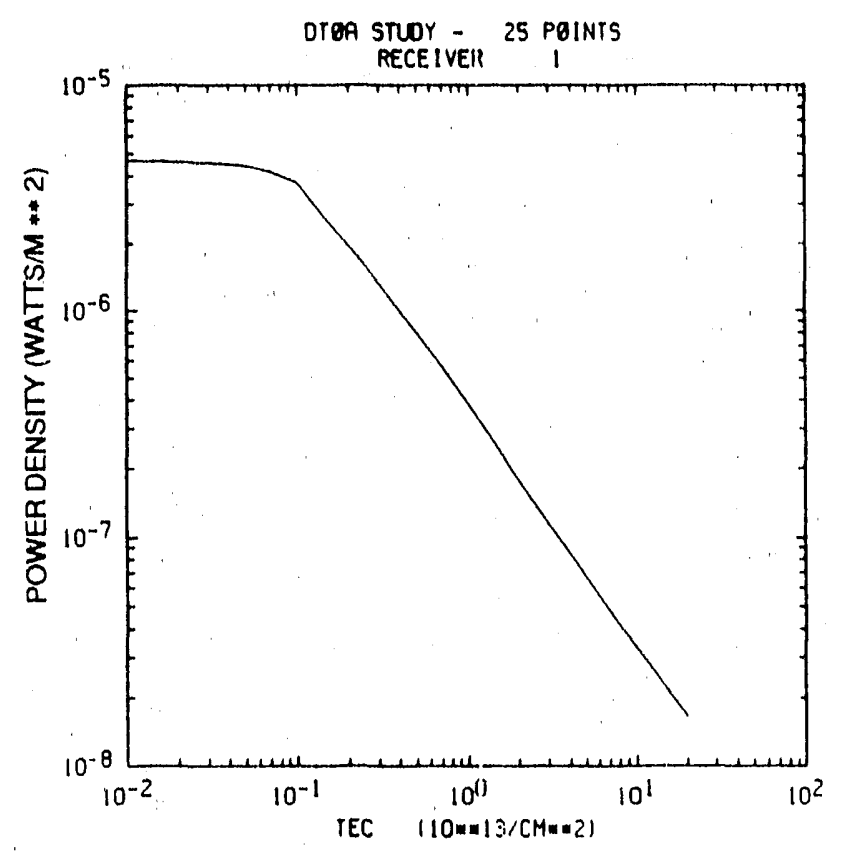

$13 \mathrm{e}$

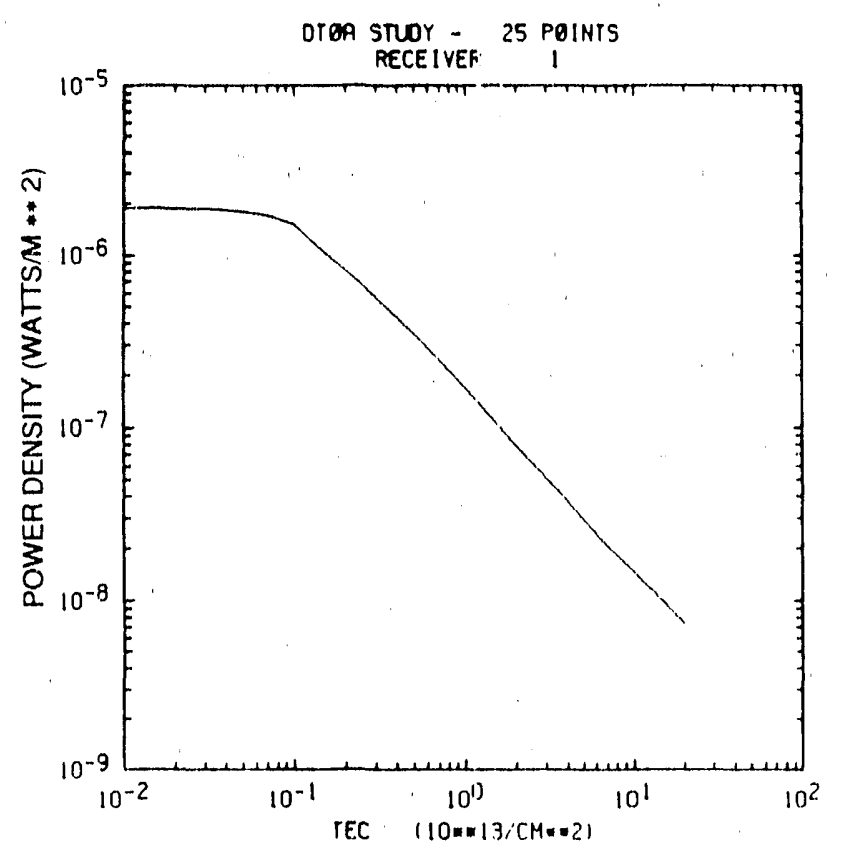

$13 \mathrm{~g}$

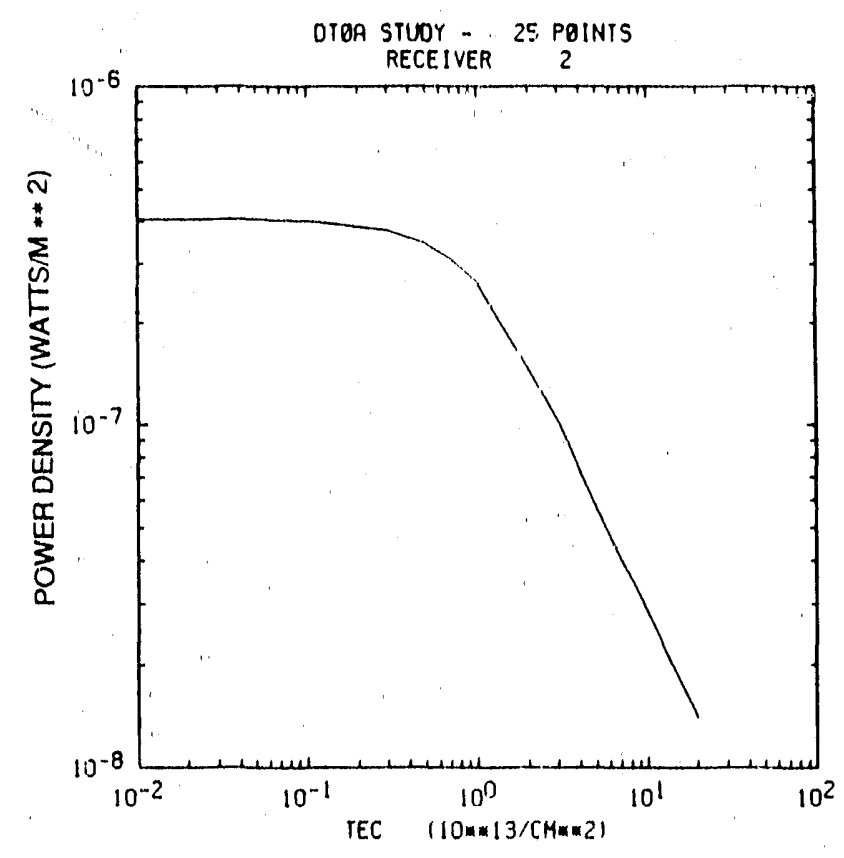

$13 f$

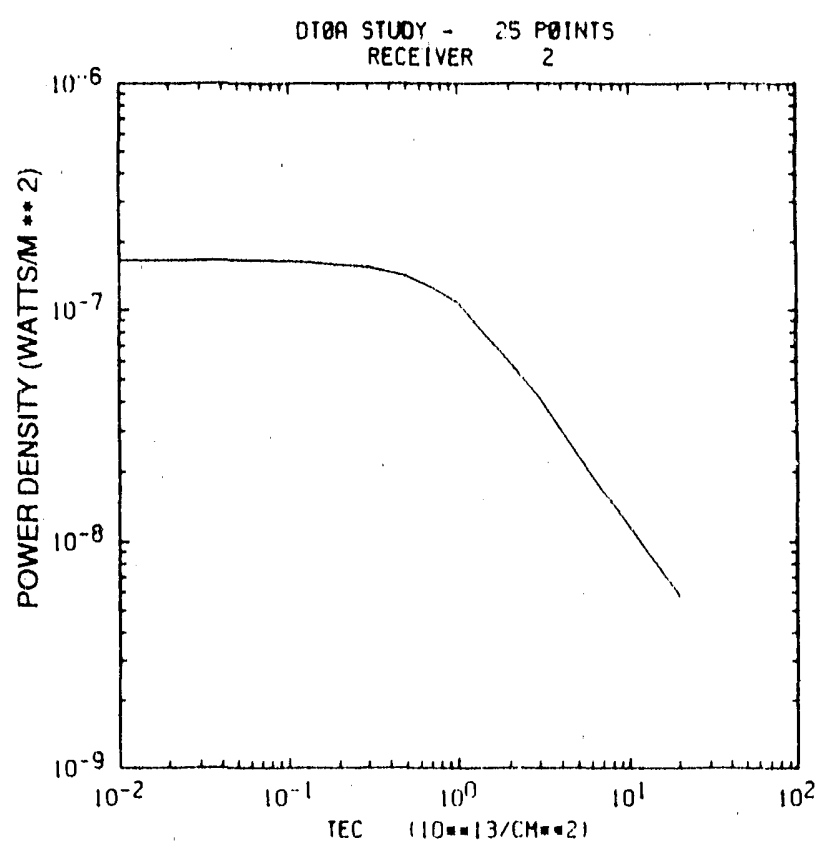

Figures $13 \mathrm{e}-\mathrm{h}$ Maximum RMS power density (Watts $/ \mathrm{m}^{2}$ ) at $1000 \mathrm{~km}$ range, measured in the 5 and $20 \mathrm{MHz}$ bandwidth receivers centered at $80 \mathrm{MHz}$ for the L01 pulse at $17^{\circ}$ elevation (c and $\left.\mathrm{f}\right) ; \mathrm{LO} 2$ pulse at $42^{\circ}$ clevation ( $\mathrm{g}$ and $\mathrm{h}$ ). 


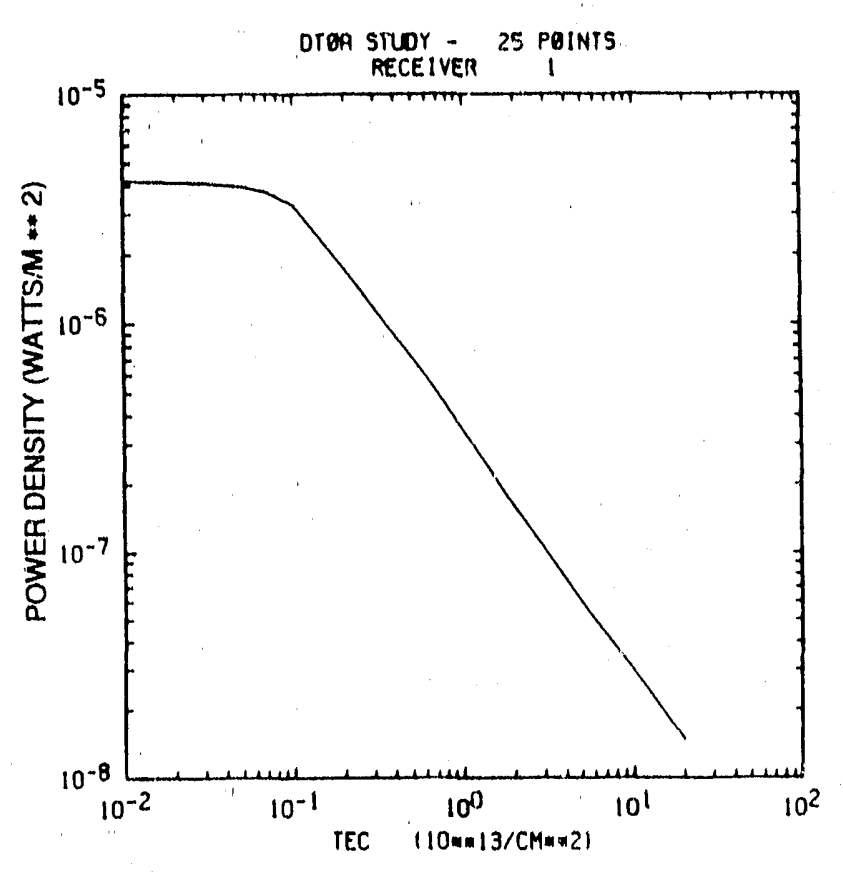

$13 \mathrm{i}$

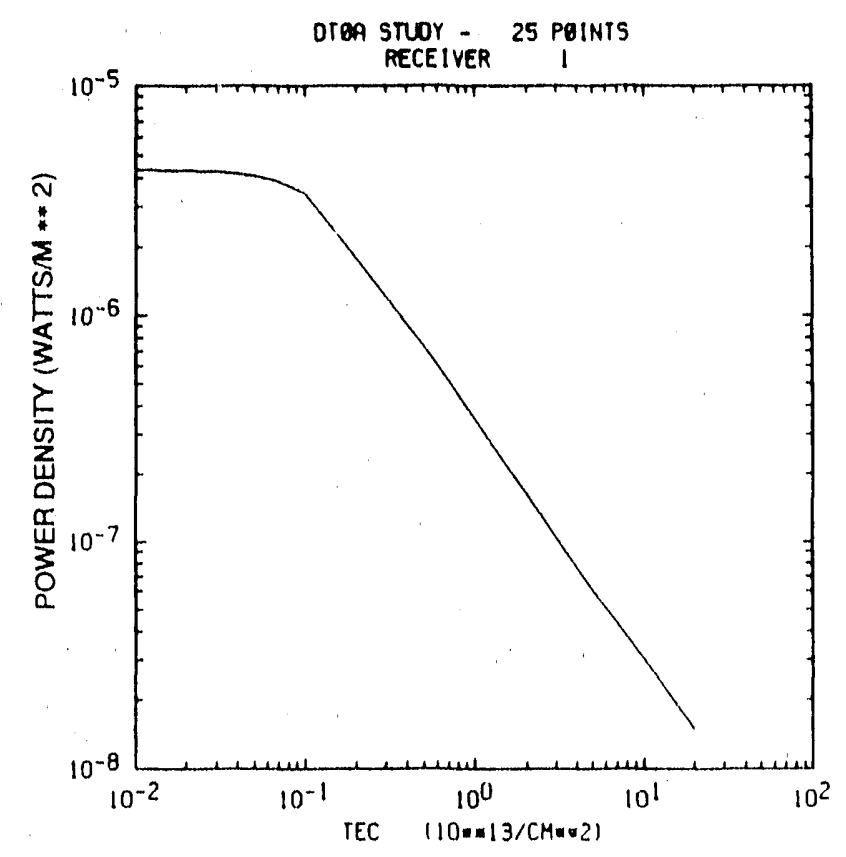

$13 \mathrm{k}$

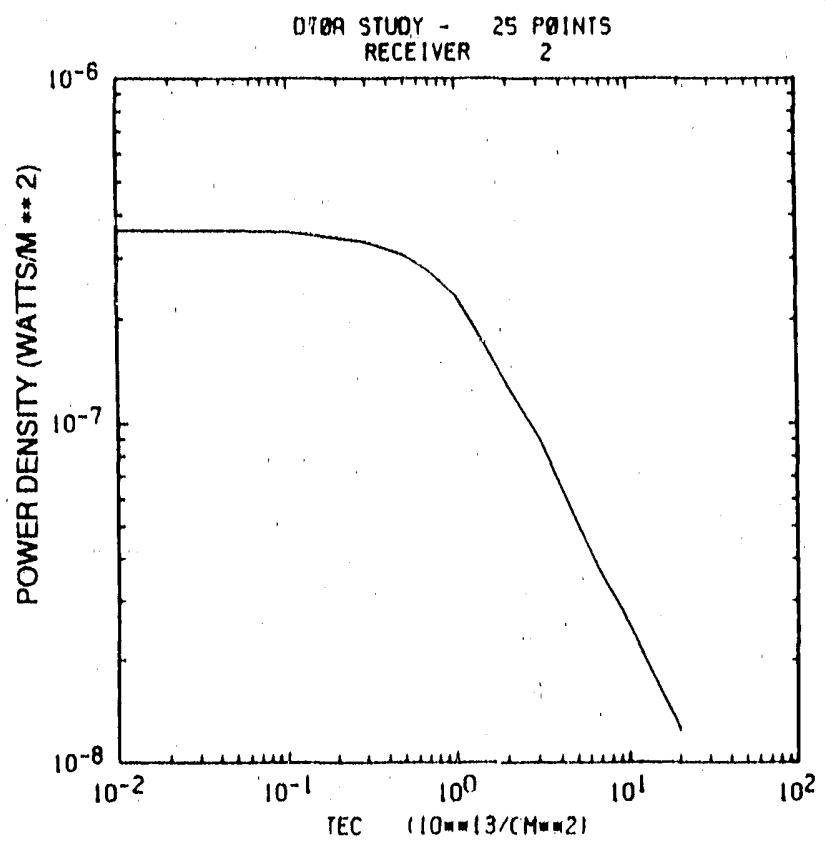

$13 j$

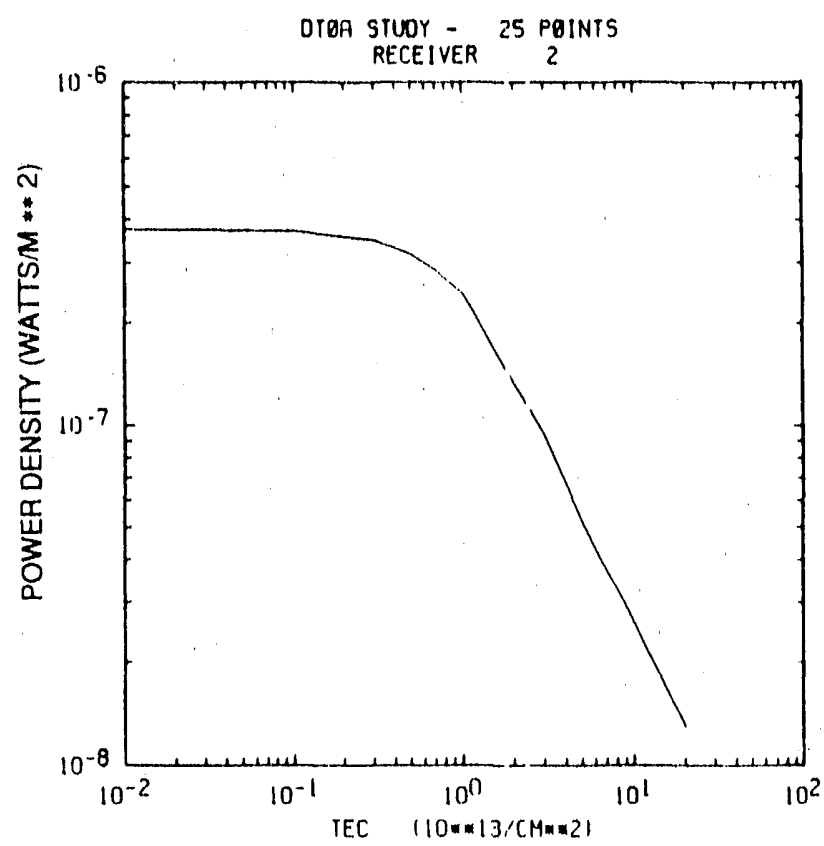

131

Figures 13i-1: Maximum RMS power density (Watts $/ \mathrm{m}^{2}$ ) at $10(0) \mathrm{km}$ range, measured in the 5 and $20 \mathrm{MHz}$ bandwidth receivers centered at $80^{\circ}$ " $\mathrm{Hz}$ for the L(02 pulse at $30^{\circ}$ elcvation ( $\mathrm{i}$ and $\mathrm{j}$ ); and $\mathrm{L} .02$ pulse at $17^{\circ}$ elevation ( $\mathrm{k}$ and 1 ). 


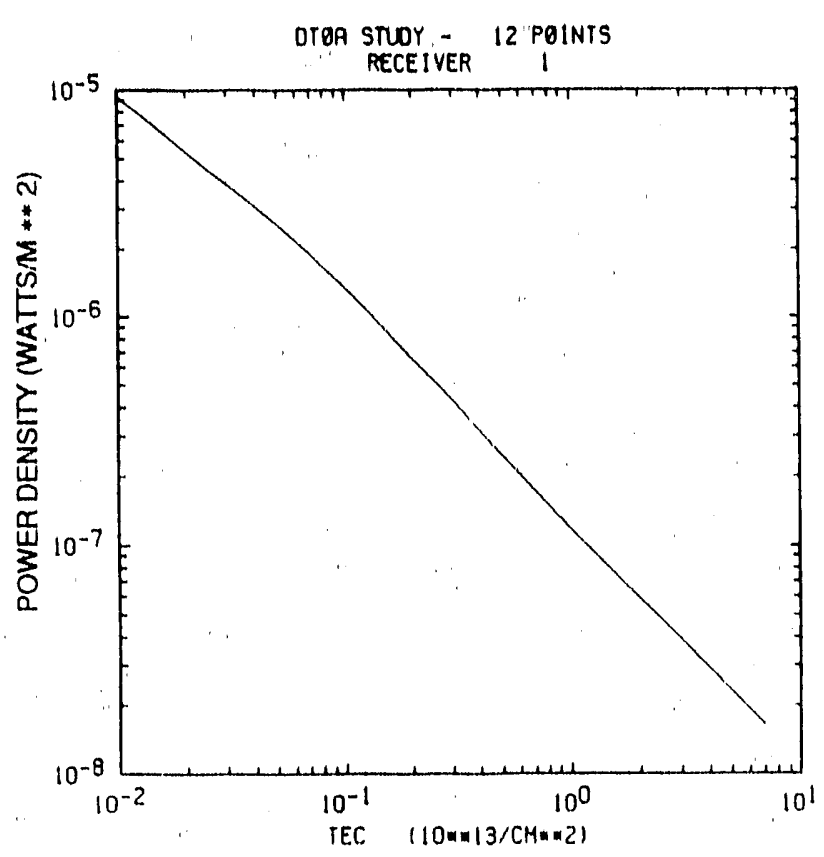

$14 a$

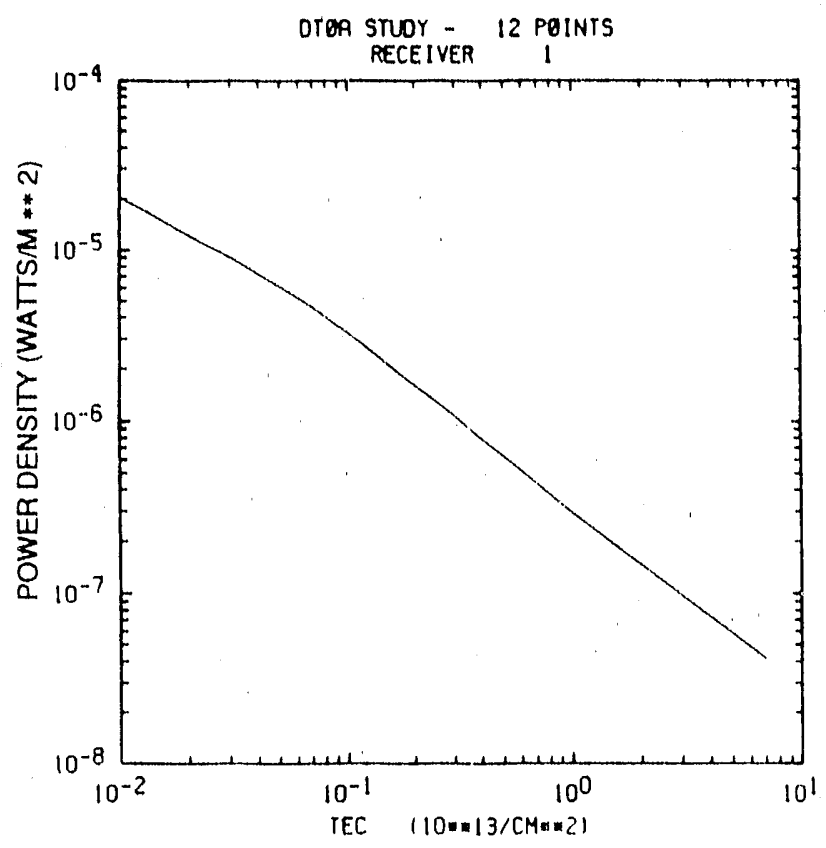

$14 \mathrm{c}$

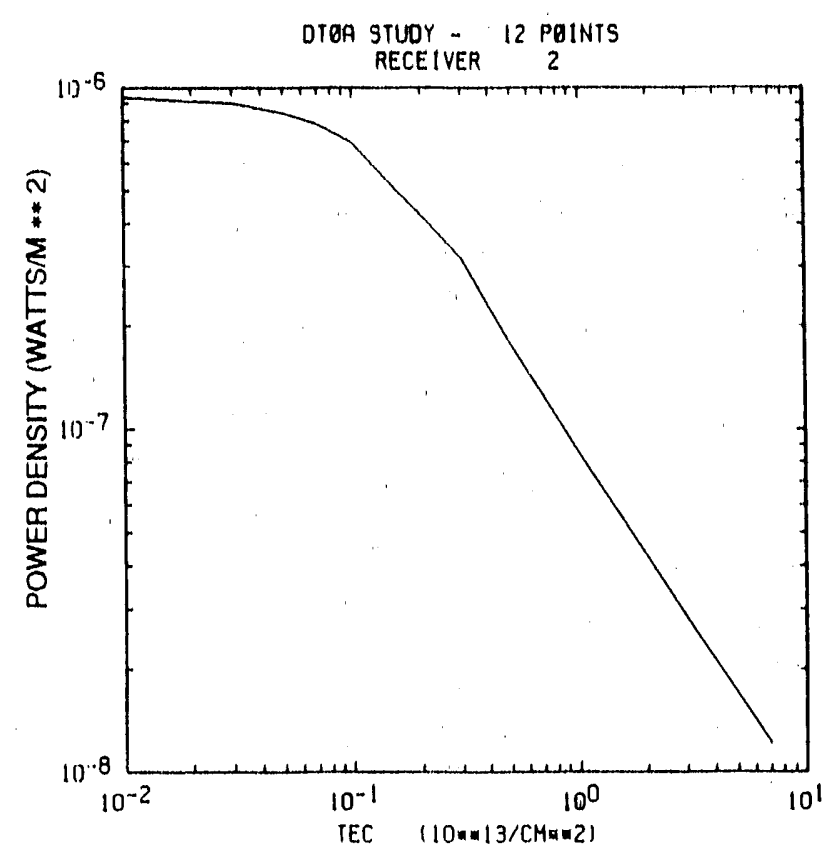

$14 \mathrm{~b}$

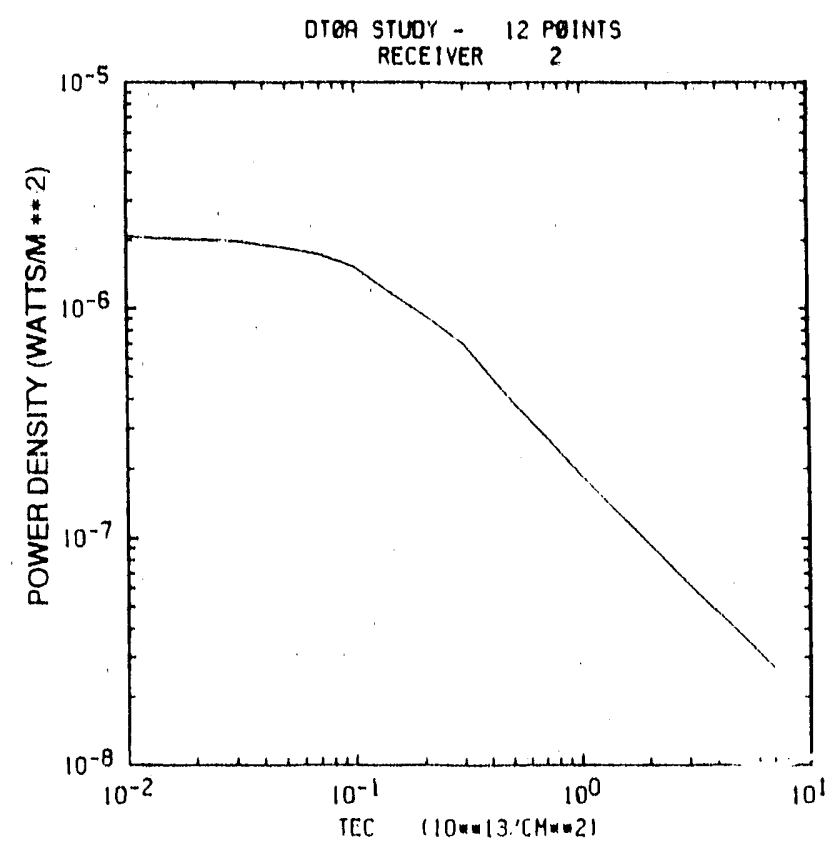

Figures 14a-d: Maximum RMS power density (watts $/ \mathrm{m}^{2}$ ) at $1000 \mathrm{~km}$ range, measured in the 5 and $20 \mathrm{MH} \%$ bandwidth receivers centered at $40 \mathrm{MHz}$ for the VPD L01 pulse at $42^{\circ}$ elevation (a and b); L01 pulse at $30^{\circ}$ elevation (c and d). 


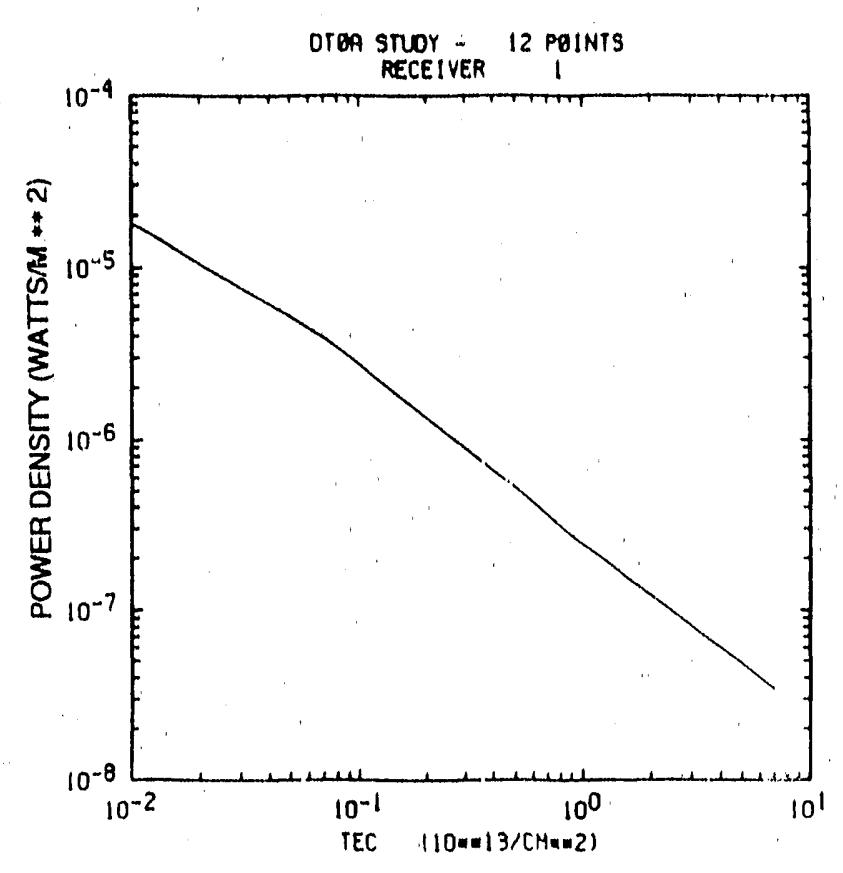

$14 \mathrm{e}$

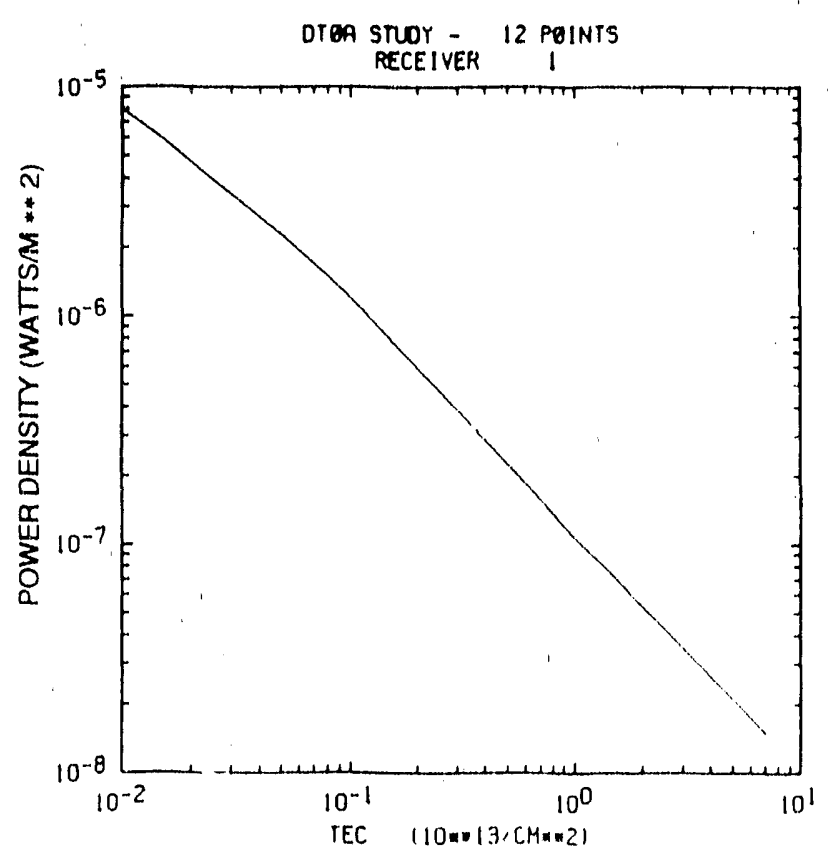

$14 \mathrm{~g}$

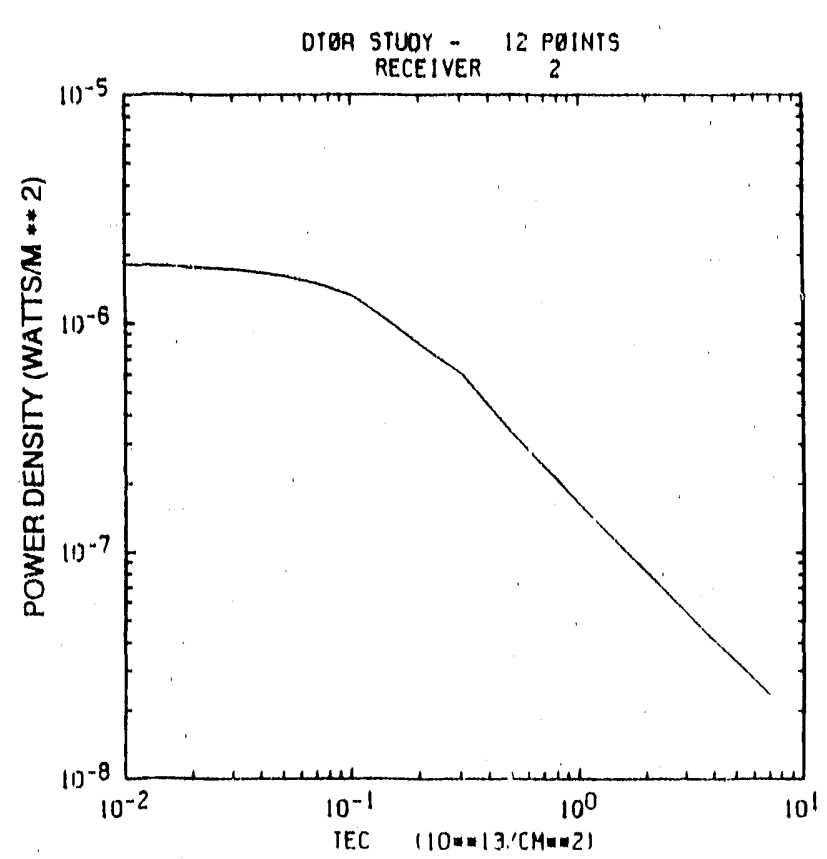

141

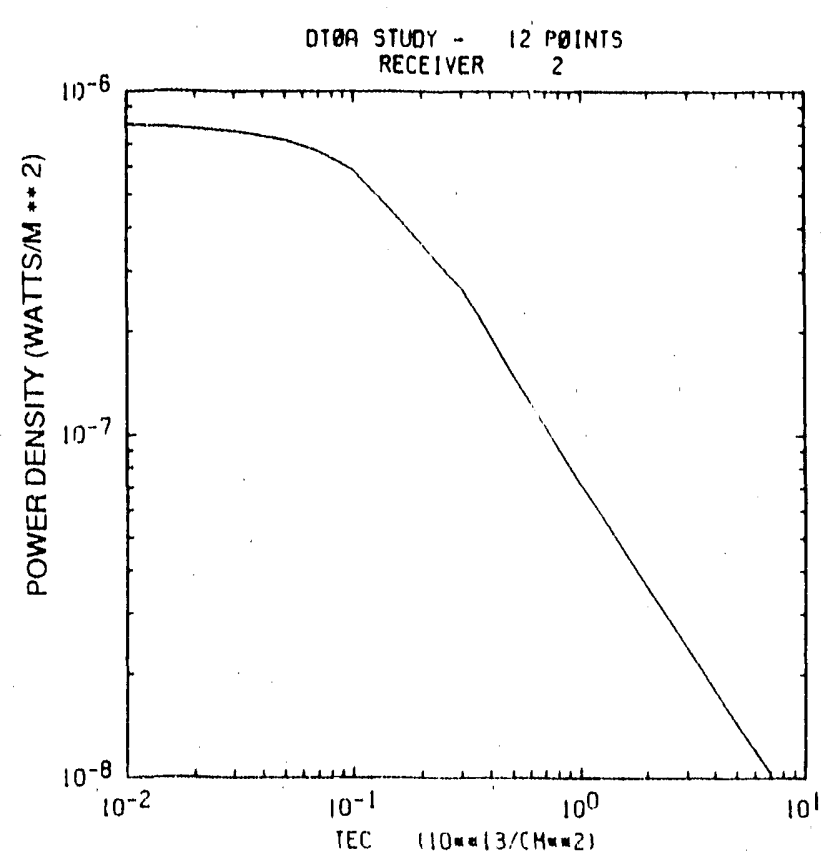

$14 \mathrm{~h}$

Figures $14 \mathrm{e}-\mathrm{h}$ : Maximum RMS power density (watts $/ \mathrm{m}^{2}$ ) at $1000 \mathrm{~km}$ range, measured in the 5 and $20 \mathrm{MH}$, bandwidlh receivers centered at $40 \mathrm{MHz}$ for the L01 pulse at $17^{\circ}$ elevation (e and $\mathrm{l}$ ); L()2 pulse al $42^{\circ}$ elevaltion ( $\mathrm{g}$ and $\mathrm{h}$ ). 


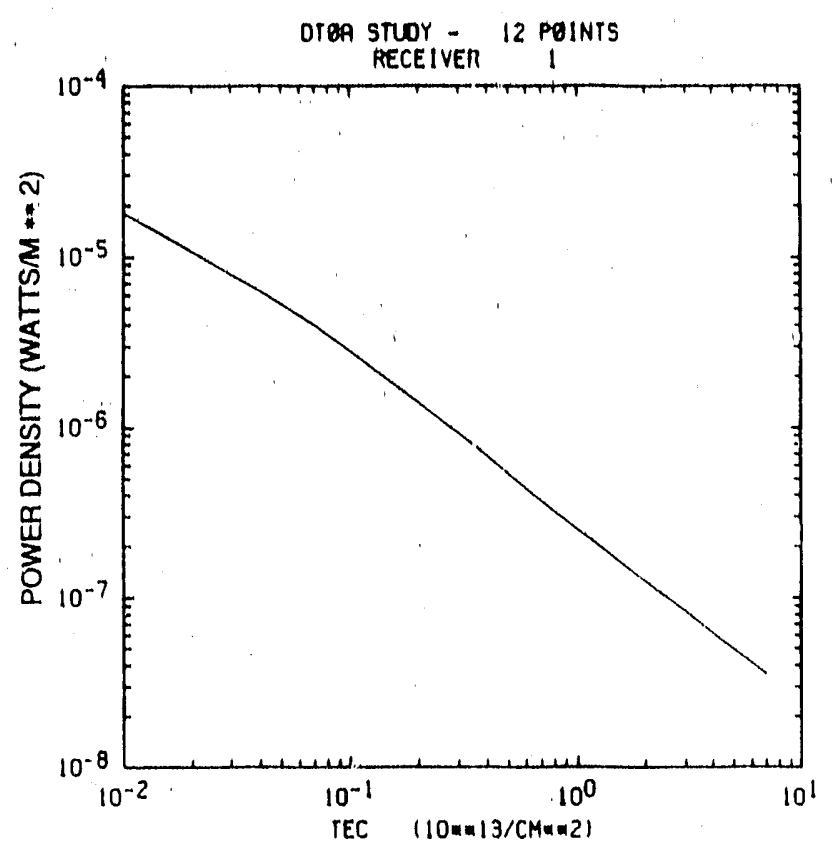

$14 \mathrm{i}$

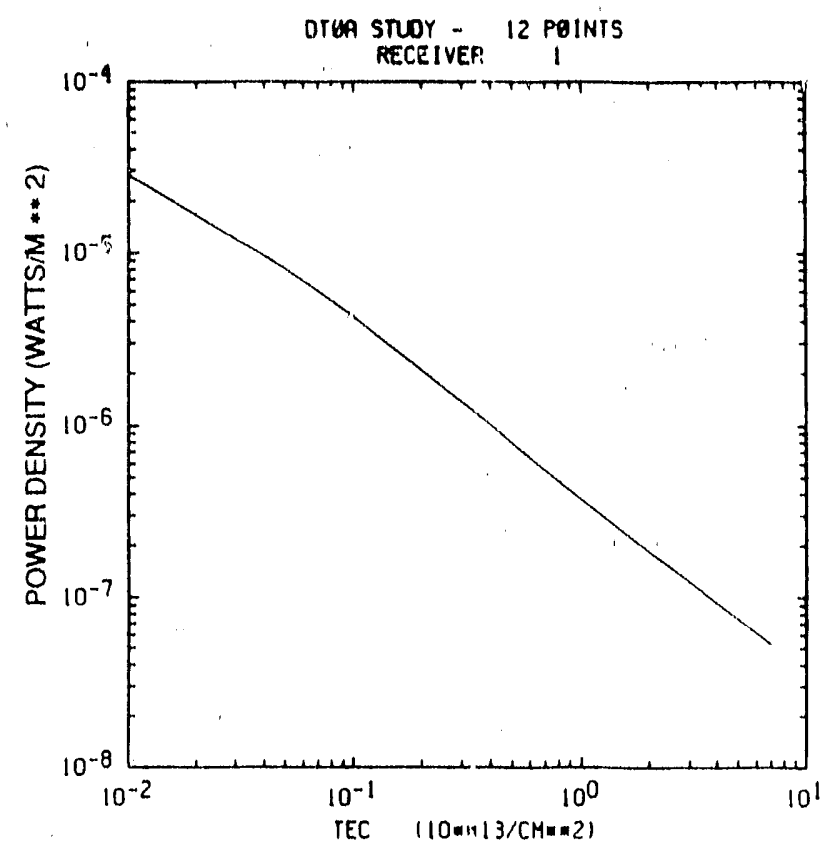

$14 \mathrm{k}$

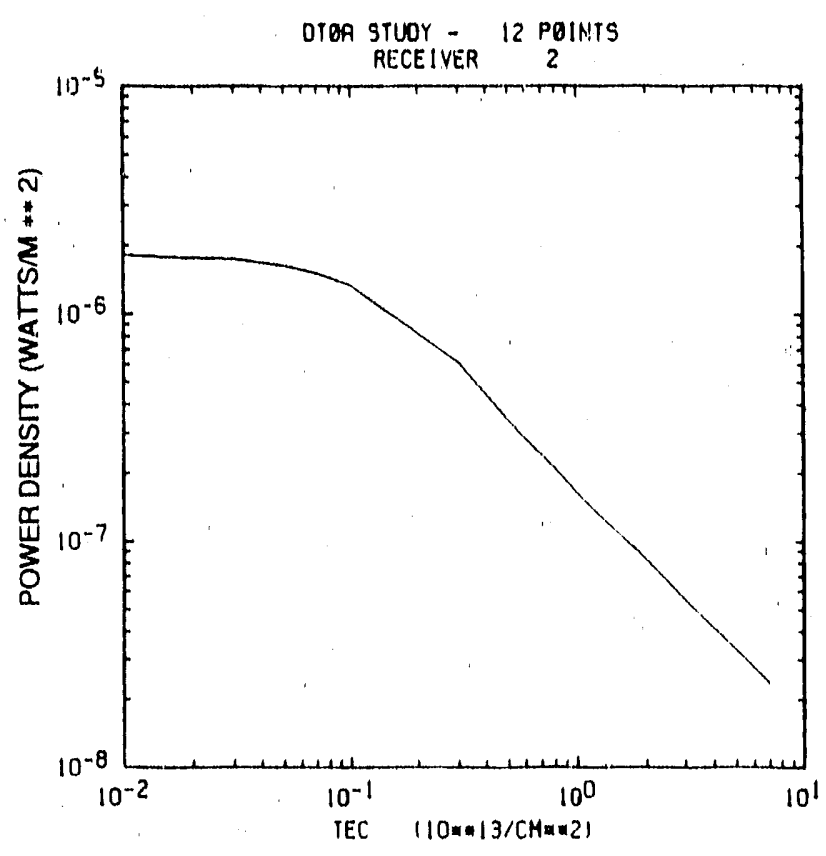

$14 \mathrm{j}$

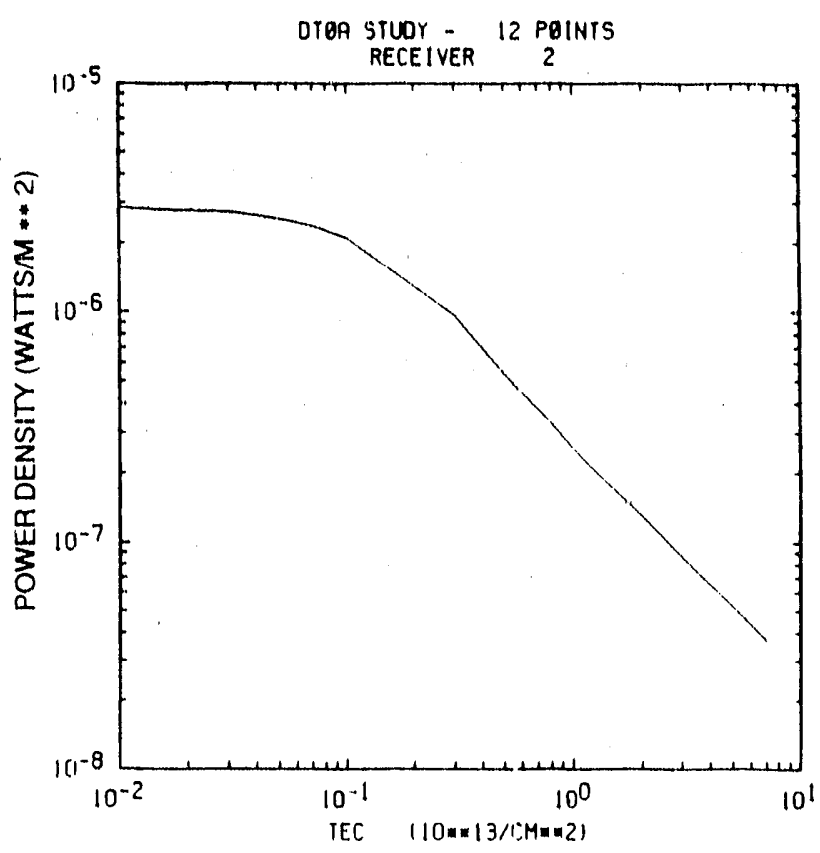

141

Figures 14i-l: Maximum RMS power density $\left(\right.$ watts $/ \mathrm{m}^{2}$ ) at $1000 \mathrm{~km}$ range, measured in the 5 and $20 \mathrm{MHz}$ bandwidth receivers centered at $40 \mathrm{MHz}$ for the $\mathrm{L}\left(22\right.$ pulse at $30^{\circ}$ elevation ( $\mathrm{i}$ and $\mathrm{j}$ ); and $\mathrm{L}\left(02\right.$ pulse at $17^{\circ}$ elevation ( $\mathrm{k}$ and $\mathrm{l}$ ). 


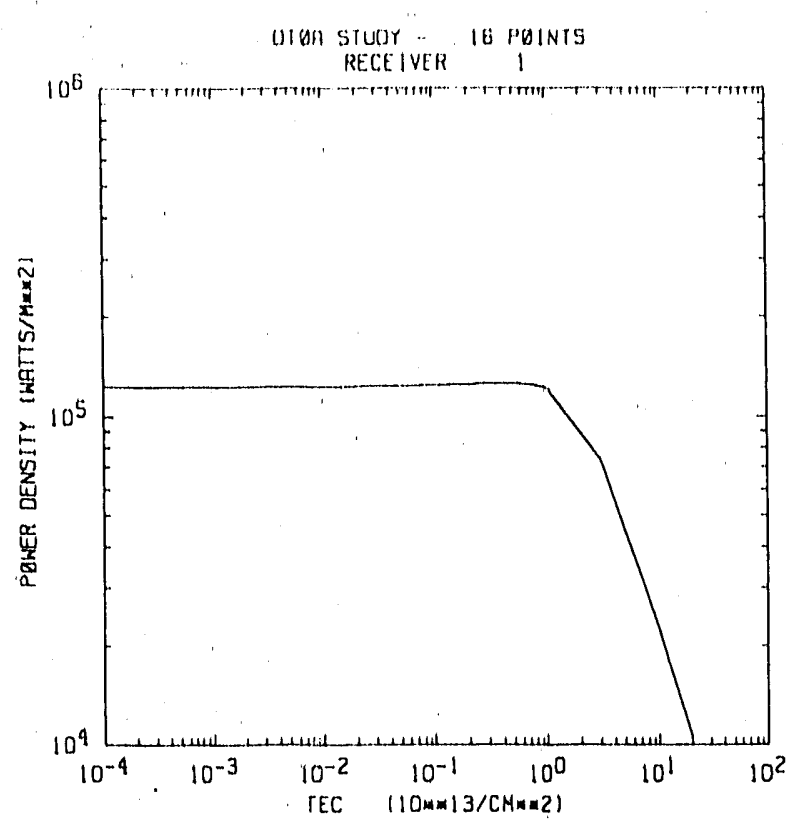

$15 a$

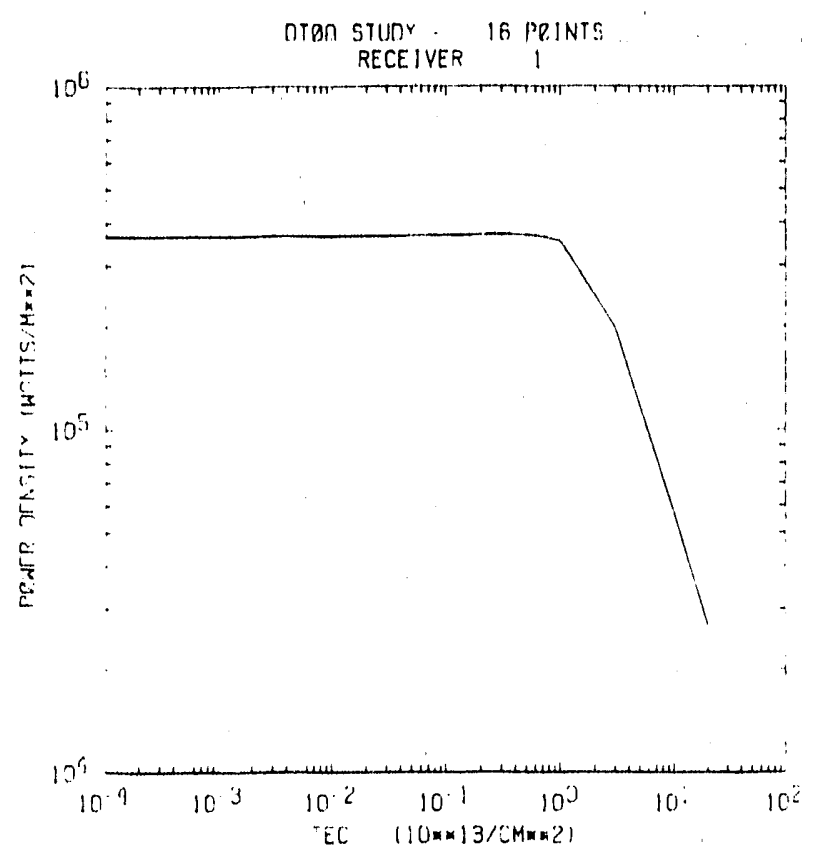

$15 c$

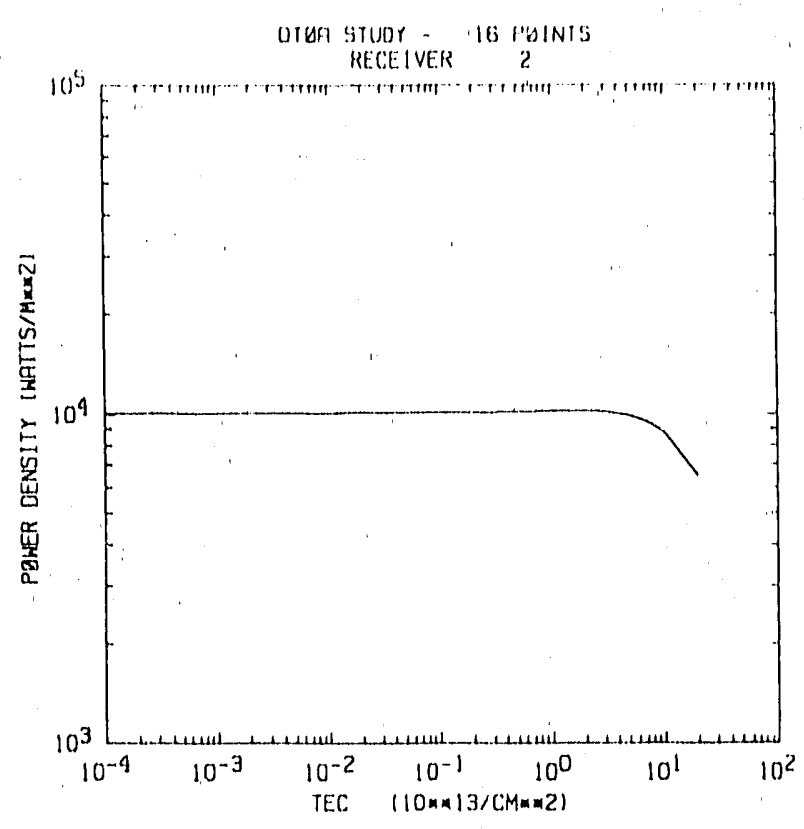

$15 b$

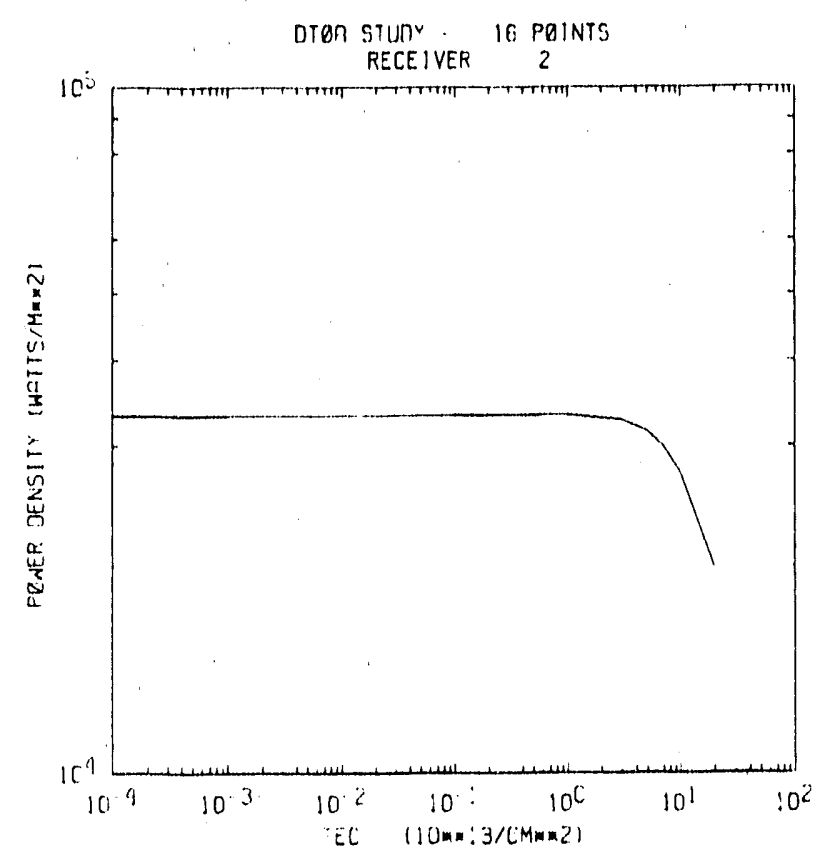

$15 d$

Figures 15a-d: Maximum RMS power density $\left(\right.$ watts $\left./ \mathrm{m}^{2}\right)$ at $1 \mathrm{~m}$ range, measured in the 5 and 20 MHz band width receivers centered at $200 \mathrm{MHz}$ for the HPD pulse at $20^{\circ}$ elevation and $37^{\circ}$ azimuth (a and b); and HPD pulse at $20^{\circ}$ elevation and 9()$^{\circ} \quad$ azimuth $(\mathrm{c}$ and $\mathrm{d})$. 


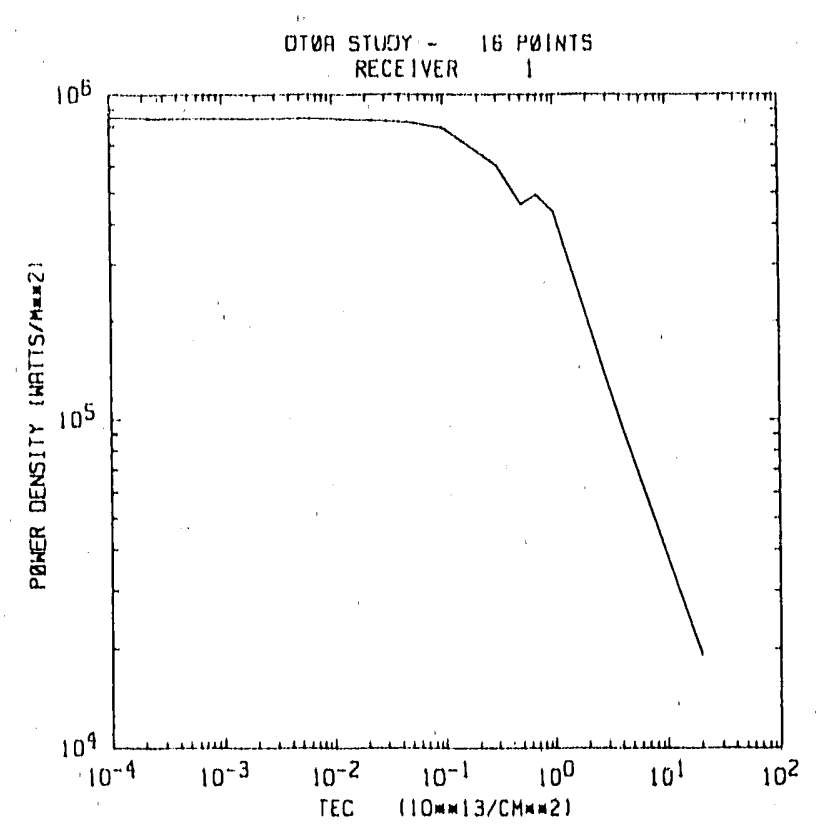

$16 a$

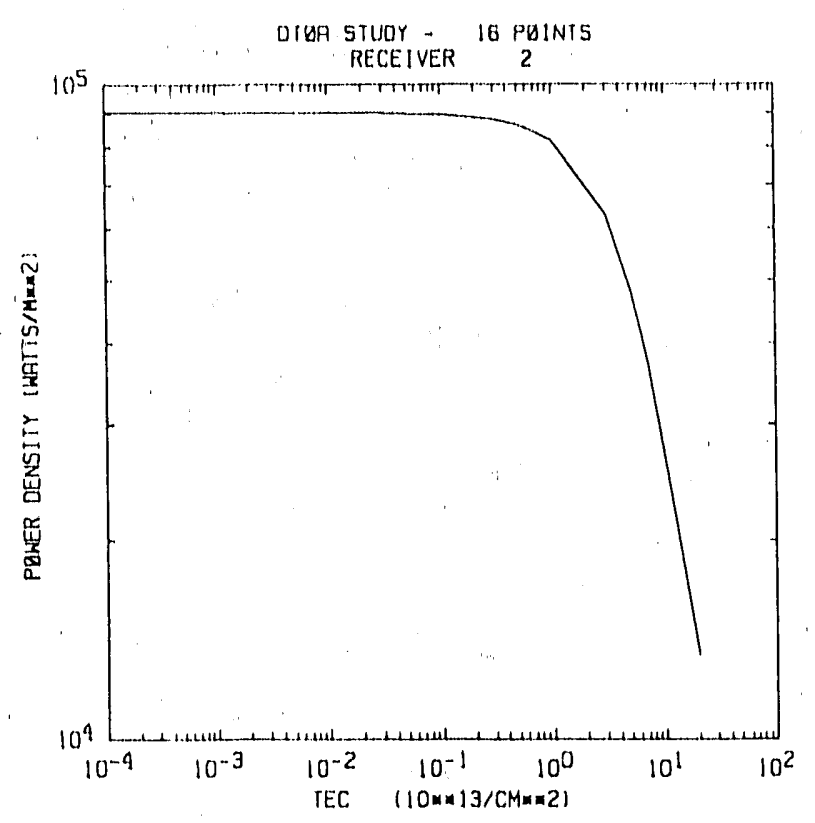

$16 b$

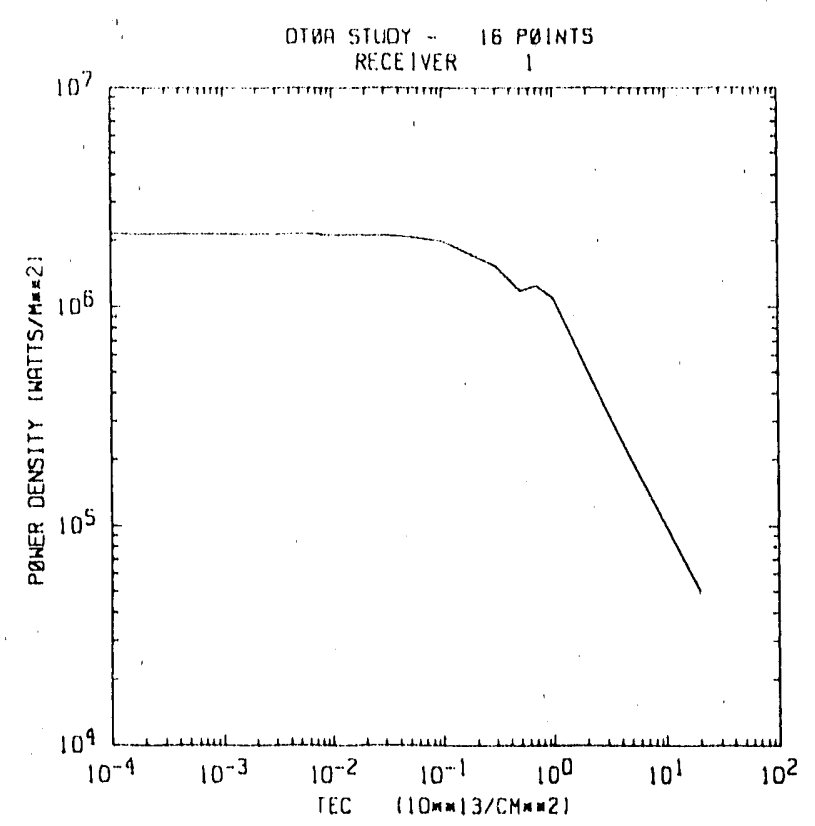

$16 \mathrm{c}$

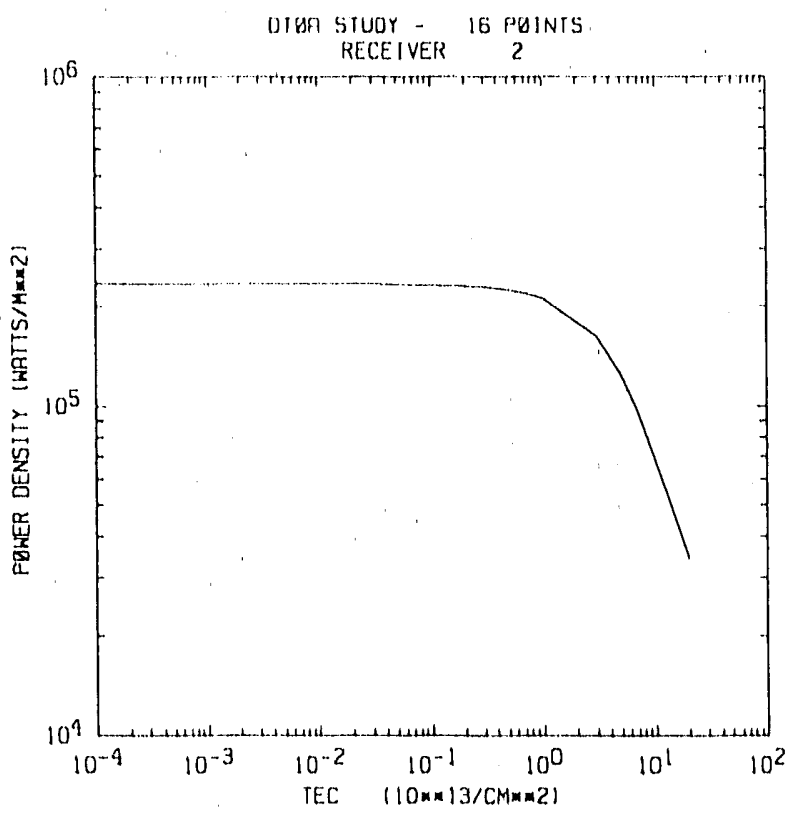

$16 d$

Figures 16a-d: Maximum RMS power density (watts $/ \mathrm{m}^{2}$ ) at $1 \mathrm{~km}$ range, measured in the 5 and $20 \mathrm{MH}$, bandwidth receivers centered at $120 \mathrm{MHz}$ for the $\mathrm{HPD}$ pulse at $20^{\circ}$ elevation and $37^{\circ}$ azimuth (a and b); and HPD pulse at $20^{\circ}$ clevation and 9()$^{\circ}$ azimuth $(\mathrm{c}$ and $\mathrm{d})$. 


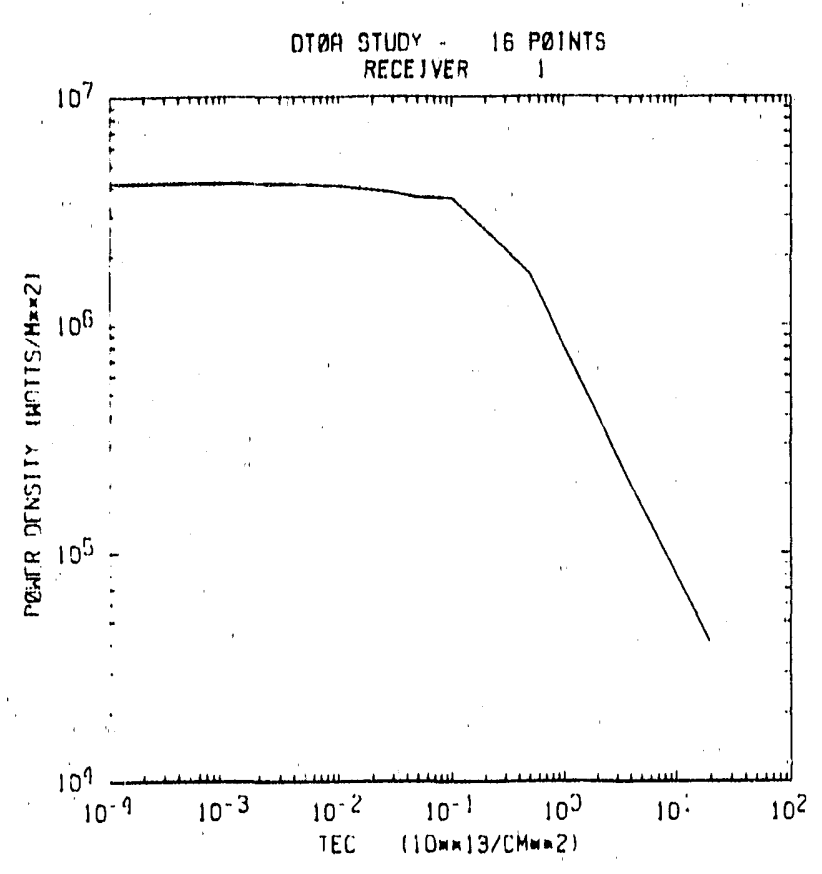

$17 \mathrm{a}$

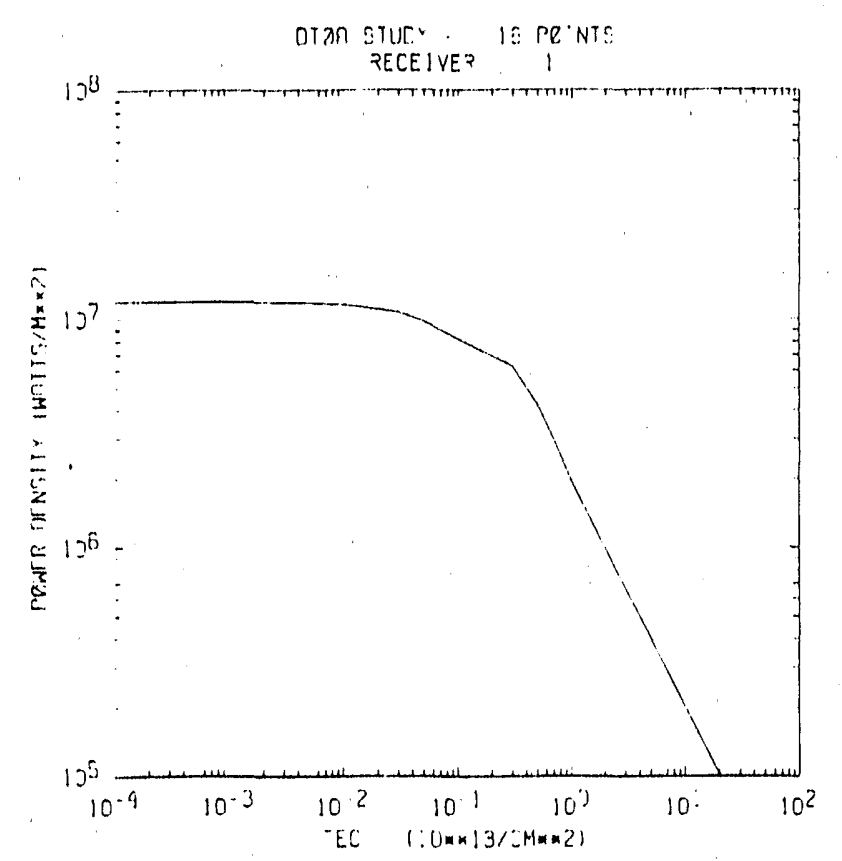

$17 \mathrm{c}$

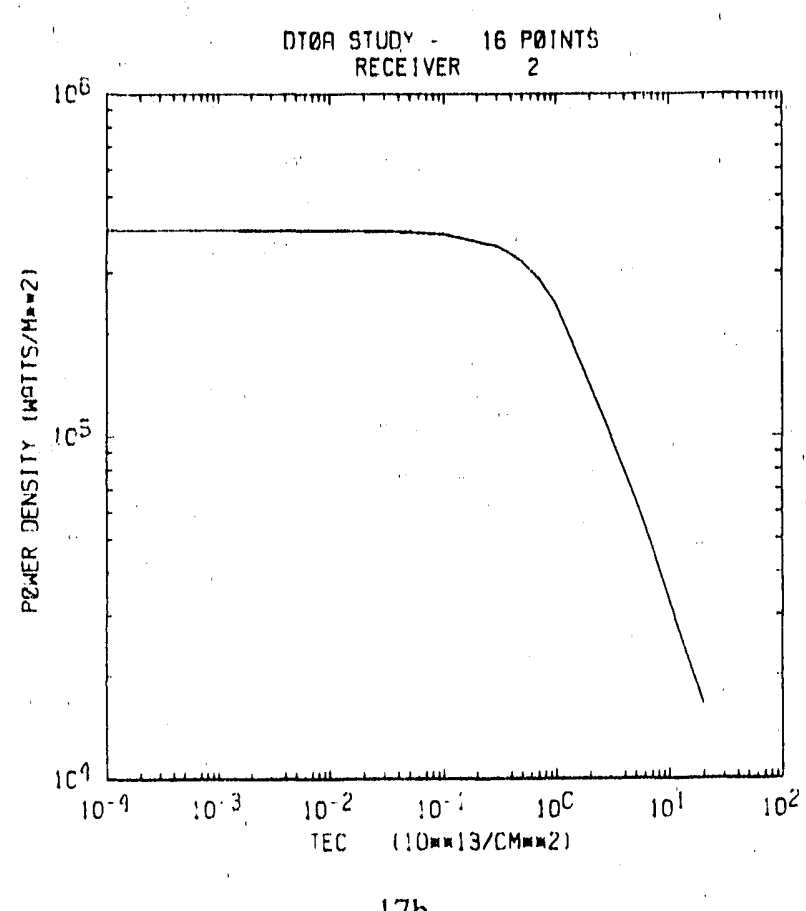

$17 b$

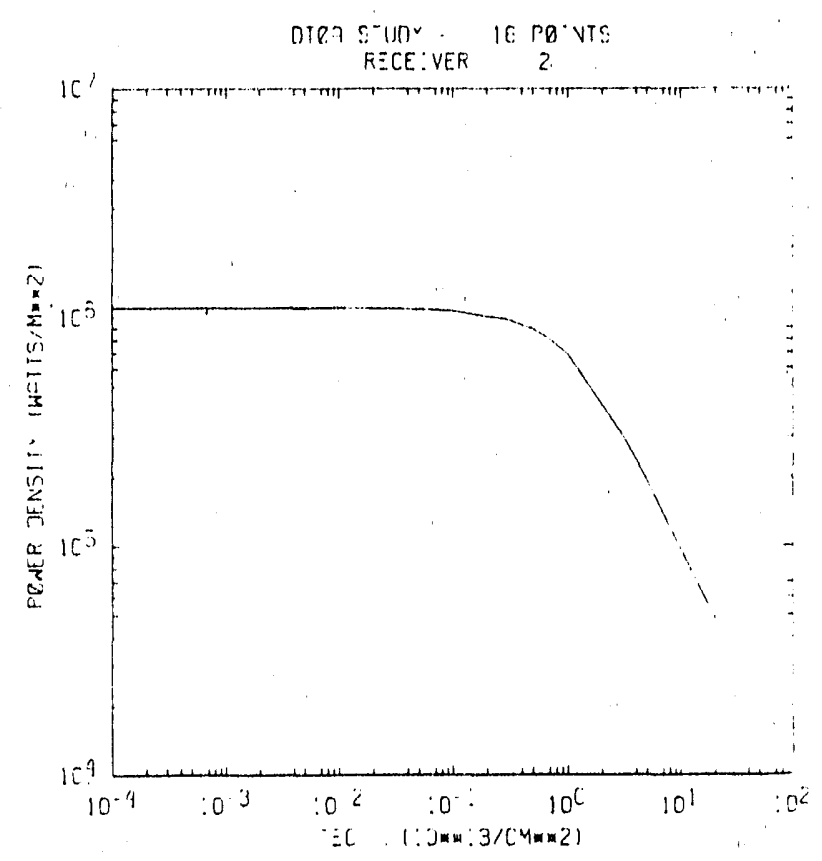

$17 \mathrm{~d}$

Figures 17a-d: Maximum RMS power density (watts $/ \mathrm{m}^{2}$ ) at $1 \mathrm{~m}$ range, measured in the 5 and $20 \mathrm{MHz}$ bandwidth receivers centered at $80 \mathrm{MHz}$ for the HPD pulse at $20^{\circ}$ elcvation and $37^{\circ}$ azimuth (a and b); and HPD pulse at $20^{\circ}$ elevation and 9()$^{\circ}$ arimuth $(c$ and $d)$. 


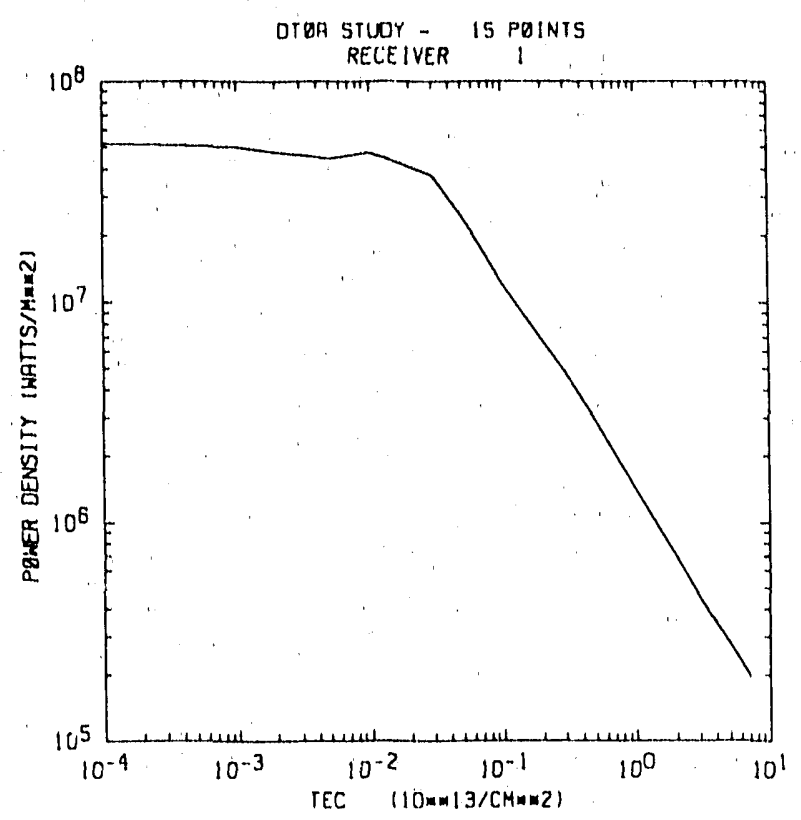

$18 \mathrm{a}$

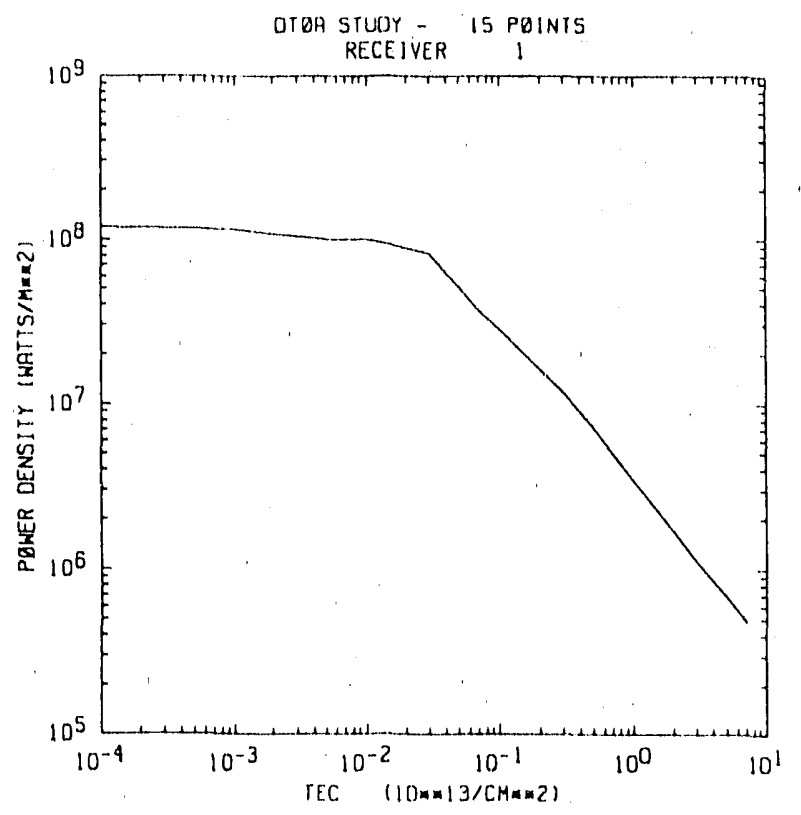

$18 \mathrm{c}$

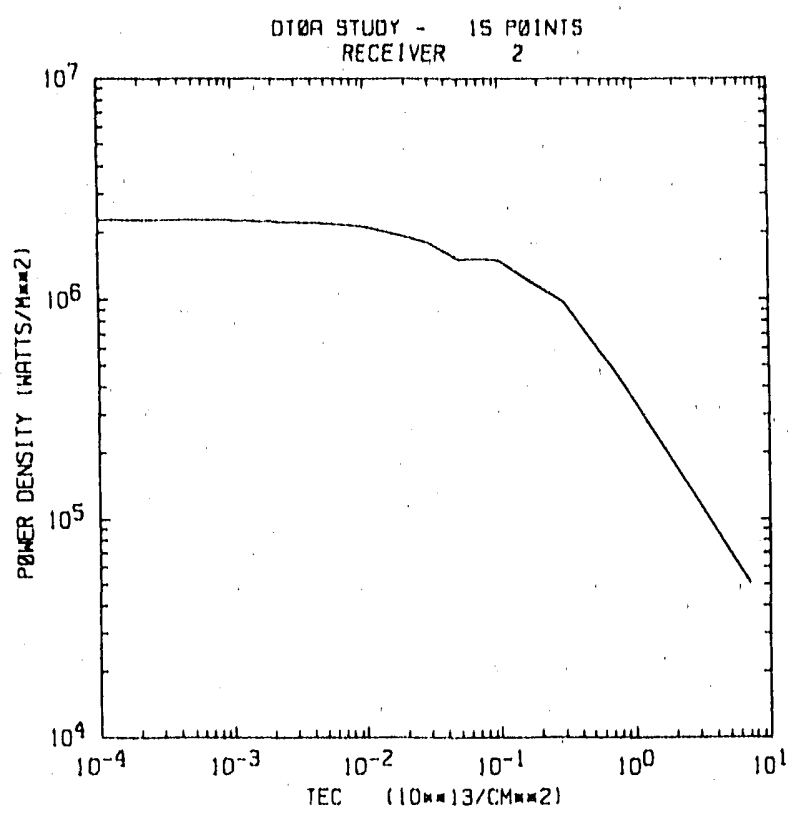

$18 \mathrm{~b}$

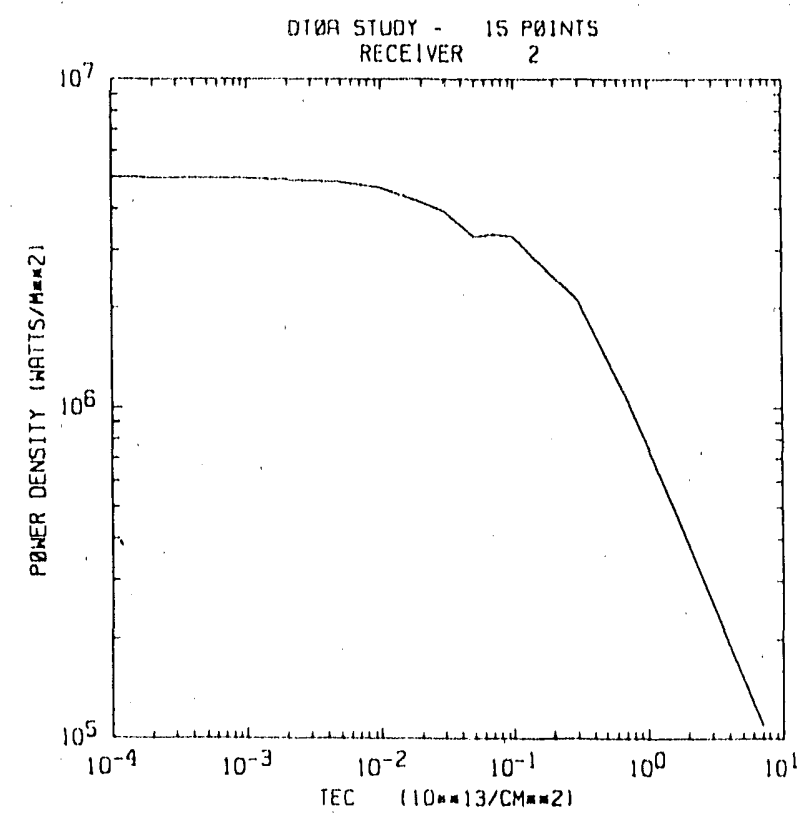

$18 d$

Figures 18a-d: Maximum RMS power density (watts $/ \mathrm{m}^{2}$ ) at $1 \mathrm{~m}$ range, measured in the 5 and 20 MH $/$ bandwidth receivers centered at $40 \mathrm{MHz}$ for the HPD pulse at $20^{\circ}$ elevation and $37^{\circ}$ azimuth $\left(\mathrm{a}\right.$ and $\mathrm{b}$ ); and HPD pulsc at $20^{\circ} \mathrm{clevation}$ and 9()$^{\circ}$ azimuth ( $c$ and $d$ ). 


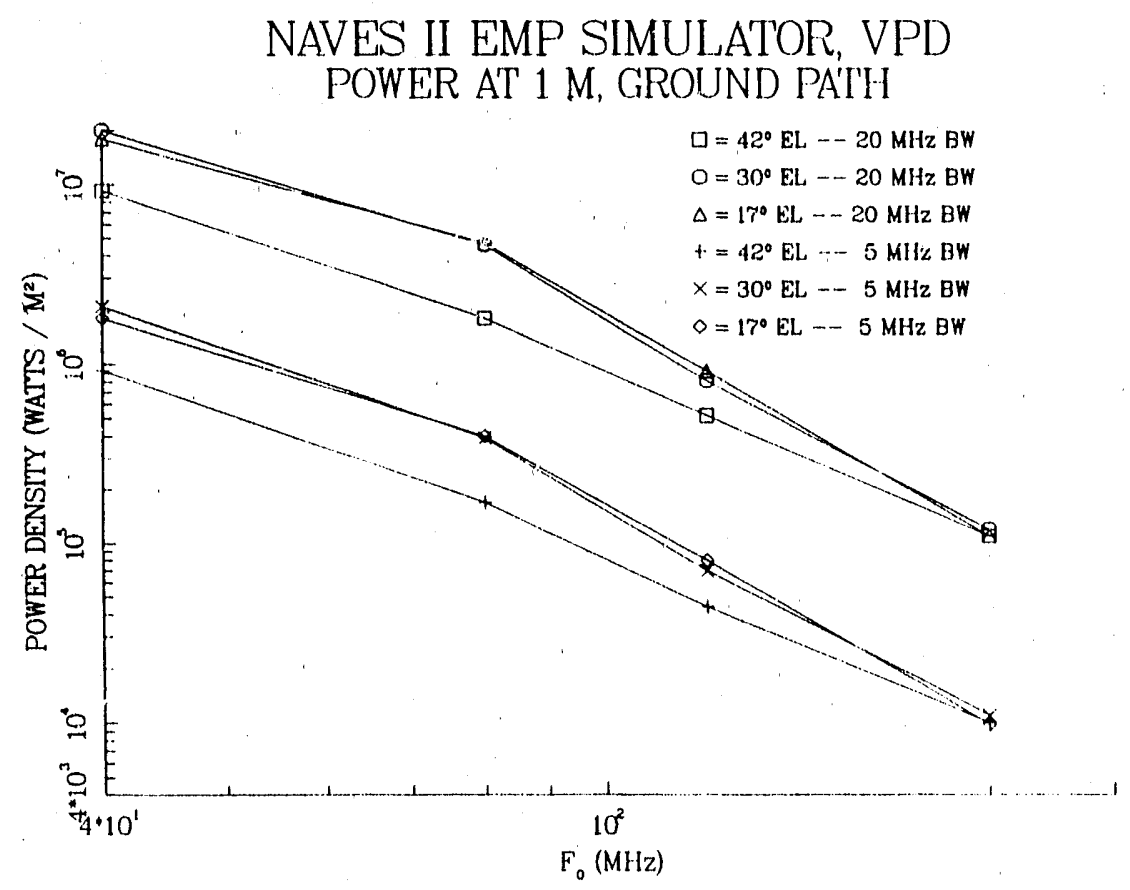

$19 \mathrm{a}$

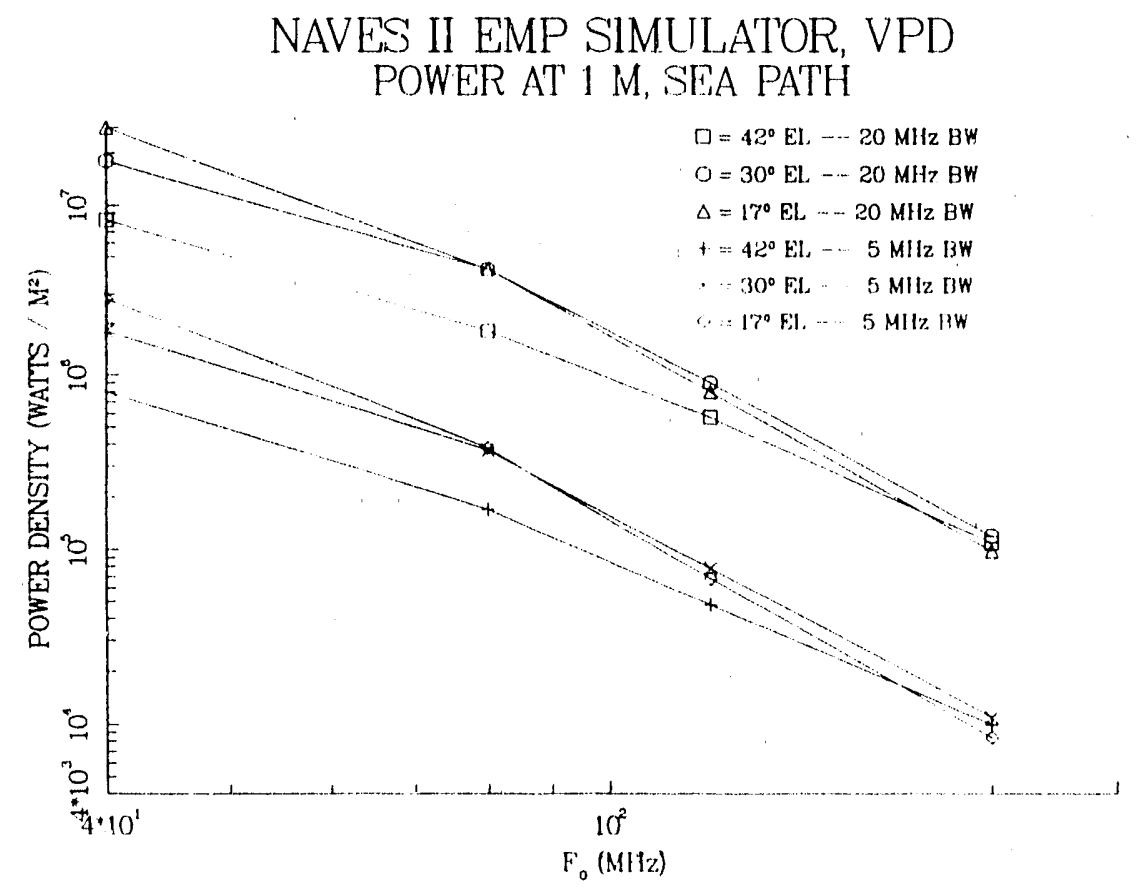

$19 b$

Figures 19a-b: Maximum RMS power density $\left(\right.$ watts $/ \mathrm{m}^{2}$ ) at $1 \mathrm{~m}$ range, measured in 5 and $20 \mathrm{MH} z$ bandwidth receivers as a function of frequency for the VPD pulse at $42^{\circ}, 30^{\circ}$, and $17^{\circ}$ elevation and for a ground path (19a) and a sea path (19) 


\section{TACAMO EMP SIMULATOR, HPD \\ POWER AT $1 \mathrm{M}, \mathrm{EL}=20$}

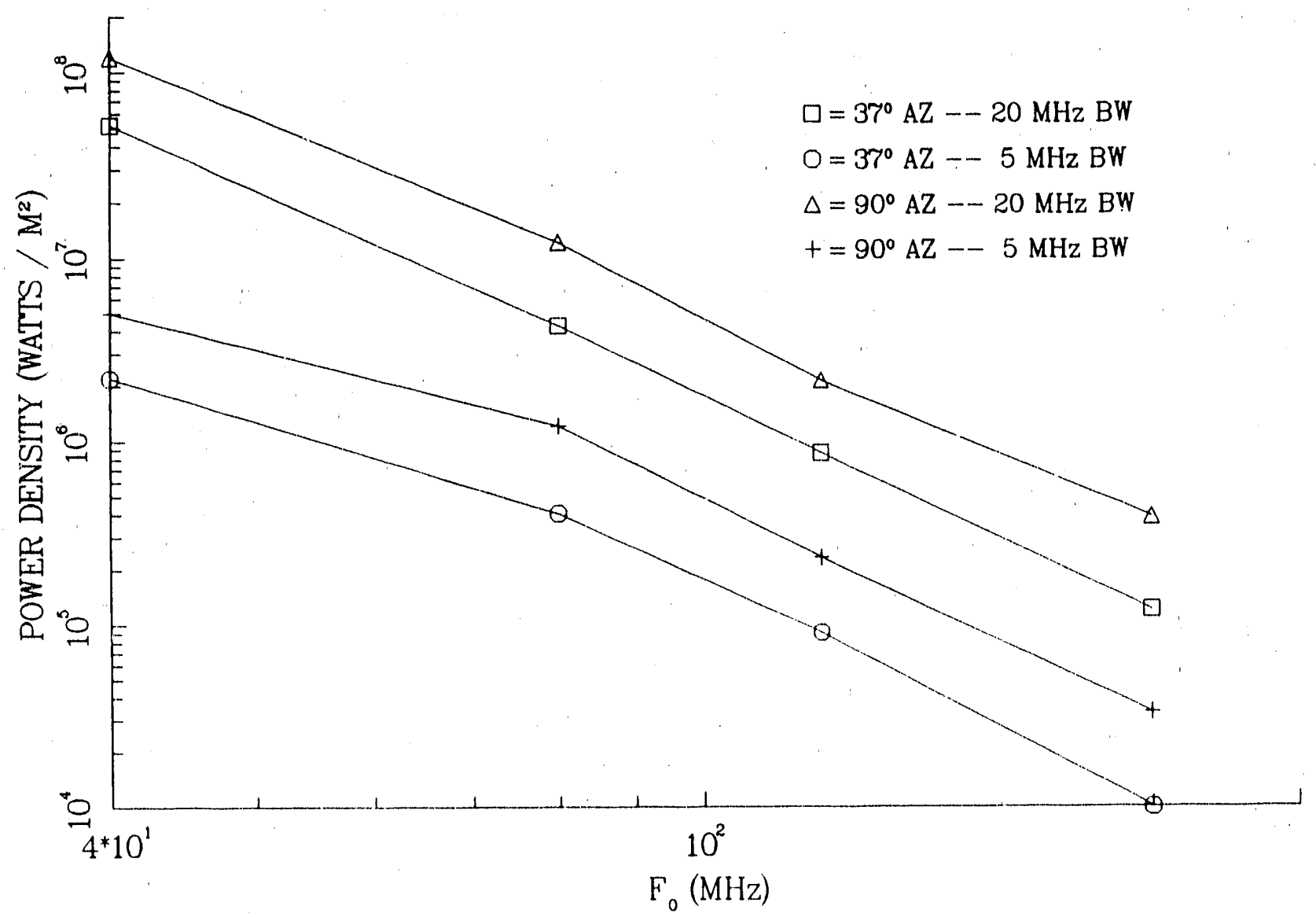

Figure 20: Maximum RMS power density (watts $/ \mathrm{m}^{2}$ ) at $1 \mathrm{~m}$ range, measured in 5 and $20 \mathrm{MH} \%$ bandwidth receivers as a function of frequency for the HPD pulse at $20^{\circ}$ elevation and $37^{\circ}$ and $90^{\circ}$ azimuth measured relative to the axis of the simulator. 

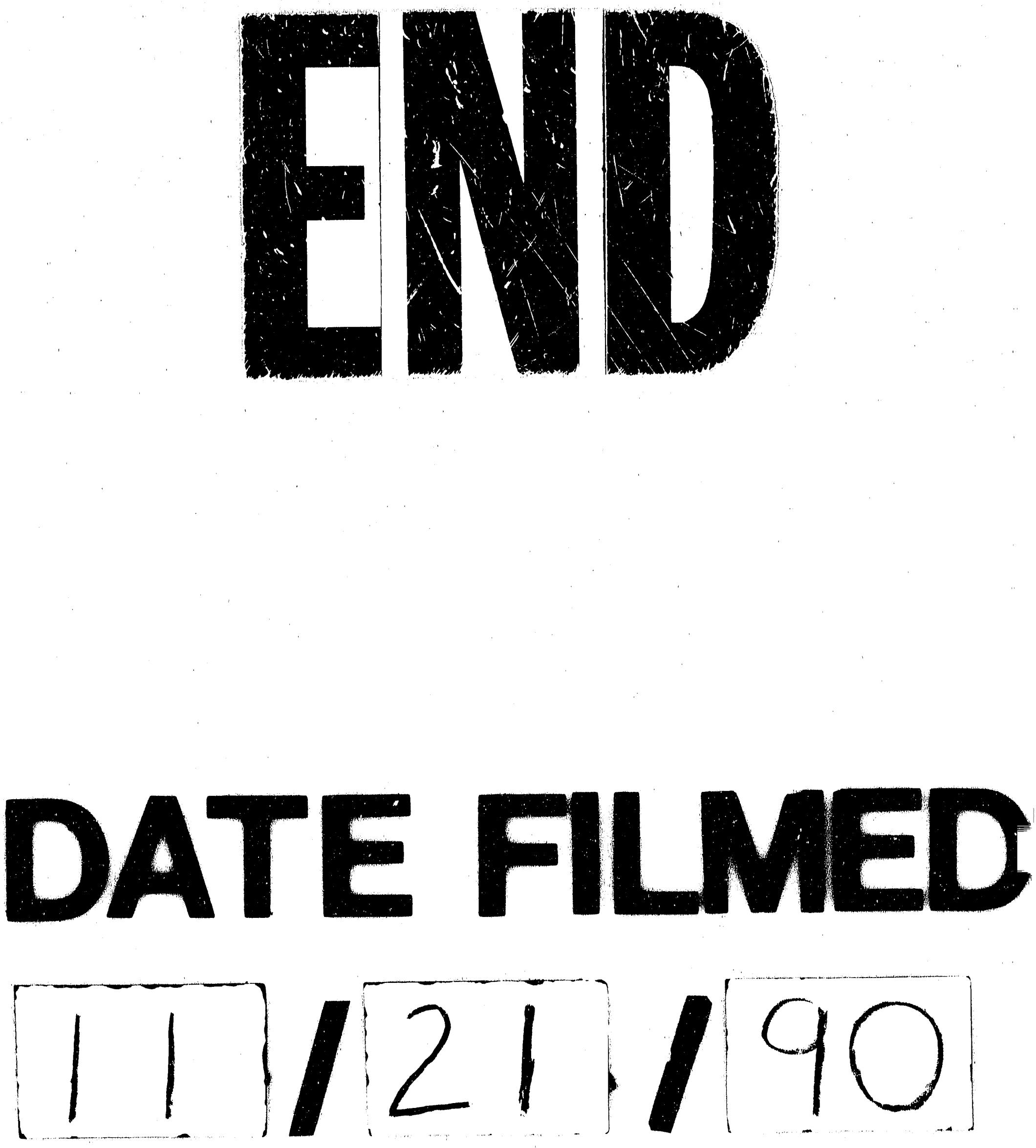
